Laís Cavalca Cardoso

\title{
Detalhamento funcional do papel de CD99 em astrocitomas
}

\author{
Tese apresentada à Faculdade de Medicina da \\ Universidade de São Paulo para obtenção do título de \\ Doutor em Ciências
}

Programa de Neurologia

Orientadora: Dra. Sueli Mieko Oba Shinjo

(Versão corrigida. Resolução CoPGr 6018/11, de 13 de outubro de 2011. A versão original está disponível na Biblioteca da FMUSP)

\section{São Paulo}




\section{Dados Internacionais de Catalogação na Publicação (CIP)}

Preparada pela Biblioteca da

Faculdade de Medicina da Universidade de São Paulo

Creprodução autorizada pelo autor

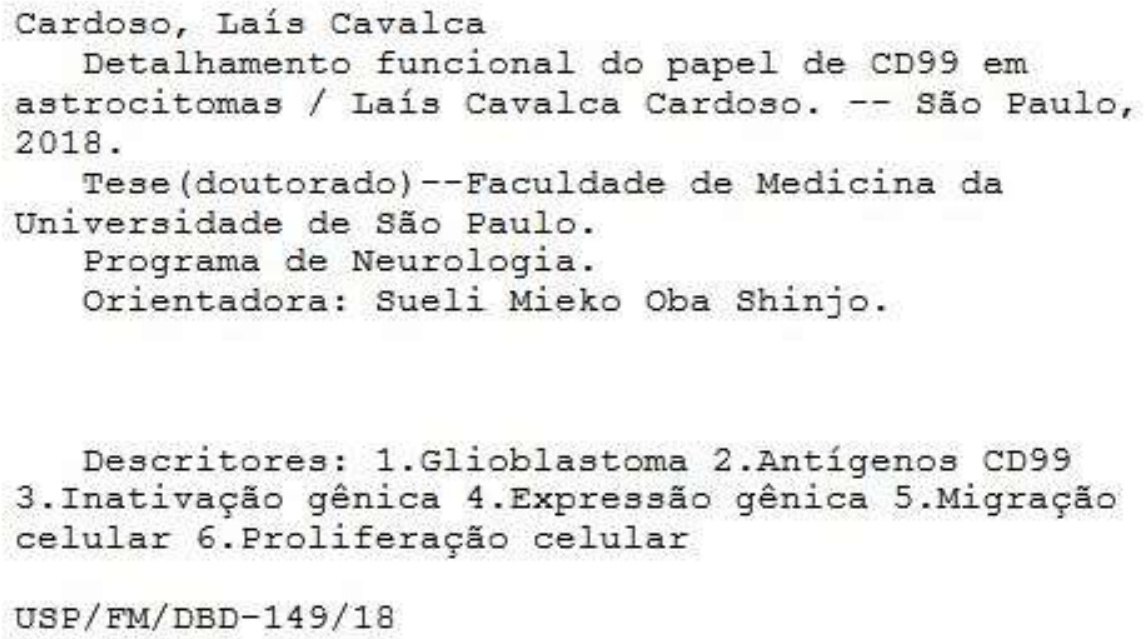

Responsável: Kátia Maria Bruno Ferreira - CRB-8/6008 
Nome: CARDOSO, Laís Cavalca

Título: Detalhamento funcional do papel de CD99 em astrocitomas

Tese apresentada à Faculdade de Medicina da Universidade de São Paulo para obtenção do título de Doutor em Ciências.

Aprovado em: 20/07/2018

\section{MEDICINA TSP \\ De ocordo com o disposto no Regimento da Pós-Graduaç5o da Universidade de SSo Paula os Examinadores consideraram o(a) candidato(a) LAIS CAVALCA CARDOSO}

\section{Săo Paulo, 20 de juho de 2018}

COMISSÃO EXAMINADORA

\section{L those:}

Sueli Mieko Obarshinjo-PRESIDENTE

(x) APR ( ) REP. MIYUki Uno - TITULAR

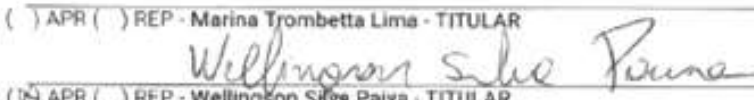

(N) APR ( ) REP - Wellingson Sirg Paiya - TITULAR

$\sqrt{\text { JAPR ( ) RER-Suely Kazue N\$gahashi Marie - TITULAR }}$

( TAPR ( ) REP' Ebervel Gadeha Figueiredo - SUPLENTE

( ) APR ( ) REP - Flávio Key MLura -SUPLENTE

( ) APR ( ) REP - Adriana Bastos Conforto - SUPLENTE

( TAPR ( ) REP - Kátia Căndido Carvalho - SUPLENTE

( $A$ APR ( ) REP. Roseli da Silva - SUPLENTE

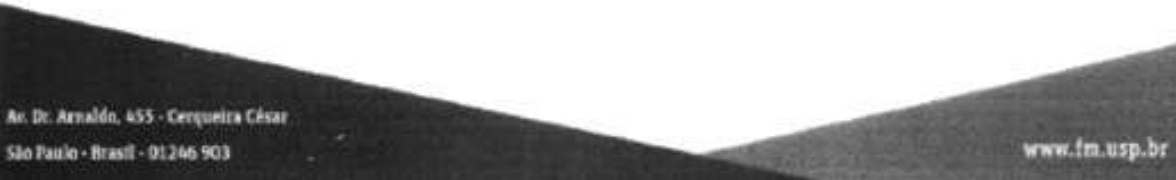


Agradeço

A Deus que sempre me deu forças e guiou o meu caminho.

Aos meus pais pelo amor incondicional e por todo apoio durante essa jornada.

À minha querida irmã Natália que sempre me incentivou com muito otimismo. Ao Thiago pela compreensão, apoio, amizade e acima de tudo o amor. À Rosangela e Amorim por todo apoio e amizade. 
Agradecimentos

À minha orientadora Dra. Sueli Mieko Oba-Shinjo que foi além dos ensinamentos científicos, sempre me incentivando e me encorajando com o seu exemplo de amor e dedicação pela sua profissão. Obrigada Sueli, pois inúmeras vezes foi uma grande amiga me oferecendo todo o seu apoio e compreensão.

À Profa. Dra. Suely Kazue Nagahashi Marie, agradeço pela amizade e pelas valiosas contribuições e incentivo no desenvolvimento deste trabalho.

Aos funcionários do laboratório, Luiz, Rosa, Márcia, Darcy, Camila, Mônica, Nice, Eliene e Thaís Freire pelo apoio e amizade.

Aos companheiros de laboratório Isabele, Stella, Thaís Galatro, Carlos Eduardo, Tawani, Fernanda, Natália, Daiane, Amanda, Adaliana, Paula Sola pela contribuição e momentos alegres.

Ao Dr. Antônio Lerário que realizou as análises do transcriptoma.

Ao Dr. Erico Costa e Dr. Flávio Miura por dispor do seu tempo para nos ensinar o modelo animal.

As amigas Mussya, Miyuki e Mazé por toda a ajuda e colaboração neste trabalho.

Um agradecimento especial aos amigos que me ajudaram de forma direta ou indireta, Mara Junqueira, Marina Trombetta, Kátia Carvalho, Ana Lúcia, Thaís Lima e Cássia Custódio.

De forma especial agradeço minhas queridas amigas: 
Roseli pelos inúmeros cafés, pandoras e puxões de orelhas que me motivaram a terminar esse trabalho.

Sofia que desde o primeiro dia tem me apoiado e incentivado, muito obrigada pelos cafés e momentos divertidos que passamos juntas.

Talita que com sua força e determinação tem sido um exemplo para mim. Agradeço pela sua amizade e por toda sua ajuda neste trabalho.

À Fundação de Amparo à Pesquisa do Estado de São Paulo (FAPESP) (Processos $n^{\circ}$ 2015/03995-9, bolsa de doutorado, e n²015/03614-5, Projeto Regular), ao CNPq e à Fundação Faculdade de Medicina pelo suporte financeiro. 


\section{RESUMO}

Cardoso LC. Detalhamento funcional do papel de CD99 em astrocitomas[tese]. São Paulo: Faculdade de Medicina, Universidade de São Paulo; 2018.

O glioblastoma (GBM) é o tumor cerebral maligno mais comum e agressivo em adultos. Uma combinação de terapia padrão com outras terapias baseadas no conhecimento de sua biologia é necessária para melhorar a sobrevida de pacientes com GBM. Muitos estudos foram desenvolvidos em busca de proteínas de membrana expressas em GBM, pois são potenciais alvos para imunoterapia. A proteína transmembrânica CD99 foi descrita como altamente expressa em astrocitomas de diferentes graus de malignidade. Embora seu mecanismo de ação ainda não seja totalmente compreendido, CD99 está envolvido na adesão e migração celular em diferentes tipos de tumores. O gene CD99 codifica duas proteínas distintas, denominadas isoforma 1, maior, de $32 \mathrm{kDa}$, e isoforma 2, gerada por splicing alternativo e menor, de $28 \mathrm{kDa}$. No presente estudo, foi demonstrada a expressão predominante da isoforma $1 \mathrm{em}$ astrocitomas de diferentes graus de malignidade em comparação com o cérebro normal, bem como na linhagem celular de GBM humano U87MG. O transcriptoma das células U87MG transfectadas com siRNA para CD99 foi analisado em relação ao controle. Um total de 2.670 genes diferencialmente expressos foi identificado. Uma análise de enriquecimento no banco de dados DAVID revelou os seguintes processos como os mais significativos: junções aderentes célula-célula; adesão célula-célula envolvendo ligação de caderina e adesão celular. Ensaios funcionais baseados nestes achados (migração, invasão e adesão) foram realizados com células U87MG após o silenciamento de CD99 com dois shRNAs diferentes. A eficiência de silenciamento foi de 80 e 97\%, para o shCD991 e 2, respectivamente, confirmada a nível de expressão do gene e da proteína. O silenciamento de CD99 reduziu a migração e invasão para ambos os shRNAs, com diminuição mais acentuada da migração para o shCD99 2, com maior nível de silenciamento de CD99. No ensaio de adesão, a linhagem U87MG shCD99 1 apresentou propriedades adesivas mais baixas que o controle, enquanto o shCD99 2 apresentou resultado oposto, com maior adesão celular do que seu controle. Provavelmente o silenciamento de CD99 afetou a redução da adesão celular em um padrão distinto, sugerindo que o resultado pode ser dependente do nível de expressão remanescente de CD99. Além disso, o CD99 e a faloidina colocalizaram nos lamelipódios e filopódios, sugerindo um papel importante no rearranjo do citoesqueleto. Foi demostrado, ainda, que o silenciamento de CD99 levou à redução da proliferação celular in vitro e diminuição do tumor in vivo. Camundongos imunodeficientes nos quais foram implantadas células silenciadas no cérebro apresentaram uma maior sobrevida que os animais que receberam células controle. A via de sinalização pela qual CD99 modula a proliferação no GBM ainda precisa ser elucidada. Migração, invasão e proliferação são as principais características do GBM que limitam uma ressecção cirúrgica completa e, consequentemente, levam frequentemente à recorrência. Portanto, análises posteriores das vias ativadoras do CD99 no contexto da migração, invasão, proliferação celular e apoptose são válidas para revelar novas estratégias terapêuticas para limitar a progressão do GBM.

Descritores: glioblastoma; antígeno CD99; inativação gênica; expressão gênica; migração celular; proliferação celular. 


\begin{abstract}
Cardoso LC. Functional detailing of CD99 role in astrocitomas[thesis]. São Paulo: "Faculdade de Medicina, Universidade de São Paulo"; 2018.

Glioblastoma (GBM) is the most common and aggressive malignant brain tumor in adults. A combination of standard therapy with other biologically based therapies is necessary to improve the survival of patients with GBM. Many studies have been developed in pursuit of expressed membrane proteins in GBM, which are potential targets for immunotherapy. The transmembrane protein CD99 is highly expressed in different malignant grades of astrocytomas. Although its mechanism of action is not still fully understood, CD99 is involved in cell adhesion and migration in different type of tumors. The CD99 gene encodes two distinct transmembrane proteins, named isoform 1, longer with $32 \mathrm{kDa}$, and isoform 2, generated by alternative splicing, shorter with $28 \mathrm{kDa}$. In the present study, we demonstrated predominant expression of isoform 1 in astrocytomas of different malignant grades compared to normal brain, and in the human GBM cell line U87MG. The transcriptome of U87MG cell line transfected with siRNA for CD99 was analyzed in relation to control. A total of 2.670 differentially expressed genes were identified. An enrichment analysis by DAVID Bioinformatics Database revealed the following processes as the most significant: cell-cell adherens junction; cadherin binding involved in cell-cell adhesion and cell-cell adhesion. Functional assays based on these findings (migration, invasion and adhesion) were performed with U87MG cells after knocking down CD99 with two different shRNAs. The CD99 silencing efficiency was 80 and 97\%, for shCD99 1 and 2, respectively, confirmed at gene and protein level. The CD99 knockdown reduced migration and invasion for both shRNA, with the highest decrease of migration observed in the higher CD99 knocked down cells. In adhesion assay, shCD99 1 U87MG showed lower adhesive properties than the control, whereas shCD99 2 cells presented opposite results, with higher cell adhesion than control. Probably CD99 knockdown affected in the reduction of cell adhesion in a distinct pattern, suggesting that the result is dependent on CD99 remaining expression level. Additionally, CD99 and phalloidin colocalized at lamellipodia and filopodia, sugesting that CD99 plays an important role to cytoskeleton rearrangement. It has also been demonstrated that CD99 silencing caused reduction of cell proliferation in vitro and decreased tumor in vivo. Immunodeficient mice in which knocked down cells were implanted in the brain had a longer survival than animals that received control cells. The signaling pathway by which CD99 modulates proliferation in GBM still needs to be elucidated. Migration, invasion and proliferation are major characteristics of GBM, which limits the complete surgical tumor resection, and consequently leads to tumor recurrence. Therefore, further analysis of CD99 activating pathways in the context of cell migration, invasion, proliferation and apoptosis is worthwhile to unveil new therapeutic strategies to halt GBM progression.
\end{abstract}

Descriptors: glioblastoma; antigens, CD99; gene silencing; gene expression; cell movement; cell proliferation. 


\section{LISTA DE ABREVIATURAS E SIGLAS}

ACTR2/ARP2 Homólogo de proteína 2 relacionada com actina

AGI Astrocitoma pilocítico

AGII Astrocitoma grau II

AGIII Astrocitoma grau III

AKT Serina/treonina quinase

AP-1 Fator de transcrição AP-1

ARP2/3 Proteína relacionada à actina do complexo $2 / 3$

ARPC1A Proteína relacionada à actina complexo $2 / 3$ subunidade $1 \mathrm{~A}$

ATRX Alpha-Thalassemia X-Linked Intellectual Disability Syndrome

BAI1 Domínio contendo I-BAR

BCRP ATP binding cassette subfamily $G$ member 2

BRAF Proto-oncogene B-Raf

CAPPesq Comitê de Ética para Análise de Projetos de Pesquisa

CDC42 Ciclo de divisão celular 42

CDNA Ácido desoxirribonucléico complementar

CEUA Comissão de Ética no Uso de Animais do Biotério Central da FMUSP

$\mathrm{CO}_{2} \quad$ Dióxido de carbono

COL6A2 Cadeia alfa 2 do colágeno tipo VI

CONEP Comissão Nacional de Ética em Pesquisa

c-Src c-terminal Src quinase

CTTN Cortactina

DAPI 4',6'-diamidino-2-fenindol

DIAPH1 Diafáno relacionada a formina 1

DMEM Meio modificado de Dulbeco

DNM2 Dinamina 2

DP

Duplo Positivo

EDTA Ácido etilenodiamino tetra-acético

EGFR Receptor de fator de crescimento epidermal

ERK Proteína quinase ativada por mitógeno

EWS-FLI Fator de transcrição que regula expressão gênica no Sarcoma de Ewing

EZR Ezrina

FAK ou PTK2 Quinase de adesão focal

FDA Administração de Alimentos e Medicamentos

FN1 Fibronectina 1

Fos B Fator de transcrição da família Fos

GBM Glioblastoma

GO Terms Gene Ontology Terms

GUSB Glucuronidase beta

HC-FMUSP Hospital das Clínicas da Faculdade de Medicina da Universidade de São Paulo

HEK293T Células embrionárias de rim humano 293

HPRT Hipoxantina fosforribosil transferase

HRAS Proto-oncogene HRas 


\begin{tabular}{|c|c|}
\hline HRP & Peroxidase de rábano \\
\hline ICAM-1 & Molécula de Adesão Intercelular 1 \\
\hline IDH & Isocitrato desidrogenase \\
\hline IGF-1R & Receptordo fator de crescimento insulina-símile 1 \\
\hline $\lg G$ & Imunoglobulina G \\
\hline IPP & Intracisternal A particle-promoted polypeptide \\
\hline ITGA & Subunidade alfa da integrina \\
\hline IVIS & Sistema de imagem in vivo \\
\hline JNK & Proteína quinase ativada por mitógeno \\
\hline JunD & Proto-oncogene JunD \\
\hline KEGG & Enciclopédia de Genes e Genoma de Kioto \\
\hline LAMA5 & Laminina 5 \\
\hline LFA-1 & Antígeno 1 associado à função linfocitária \\
\hline LIM & Laboratório de Investigação Médica \\
\hline MAPK & Proteína quinase ativada por mitógenos \\
\hline MDM2 & Murine double minute 2 \\
\hline MEC & Matriz extracelular \\
\hline $\mathrm{MHC}$ & Complexo principal de histocompatibilidade \\
\hline $\operatorname{miR}$ & Micro RNA \\
\hline MLC & Cadeia leve da miosina \\
\hline MMP-9 & Metaloproteinase 9 \\
\hline $\mathrm{MOI}$ & Multiplicidade de Infecção \\
\hline MPSS & Sequenciamento maciço de assinatura paralela \\
\hline MSN & Moesina \\
\hline mTOR & Proteínaalvoda rapamicina em mamíferos \\
\hline NB-2 & Nível de Biossegurança 2 \\
\hline NF1 & Neurofibromatose tipo 1 \\
\hline$N F-\kappa B$ & Fator nuclear kappa B \\
\hline NK & Natural killer \\
\hline NN & Não-neoplásico \\
\hline NTC & Non-Targeting Control \\
\hline OMS & Organização Mundial de Saúde \\
\hline OPN & Osteopontina \\
\hline $\mathrm{pb}$ & Pares de base \\
\hline PBS & Tampão fosfato salina \\
\hline PCR & Reação em cadeia da polimerase \\
\hline PDGFRA & Receptor do fator de crescimento derivado de plaqueta alfa \\
\hline PI3K & Fosfatidilinositol 3 quinase \\
\hline PIN1 & Peptidilprolil cis / trans isomerase \\
\hline PKA & Proteína quinase $A$ \\
\hline PKC & Proteána quinase $\mathrm{C}$ \\
\hline PTPN12 & Protein tyrosine phosphatase, non-receptor type 12 \\
\hline qRT-PCR & PCR quantitativo em tempo real \\
\hline Rac1 & Famíliadas pequenas proteínas sinalizadoras RhoGTPases \\
\hline RAF1 & Raf-1 Proto-Oncogene, Serine/Threonine Kinase \\
\hline
\end{tabular}


RAS Vírus de sarcoma de rato

RB1 Corepressor transcricional RB 1

RDX Radixina

Rho GTPases da família Rho

RhoGap GTPase-activator protein for Rho-like GTPases

RNA Ácido ribonucléico

ROCK2 Rho associated coiled-coil containing protein kinase 2

ROI Região de interesse

RPKM Reads per Kilobase Million

RPM Rotações por minuto

RUNX2 Runt related transcription factor 2

SFB Soro fetal bovino

SHP2 Protein tyrosine phosphatases, non-receptor type

ShRNA short hairpin RNA

SIRNA small interfering RNA

SNC Sistema Nervoso Central

TCGA Atlas do Genoma do Câncer

TCR Receptor de células T

THBS1 Trombospondina 1

TP53 Gene da proteína tumoral p53

Tris-EDTA Tris-ácido etilenodiamino tetra-acético

WASF1 Was Protein Family Member 


\section{LISTA DE FIGURAS}

Figura 1. Representação das isoformas 1 e 2 de CD99 humana

Figura 2. Representação esquemática dos processos biológicos regulados por CD99. 22

Figura 3. Representação esquemática da sinalização de CD99 em células de sarcoma de Ewing.

Figura 4. Mecanismo molecular mediado pela isoforma 2 de CD99 na regulação da motilidade celular.

Figura 5. Representação esquemática dos efeitos funcionais da superexpressão de CD99 em células de osteossarcoma.

Figura 6. Análise de expressão do gene e da proteína CD99 em astrocitomas

Figura 7. Expressão das isoformas 1 e 2 de CD99 na linhagem U87MG

Figura 8. Expressão das isoformas 1 e 2 de $C D 99$ em 22 amostras de astrocitoma pilocítico (AGI), 26 astrocitomas de baixo grau (AGII), 17 astrocitomas anaplásico (AGIII), 84 GBM e 19 amostras de tecido não neoplásico (NN).....

Figura 9. Expressão de CD99 em diferentes subtipos moleculares de GBM .53

Figura 10. Análise de expressão de CD99 após silenciamento de CD99 por siRNA da linhagem U87MG.

Figura 11. Análise do transciptoma da linhagem celular U87MG knockdown para CD99 por SiRNA

5

Figura 12. Análise do transcriptoma da linhagem celular U87MG knockdown para CD99 por SiRNA.

Figura 13. Análise de células vivas da linhagem U87MG após transdução com partículas lentivirais

Figura 14. Silenciamento da expressão de CD99 por shRNA na linhagem U87MG. 59

Figura 15. Papel de CD99 na migração da linhagem U87MG .60

Figura 16. Papel de CD99 na migração da linhagem U87MG em ensaio de monitorado. 61 
Figura 17. Papel de CD99 na invasão da linhagem U87MG. .62

Figura 18. Papel do CD99 na adesão celular da linhagem U87MG .....................................63

Figura 19. Curva de proliferação da linhagem U87MG shCD99 1 (A) e shCD99 2(B) .............64

Figura 20. Expressão e localização da proteína CD99 na linhagem U87MG...........................65

Figura 21. Co-localização de CD99 e faloidina nas células U87MG silenciadas para CD99 e controles.

Figura 22. Efeito do silenciamento com shCD99 1 no crescimento tumoral da linhagem U87MG no modelo ortotópico in vivo.

Figura 23. Efeito do silenciamento com shCD99 2 no crescimento tumoral da linhagem U87MG no modelo ortotópico in vivo.

Figura 24. Representação esquemática de vias de sinalização de adesão focal e regulação do citoesqueleto de actina...... 77 


\section{LISTA DE TABELAS}

Tabela 1. Tamanho do produto e sequência dos oligonucleotídeos utilizados para as reações

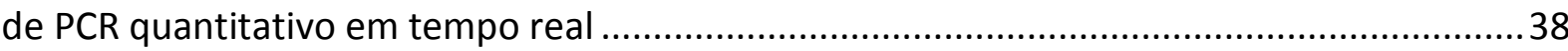

Tabela 2. Sequências dos shRNAs controle e do gene CD99

Tabela 3. Volumes correspondentes a MOI de 1 para a linhagem U87MG transduzida com shCD99 1, shCD99 2 e scrambled 


\section{SUMÁRIO}

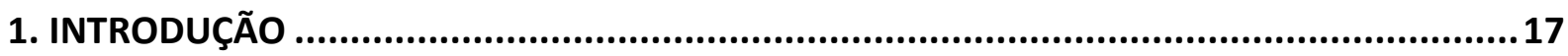

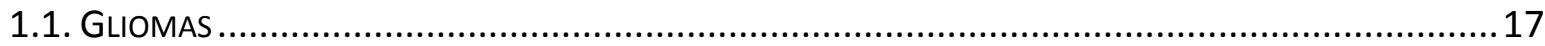

1.1.1. Astrocitomas pilocíticos ........................................................................ 18

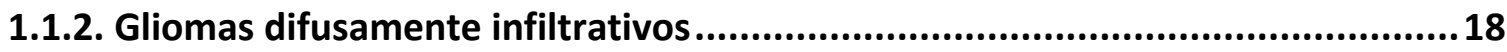

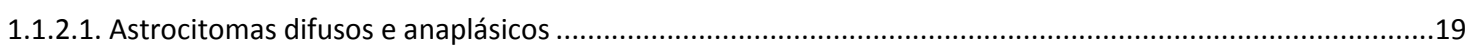

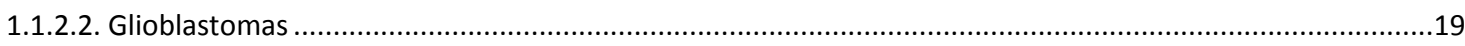

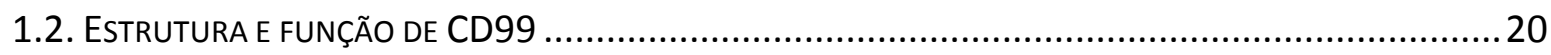

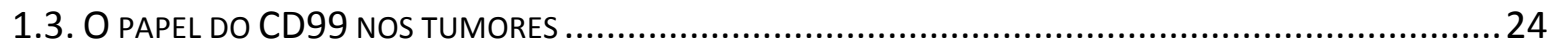

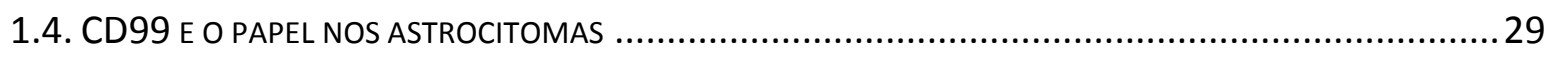

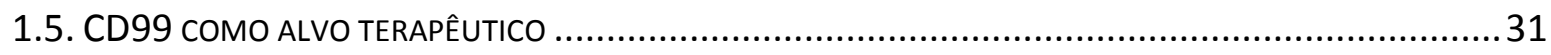

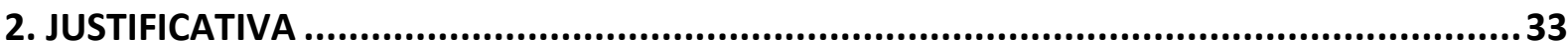

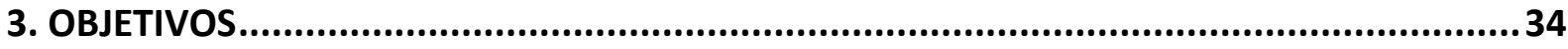

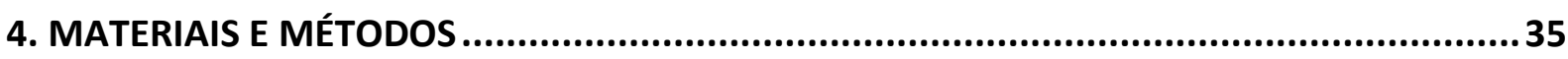

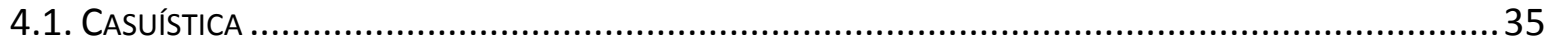

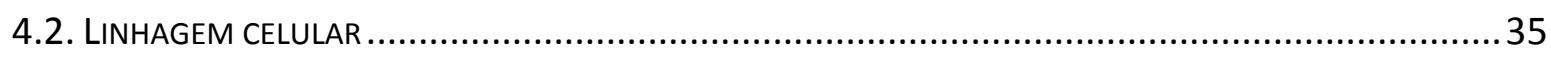

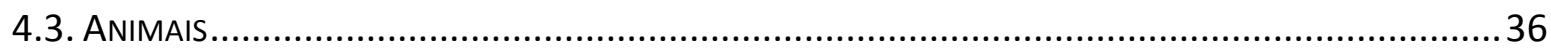

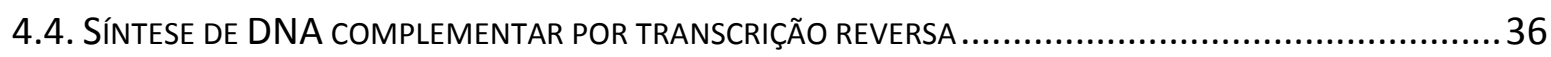

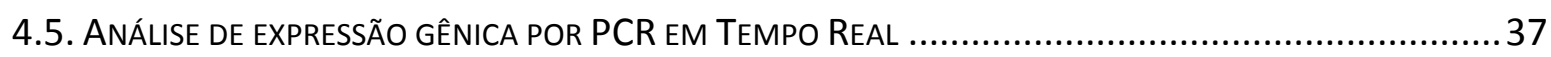

4.6. SILENCIAMENTO POR RNA DE INTERFERÊNCIA PEQUENO (SIRNA) .....................................38

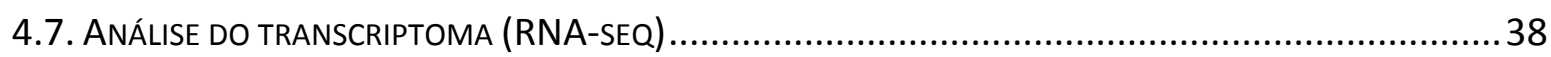

4.7.1. Análise de genes diferencialmente expressos de células U87MG após silenciamento com siRNA................................................................................... 38

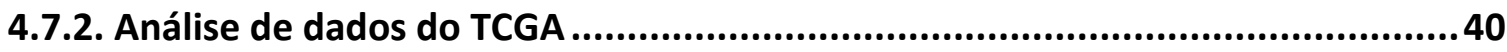

4.8. GERAÇÃO DA LINHAGEM U87MG SILENCIADA PARA CD99 POR SHRNA (SHORT HAIRPIN RNA) ........40

4.8.1. Titulação da concentração de puromicina ................................................... 40

4.8.2. Obtenção dos plasmídeos ..........................................................................41

4.8.3. Produção das partículas lentivirais ............................................................... 42

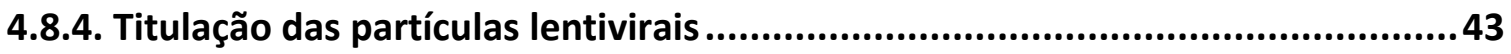

4.8.5. Transdução da linhagem U87MG ............................................................ 43

4.8.6. Expressão da proteína por Western blot...........................................................44

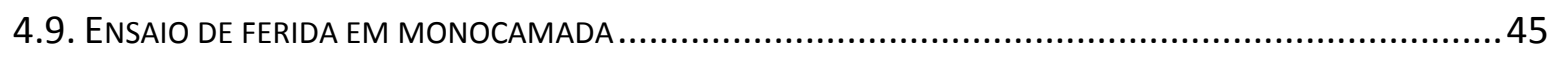

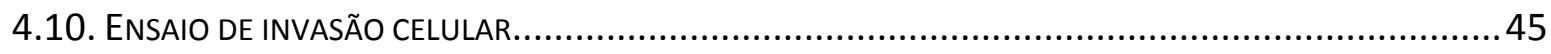

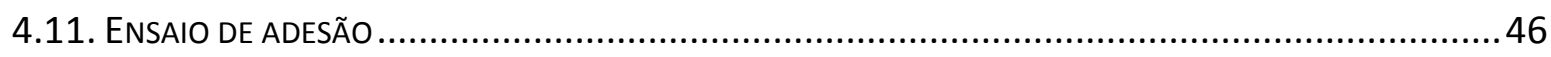

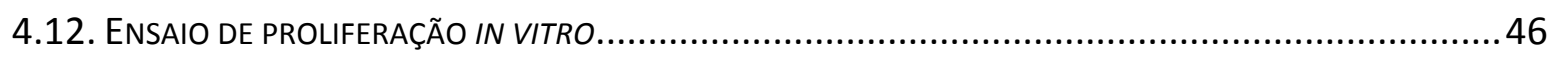

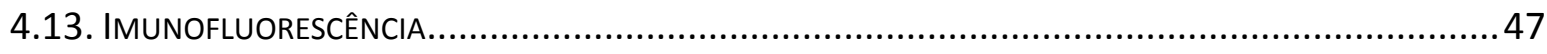

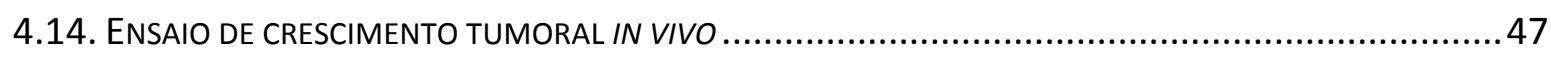




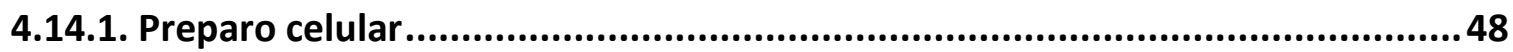

4.14.2. Implantação das células tumorais ..............................................................48

4.14.3. Monitoramento do crescimento tumoral por fluorescência ..........................49

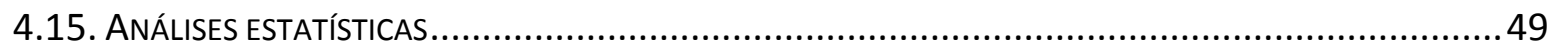

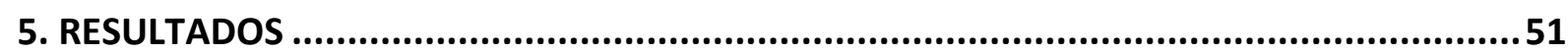

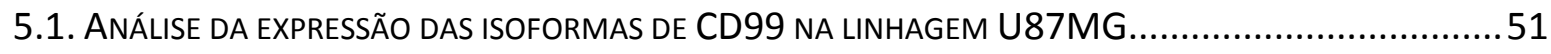

5.2. ANÁLISE DA EXPRESSÃO GÊNICA DE CD99 EM ASTROCITOMAS E SUBTIPOS MOLECULARES DE GBM .....51

5.2.1. Expressão das isoformas de CD99 em astrocitomas de diferentes grau de malignidade ...............................................................................................51

5.2.2. Expressão de CD99 em subtipos moleculares de GBM.................................52

5.3. ANÁLISE DO TRANSCRIPTOMA DA LINHAGEM U87MG SILENCIADAS POR SIRNA ..............................53

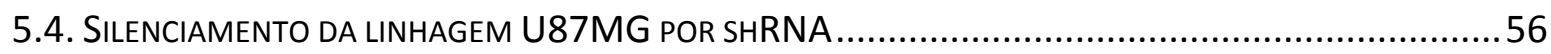

5.4.1. Determinação da MOI (Multiplicidade de Infecção) ....................................57

5.4.2. Validação do silenciamento na linhagem U87MG ........................................58

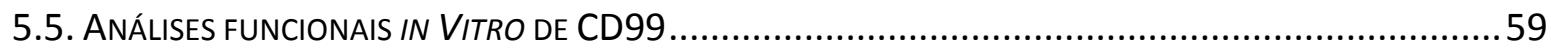

5.5.1. Ensaio de ferida em monocamada ............................................................59

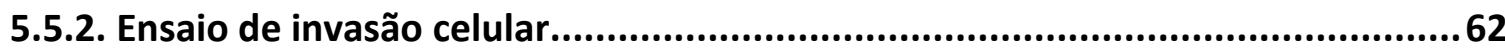

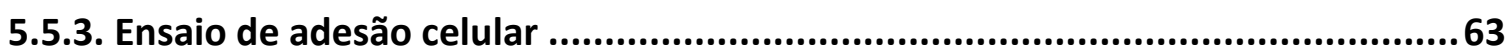

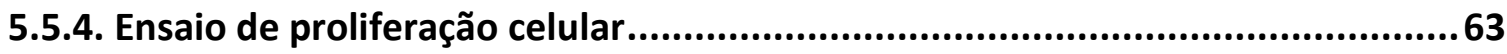

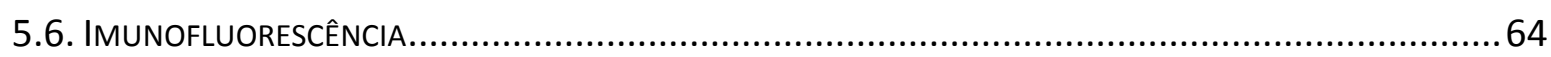

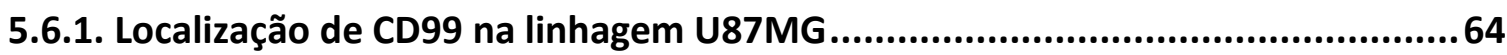

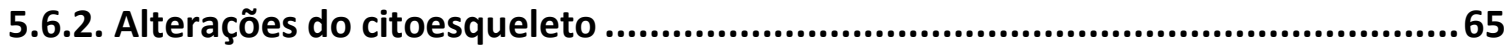

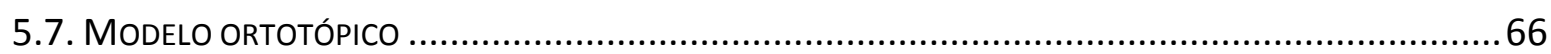

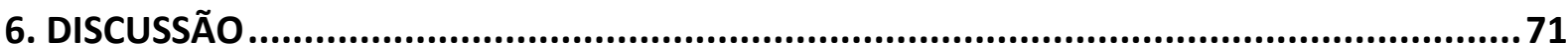

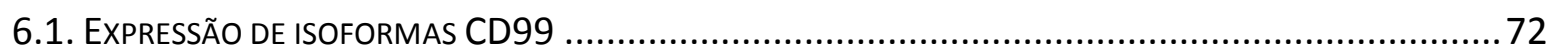

6.2. ANÁLISE DO RNA-SEQ, VIAS DE SINALIZAÇÃO MODULADAS POR CD99 …................................. 73

6.3. INFLUÊNCIA DE CD99 SOBRE MIGRAÇÃO, INVASÃO E ADESÃO CELULAR ......................................... 74

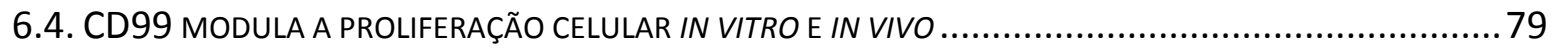

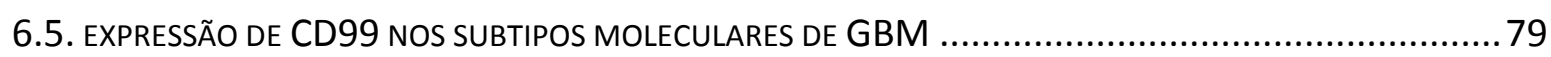

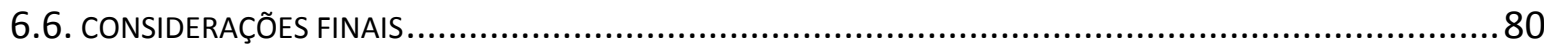

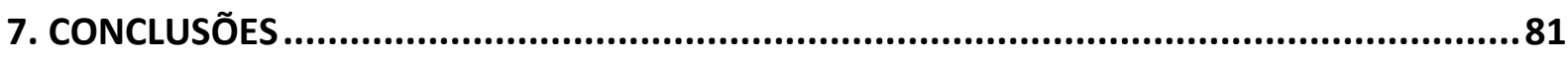

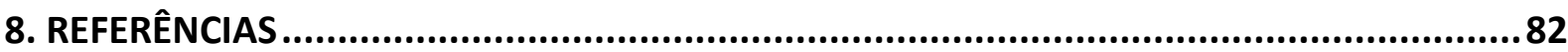

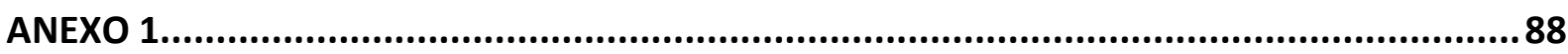

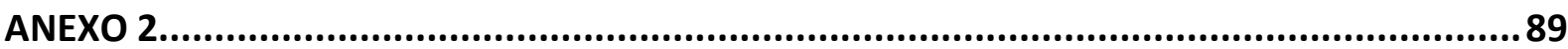




\section{INTRODUÇÃO}

\subsection{GLIOMAS}

O termo glioma abrange todos os tumores que surgem das células da glia e incluem os astrocitomas, oligodendrogliomas, oligoastrocitomas e ependimomas. São os tumores primários mais frequentes do Sistema Nervoso Central (SNC), entre os quais os astrocitomas totalizam $60 \%$ (1). Os gliomas correspondem a $27 \%$ de todos os tumores do SNC e cerca de $80 \%$ dos tumores malignos cerebrais, com maior incidência na faixa etária dos 75 aos 84 anos e no sexo masculino $(2,3)$. Segundo o INCA no Brasil estimam-se 5.810 casos novos de câncer so Sistema Nervoso Central (SNC) em homens e 5.510 em mulheres para cada ano do biênio 2018-2019. Nos Estados Unidos, a incidência anual de gliomas é de aproximadamente 3,2 casos a cada 100.000 indivíduos. A cada ano, aproximadamente 22.500 novos casos de tumores primários malignos são diagnosticados em adultos nos EUA, dentre os quais $70 \%$ são gliomas malignos (4).

A Organização Mundial de Saúde (OMS) classifica os gliomas de acordo com seu grau de malignidade em uma escala de I a IV, considerando características histológicas e alterações genéticas do tumor (5). Anteriormente a classificação dos tumores cerebrais se baseava apenas em suas características histológicas. Atualmente entende-se que os tumores cerebrais compartilham características genéticas comuns a alguns tumores e raras a outros, sendo que a compreensão dessas similaridades e diferenças genéticas tem permitido uma classificação mais adequada para um tratamento direcionado. Em relação à histologia, os astrocitomas são classificados de acordo com a presença dos seguintes indicadores morfológicos de anaplasia: 1) atipia nuclear, 2) mitoses, 3) proliferação endotelial e 4) necrose (1). Adicionalmente, os astrocitomas do grau II a IV são denominados astrocitomas difusamente infiltrativos, pela característica de invadir o tecido cerebral normal circunjacente, tornando a resseç̧ão cirúrgica total praticamente impossível (1). A classificação atual da OMS rompe com o princípio centenário de diagnóstico baseado inteiramente em microscopia, incorporando parâmetros moleculares na classificação dos tumores do SNC (5). A classificação molecular foi combinada à histológica para melhor 
classificar esses tumores, por exemplo, a classificação mais atual mescla os padrões previamente utilizados como dados de mutação, principalmente referente aos genes IDH1 e $I D H 2$, cujas alterações ocorrem precocemente no processo de tumorigênese dos gliomas difusos (6).

\subsubsection{Astrocitomas pilocíticos}

Os astrocitomas pilocíticos (grau I) são relativamente circunscritos, crescem lentamente e formam um cisto. Compreendem de 5 a $6 \%$ de todos os gliomas, são detectáveis por ressonância magnética e são curáveis por remoção cirúrgica (1). São mais frequentes em crianças e jovens adultos, nos quais o tumor pode surgir no cerebelo, hipotálamo e região do terceiro ventrículo.

A associação genética entre astrocitoma grau l e alterações no gene NF1 (neurofibromatosis type I) é bem conhecida. NF1 é um gene supressor de tumor que regula negativamente o oncogene RAS. Quando constitutivamente ativado, o gene RAS leva à ativação subsequente da via de sinalização mTOR (mammalian target of rapamycin) e dos fatores de transcrição relacionados à proliferação celular (7).

Alterações no gene $B R A F$ também estão envolvidas no astrocitoma pilocítico. A fusão entre os genes KIAA1549 e BRAF é a alteração molecular mais comum nesse tipo de tumor. O resultado dessa fusão é a perda do domínio amino-terminal da proteína BRAF ativando constitutivamente sua atividade de quinase e consequente aumento da proliferação celular $(5,8)$.

\subsubsection{Gliomas difusamente infiltrativos}

Atualmente os gliomas difusamente infiltrativos são agrupados, não apenas levando em consideração seu padrão de crescimento e comportamento, mas também considerandose os tipos mais específicos de mutações genéticas comuns dos genes IDH1 e IDH2. Nesta nova classificação da OMS, os gliomas difusos incluem grau II e grau III dos tumores astrocíticos e oligodrogliomas, além do glioblastoma grau IV (5). 


\subsubsection{Astrocitomas difusos e anaplásicos}

Os astrocitomas difusos de grau II (difusos)e III (anaplásicos) são mais comuns em adultos. Ao contrário do astrocitoma pilocítico, eles invadem o tecido encefálico normal, dificultando a ressecção cirúrgica e, portanto apresentam um pior prognóstico (9). Os astrocitomas de grau II e III podem evoluir para grau IV (10), processo este de muita relevância clínica, já que pacientes com astrocitoma difuso (grau II) apresentam sobrevida média de 7 anos, tempo que diminui pela metade em pacientes com astrocitoma anaplásico (grau III) e, no caso de pacientes com GBM, é menor que 15 meses (11).

Os astrocitomas difusos representam de 10 a $15 \%$ de todos os tumores astrocíticos, predominando em homens entre os 30 e 40 anos. Comparado a um cérebro normal, observa-se aumento moderado da celularidade com ocasional atipia nuclear, sem atividade mitótica (12).

Os astrocitomas anaplásicos acometem preferencialmente homens com idade média de 41 anos. Apresentam atividade mitótica aumentada e atipia nuclear (13). Do ponto de vista clínico, morfológico e genético, o astrocitoma anaplásico constitui um estágio intermediário na rota de progressão para um GBM (9).

Os astrocitomas difusos e anaplásicos são divididos em duas categorias baseadas em presença ou não de mutação nos genes IDH1 e IDH2: IDH-mutante e IDH-selvagem(5). Mutações nos genes $I D H 1$ e $I D H 2$ estão presentes na maioria dos casos. Mutações que inativam ATRX e TP53 também são frequentes, sendo a primeira essencial para a diferenciação entre astrocitomas de oligodendrogliomas. Alterações epigenéticas, como a metilação das ilhas CpG, estão presentes em $55 \%$ dos casos de astrocitomas difusos (14).

\subsubsection{Glioblastomas}

Os GBMs (grau IV) são os tumores do SNC mais frequentes e malignos $(47,1 \%)(15)$. Eles somam $16 \%$ de todos os tumores primários, sendo comum em adultos entre 45 e 75 anos e mais raros em crianças $(2,16)$. O GBM apresenta de três a quatro indicadores de anaplasia, atipia nuclear, altas taxas mitóticas, proliferação endotelial e/ou necrose. 0 rápido crescimento tumoral resulta em necrose com células tumorais em pseudopaliçadas 
(12). Devido à sua natureza invasiva, a ressecção cirúrgica completa é muito difícil de ser obtida, razão pela qualapresenta o pior prognóstico, com uma sobrevida média dos pacientes de 12 a 15 meses a partir do momento do diagnóstico (17).

Os glioblastomas podem ser divididos em dois subgrupos com base em uma lesão pré-existente: GBMs primários são os mais comuns e acometem indivíduos com mais de 50 anos, que surgem de novo, e GBMs secundários, que resultam da progressão de um tumor de baixo grau e acometem indivíduos mais jovens (18).

No Atlas do Genoma do Câncer (TCGA) Verhaak (2010) classificou os GBMs em quatro subtipos baseados no seu perfil de alterações moleculares: clássico, neural, proneural e mesenquimal. O subtipo proneural possui alterações em IDH1/IDH2, PDGRFA e TP53 e os pacientes são significativamente mais jovens que dos demais grupos. Os subtipos clássico e mesenquimal apresentam um padrão de alterações moleculares distintos, porém com prognóstico semelhante, pior do que o do subtipo proneural. O subtipo clássico apresenta amplificação de EGFR e apresenta melhor resposta ao tratamento agressivo (19). O subtipo mesenquimal possui mutação em RB1 e NF1. Somente o subtipo neural não possui um padrão de mutações como nos outros subtipos. É caracterizado por expressão de genes típicos de cérebro normal e os pacientes apresentam uma idade média maior entre os grupos. Apesar de um diagnóstico morfológico comum,esses subtipos possuem respostas distintasaterapia adjuvante, com impacto na sobrevida, a melhor resposta obtida no subgrupo clássico e a menor no subgrupo proneural (20).

\subsection{ESTRUTURA E FUNÇÃO DE CD99}

A placenta é um tecido normal, porém os trofoblastos compartilham algumas características comuns às células tumorais, incluindo a rápida capacidade de proliferação, invasão detecidos vizinhos, migração, angiogênese e a capacidade de escapar do sistema imunológico. Assim, a comparação entre trofoblastos e células tumorais poderia trazer conhecimento a respeito das principais vias de sinalização envolvidas nos processos de invasão e migração de GBM, favorecendo a identificação de moléculas alvo para o diagnóstico e tratamento nesse tipo de câncer. Com base nas características comuns entre 
as células tumorais e os trofoblastos, um trabalho inicial desenvolvido em nosso laboratório procurou in silico genes diferencialmente expressos em placenta e em GBM através da utilização do banco de dados MPSS (massively parallel signature sequencing) SAGE e expressão de dados de microarray publicados anteriormente para filtrar a lista de genes. Entre os genes selecionados, o CD99 foi o que apresentou a maior expressão diferencial no GBM em relação ao tecido cerebral não neoplásico (21).

CD99 é uma glicoproteína presente na membrana de células hematopoiéticas como linfócitos $T$, monócitos, células NK e linfócitos $B$, além de células não hematopoiéticas: ilhotas de Langherans no pâncreas, células de Leydig, de Sertoli e células ependimárias (22).

A proteína CD99 é codificada pelo gene CD99, também denominado MIC2, localizado no braço curto dos cromossomos X e Y. CD99 codifica duas isoformas distintas da proteína resultantes de um splicing alternativo de exons que codificam a região citoplasmática, uma com 185 aminoácidos e peso molecular de $32 \mathrm{kDa}$, conhecida como isoforma 1, e uma segunda de menor peso molecular com 28 kDa e 161 aminoácidos, denominada isoforma 2 $(23,24)$. A isoforma 1 é formada por um domínio extracelular glicosilado, um transmembrana e um intracitoplasmático de 36 aminoácidos. A isoforma 2 apresenta somente um domínio citoplasmático menor de 13 aminoácidos. A isoforma 2 contém uma inserção de 18 pb no limite dos exons 8 e 9 que introduz um códon de parada gerando um polipeptídeo truncado (25) (Figura 1).

CD99 isoforma 1

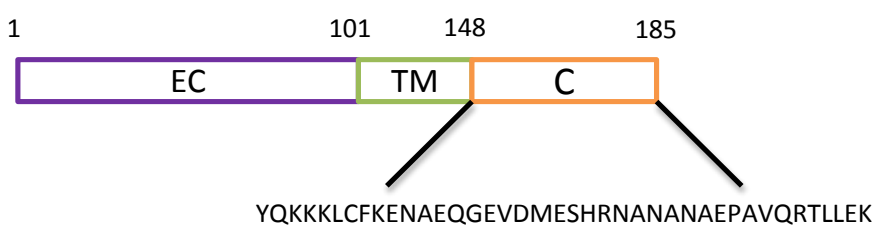

CD99 isoforma 2

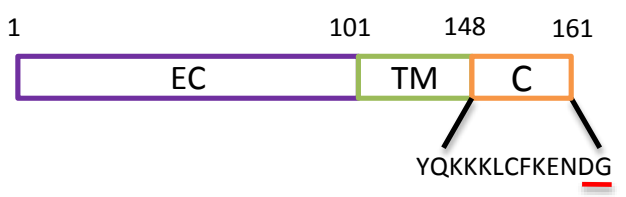

Figura 1. Representação das isoformas 1 e 2 de CD99 humana. A isoforma 1 possui um domínio citoplasmático composto por 36 aminoácidos e a isoforma 2 é uma proteína truncada no domínio citoplasmático. EC: domínio extracelular, TM: domínio transmembrana, C: domínio citoplasmático. Esquema adaptado de Lee et al.(2007). 
Além disso, as regiões citoplasmáticasdas duas isoformas de CD99 contêm uma zona rica em aminoácidos carregados positivamente e um resíduo de cisteína. As duas isoformas do CD99 podem dimerizar naturalmente na superfície celular. O processo de dimerização tem início no aparelho de Golgi e em seguida, os dímeros são exportados para a superfície da célula. Nesse ponto, o CD99 atua como um receptor que é ativado após estimulação (24).

O ligante de CD99 ainda é desconhecido e os dados a respeito de suas funções provêm de experimentos de ativação de CD99 por anticorpos agonistas, de silenciamento e superexpressão de CD99 em células hematopoiéticas (26). CD99 exerce um papel fundamental em diferentes processos biológicos (Figura 2), incluindo adesão celular, migração, apoptose, diferenciação de células T e timócitos, diapedese de linfócitos para o endotélio vascular inflamado, manutenção da morfologia celular e regulação do tráfico de proteínas intracelulares $(27,28)$.

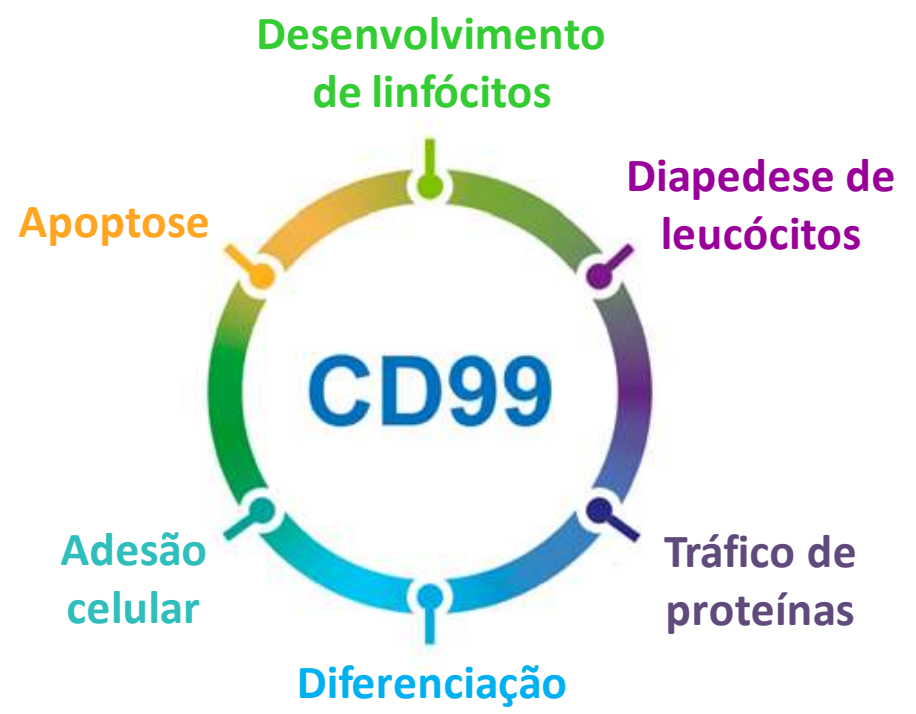

Figura 2. Representação esquemática dos processos biológicos regulados por CD99. Adaptado de Manara et al. (2018).

CD99 ativa funções celulares nos linfócitos T estritamente ligadas ao seu processo de diferenciação. A presença das duas isoformas observada nos timócitos duplo-positivos (DP) e células T imaturas é importante para indução de apoptose neste tipo celular. Este processo é ativado pela formação de um heterodímero das duas isoformas (23). Timócitos DP, quando ativados por um anticorpo agonista anti-CD99 (0662), entraram em apoptose. A expressão das isoformas 1 e 2 na linhagem celular Jurkat deficiente de CD99 foi necessária para indução de apoptose. Esse mesmo efeito, entretanto, não foi observado quando somente 
uma das isoformas foi expressa (29). Em linfócitos B normais a ligação de anticorpos agonistas anti-CD99 induziu a apoptose, sugerindo que o CD99 possa atuar na seleção clonal de linfócitos B e T (30).

Outro processo regulado por CD99 é a adesão. O ensaio de agregação homotípica reflete a importância fisiológica dos eventos de adesão célula-célula e isso requer energia e funcionamento perfeito do citoesqueleto. A utilização do anticorpo anti-CD99 induziu a agregação homotípica na linhagem de células Jurkat e nos timócitos DP. Já os timócitos simples-positivos e os linfócitos $\mathrm{T}$ periféricos, em estado de repouso ou ativados, não agregaram quando incubados com o anticorpo. Esse fenômeno foi específico de células T em estágio de maturação. A adesão de linfócitos T desencadeada por CD99 é mediada pela ativação da via da integrina $\alpha 4 \beta 1 /$ VCAM-1. A ativação da linhagem Jurkat com anticorpo anti-CD99 (0662) aumentou a afinidade da integrina $\alpha 4 \beta 1$ em minutos, resultando em maior aderência e rolamento das células no endotélio vascular inflamado (31).

As isoformas de CD99 são expressas de uma maneira célula-específica e determinam funções distintas para CD99 dependendo do tipo celular (23, 32, 33). Nos linfócitos B, as isoformas de CD99 exercem funções opostas no controle da adesão. $A$ isoforma 1 estimulou a adesão mediada pela integrina LFA-1/ICAM-1, enquanto que a isoforma 2 inibiu a adesão celular controlada por esta via. A incubação do anticorpo anti-CD99 levou à agregação homotípica e à expressão de LFA-1 na linhagem de célula IM9 (linfoblasto secretor de IgG). Por outro lado, a superexpressão da isoforma 2 de CD99 nestas mesmas células levou a uma diminuição da expressão de LFA-1 e agregação espontânea interrompida (25). Foi postulado que o domínio citoplasmático da isoforma 2 de CD99 altera a estrutura tridimensional da molécula, expondo diferentes sítios de ligação ao seu ligante (34).

Outro papel atribuído ao CD99 é o transporte de proteínas para a membrana de timócitos imaturos. A ativação de CD99 aumentou a expressão das proteínas do complexo principal de histocompatibilidade ( $\mathrm{MHC}$ ) classe I e II e do receptor de células T. A ativação de CD99 induziu a polimerização da actina, levando à mobilização das moléculas até a superfície celular (35). As proteínas do MHC formam um complexo com CD99 e CD81 capaz de modular diferentes interações imunes, incluindo adesão celular, migração e formação da 
sinapse imunológica, bem como processos intracelulares como organização de complexos de sinalização na membrana (36).

\subsection{O PAPEL DO CD99 NOS TUMORES}

Inicialmente CD99 foi descrito como um marcador de membrana importante no diagnóstico de Sarcoma de Ewing, um tumor ósseo comum em crianças e adolescentes (27, $33,37)$. No entanto, CD99 foi também identificado em outras neoplasias, incluindo tumores primitivos de neuroectoderme, carcinoma de vesícula biliar (38), hepatoblastomas (39), câncer de pulmão (40), neoplasia sólida pseudopapilar do pâncreas $(41,42)$, carcinoma de células de Merkel (43), câncer de próstata (44), rabdomiossarcoma (45), gliomas (46-48), osteossarcoma (37) e em tumores de mama (49). Entre as neoplasias hematopoiéticas, CD99 foi detectado em linfoma linfoblástico, leucemia mieloide aguda e linfoma não-Hodgkin (50, 51).

A função do CD99 nos tumores ainda não foi completamente elucidada. O sarcoma de Ewing é o modelo tumoral mais bem estudado quanto ao papel do CD99. A ativação de CD99 levou a inibição do crescimento tumoral in vitro e in vivo devido à indução da apoptose. Ocorreu também uma inibição da metástase relacionada com a adesão e consequente redução da motilidade das células $(27,33,52)$. Além disso, CD99 desempenha um papel fundamental na diferenciação celular do sarcoma de Ewing. Uma análise de expressão gênica por microarray de células da linhagem 6647 de sarcoma de Ewing tratadas com o anticorpo anti-CD99 encontrou 366 genes diferencialmente expressos, envolvidos na via MAPK/ERK, apoptose e disfunção mitocondrial (53).

Dois mecanismos de morte celular foram descritos nas linhagens de sarcoma de Ewing quando ativadas com anticorpo agonista anti-CD99. Os autores mostraram que os efeitos são mais dramáticos nas células do sarcoma de Ewing que expressam altos níveis de CD99 e são facilitados pela reativação de p53 (raramente mutado no sarcoma de Ewing), resultante da degradação do MDM2 induzida por CD99 (53). Em geral, os dados obtidos tanto no sarcoma de Ewing como na leucemia (30) indicam que a morte celular induzida por 
CD99 ocorre preferencialmente nas células que já possuem alterações genéticas, conferindo seletividade a abordagens anti-CD99 contra células tumorais.

A ativação de CD99 com anticorpo também induziu a um tipo de morte celular nãoapoptótica de células de sarcoma de Ewing através de um mecanismo denominado metuose, que consiste no acúmulo excessivo de vacúolos citoplasmáticos a partir de macropinossomos, comprometendo a viabilidade celular (54). A metuose foi confirmada ao tratarem as células com citocalasina, um inibidor específico de macropinocitose. Ainda, em células de sarcoma de Ewing, a ativação de CD99 com anticorpo promove rapidamente endocitose dependente de caveolina-1 e promove o aumento da regulação da sinalização de IGF-1R e RAS/Rac1, estimulando a formação anômala de vacúolos e morte celular por metuose (54). A metuose inicialmente foi descrita em GBM, no qual uma forma ativada de Rac1 GTPase induziu uma forma de morte celular, sugerindo que RAS age de maneira dependente da via de sinalização modulada por Rac para hiperestimular a macropinocitose em GBM (55).

O fenótipo do sarcoma de Ewing caracteriza-se por grupos de células redondas azuis indiferenciadas, cuja presença dificulta o entendimento da origem deste tumor. Há estudos que sugerem que este tumor tem origem a partir de células tronco-mesenquimais. Outra característica recorrente do sarcoma de Ewing é a presença de um fator de transcrição específico conhecido como EWS-FLI1, gerado a partir de uma translocação cromossomal, que regula a expressão de diversos genes envolvidos na regulação do ciclo celular, apoptose, migração, proliferação e diferenciação das células $(27,56)$. CD99 e EWS-FLI-1 apresentam, entretanto, papéis opostos no sarcoma de Ewing: enquanto EWS-FLI-1 induziu a diferenciação celular, CD99 foi capaz de prevenir. O mecanismo de diferenciação celular está relacionado com a expressão de um micro RNA, o miR-34. Células silenciadas para o CD99 apresentam maior expressão de miR-34, levando a uma redução da expressão de Notch 1 e NF- $\kappa B$, aumentando, assim, a diferenciação dessas células tumorais (57). O silenciamento do CD99 em linhagem de células de sarcoma de Ewing induziu uma fosforilação prolongada de ERK1/2 nuclear, alterando as funções biológicas dessa MAP quinase para o desenvolvimento e diferenciação neural, reduzindo a sinalização de $\operatorname{AKT}$ e NF-KB $(27,57)$ e orientando as células em direção a um estado de diferenciação neural terminal, independentemente da 
presença do EWS-FLI. A supressão do CD99 pode assim servir como um mecanismo de ajuste fino dos níveis regulação transcricionaldos genes, para alterar o equilíbrio em favor da diferenciação ao invés de proliferação celular (57). A Figura 3 resume as vias de sinalização ativadas por CD99 no sarcoma de Ewing.

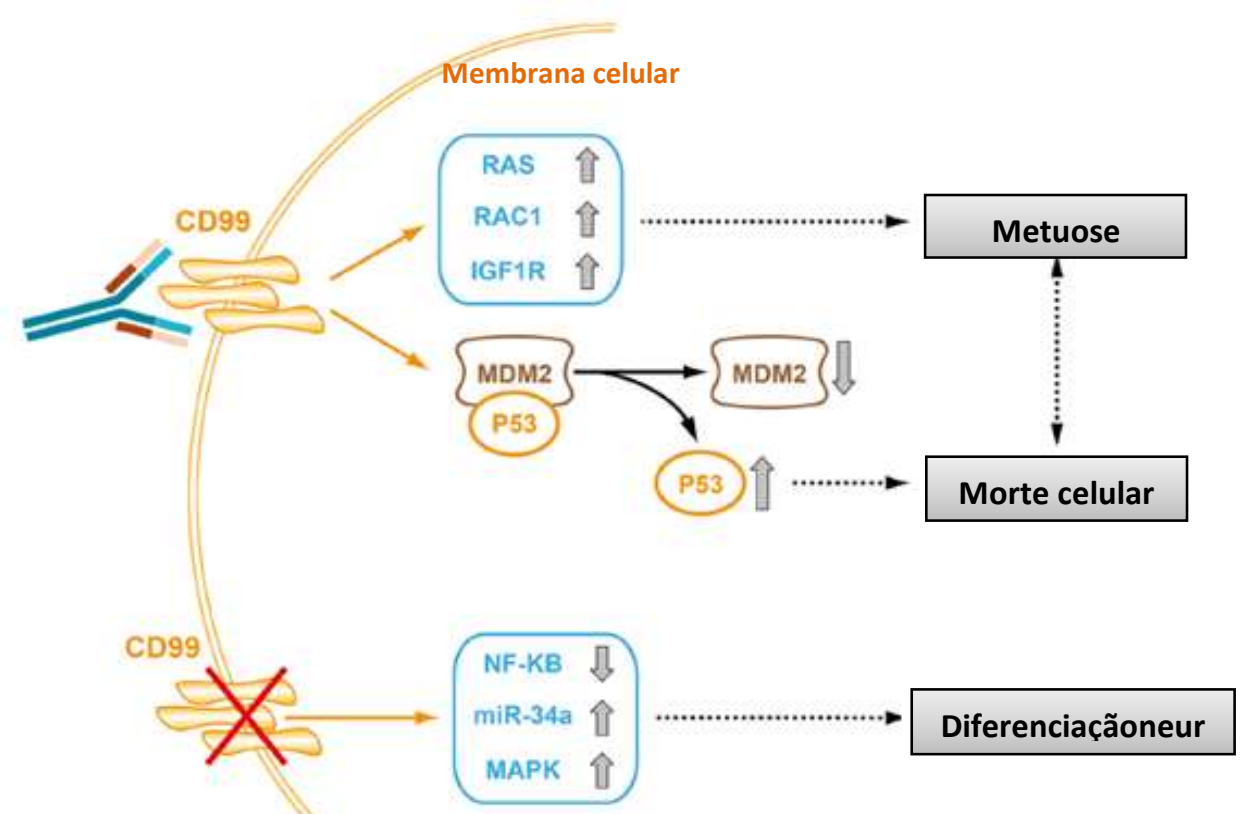

Figura 3. Representação esquemática da sinalização de CD99 em células de sarcoma de Ewing. São mostradas as relações dos mecanismos entre o silenciamento do CD99 e a regulação da diferenciação neural ou entre a ativação de CD99 mediada por anticorpo e a morte celular. Adaptado de Pasello et al.(2018).

Em tumores de mama, por sua vez, foram demonstradas diferenças no papel das isoformas de CD99. Quando a isoforma 2 de CD99 foi superexpressa na linhagem de tumor de mama, observou-se um aumento na capacidade migratória, sendo que o mesmo efeito não foi observado com o aumento da expressão da isoforma 1. Ocorre uma ativação da via ERK1/2 e JNK, via Src e PI3K/Akt, levando à modulação da expressão de MMP-9, conforme mostrado na Figura $4(32,58)$.

Um estudo analisou a expressão de CD99 em um grupo de 122 pacientes com tumor de mama e revelou a presença de CD99 apenas em 11,5\% dos casos. Houve correlação do CD99 com a baixa expressão de ciclina D1 e alta expressão de topoisomerase Il $\alpha$ (Topll $\alpha$ ). A ciclina D1 está envolvida na via de sinalização do receptor de estrógeno e a expressão de 
Topll $\alpha$ está associada com um maior grau histológico do tumor, alta proliferação e ausência de receptores hormonais (59).

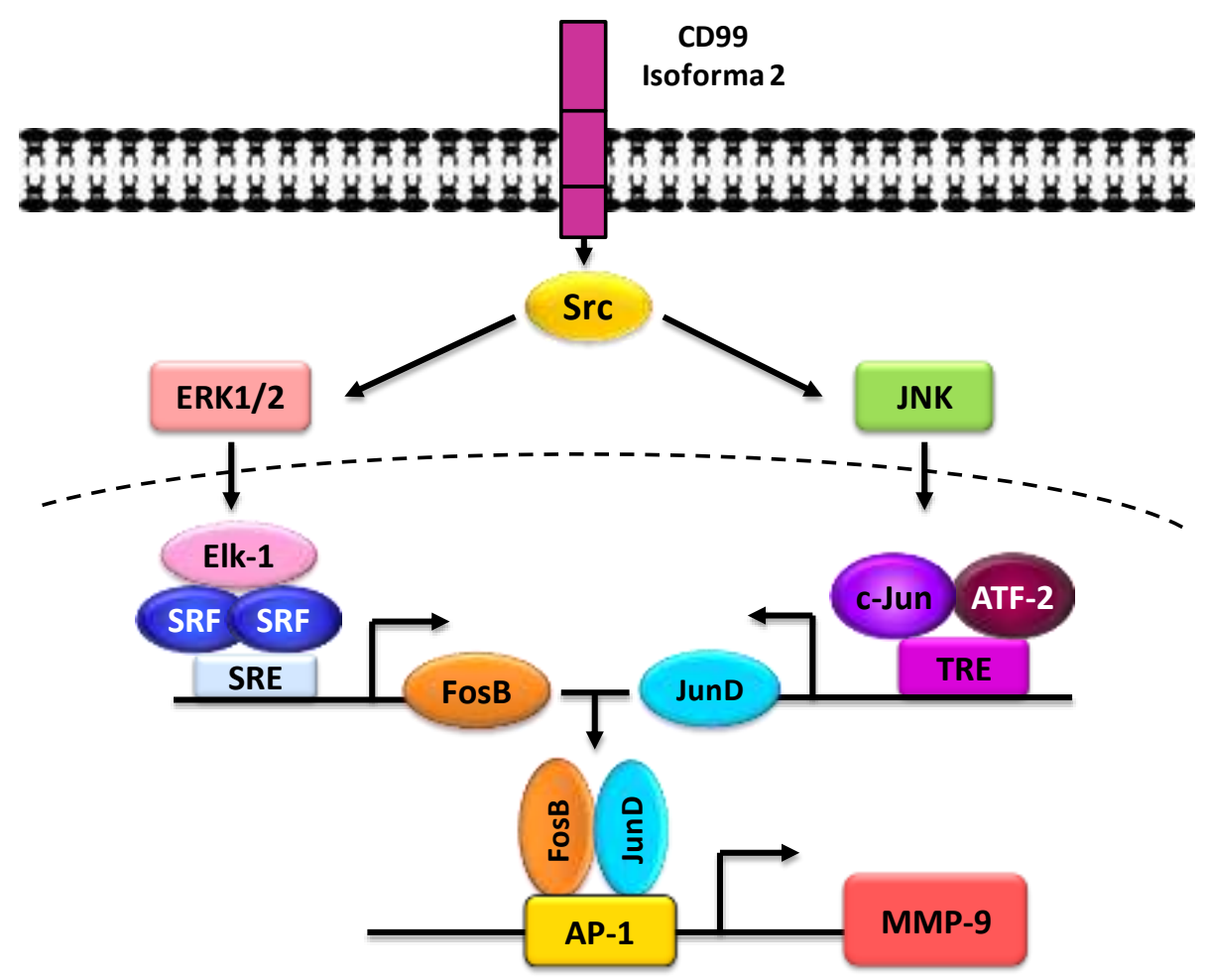

Figura 4. Mecanismo molecular mediado pela isoforma 2 de CD99 na regulação da motilidade celular. A ativação induz a fosforilação de Src e consequente ativação direta de ERK1/2 e JNK. ERK1/2 ativado modula a expressão do gene FOSB regulado por Elk-1. JNK ativado, por sua vez, regula a expressão do gene JunD mediado por c-jun. O complexo resultante JunD-FosB aumenta a expressão dos genes responsivos a AP-1, como, por exemplo, MMP-9, além de outros genes que promovem a motilidade celular. Adaptado de Byun et al.(2006).

Por outro lado, a baixa expressão de CD99 em osteossarcoma está associada com a manutenção do fenótipo metastático e pior prognóstico. Foi verificado que as isoformas 1 e 2 de CD99 desempenham efeitos opostos no osteossarcoma. A superexpressão da isoforma 1 de CD99 em linhagens de osteossarcoma diminuiu a migração e sobrevivência celular, através da indução da apoptose. CD99 forma um complexo estável com caveolina-1, uma molécula com função oncossupressora no osteossarcoma, e c-Src (37). Com a inibição de cSrc há diminuição da atividade de ROCK2 e ezrina que são proteínas multifuncionais que regulam a adesão e a motilidade celular através da conexão da actina do citoesqueleto aos componentes de matriz extracelular. Simultaneamente a $\mathrm{N}$-caderina e $\beta$-catenina são translocadas para a membrana plasmática,favorecendo a formação de junções aderentes e interações célula-célula estáveis, inibindo, assim, a migração celular. A re-expressão da 
isoforma 1 de CD99 aumenta a força de contato e reativa sinais de parada da migração celular através da neutralização da ação pro-migratória da ezrina nas células de osteossarcoma. Além disso, a expressão forçada da isoforma 1 de CD99 em células de osteossarcoma induziu a regulação negativa de genes envolvidos no remodelamento da actina do citoesqueleto e invasão celular, como $A R P 2 / 3$ e ACTR2, levando à diminuição da migração celular (60). A restauração da expressão de CD99 em linhagens celulares de osteossarcoma mostrou seu envolvimento na diferenciação deste tipo celular, semelhante à função desempenhada na diferenciação dos timócitos DP. A isoforma 2 de CD99 modula vias osteogênicas por ativação de ERK1/2 nestas células (61). A expressão forçada da isoforma 2de CD99 favorece o recrutamento de ERK1/2 para a membrana da célula aumentando a atividade das vias de sinalização de RUNX2 e AP-1, estimulando a osteoblasteogênese (28) como mostra a Figura 5. A perda de CD99 foi associada a um pior prognóstico em pacientes com osteossarcoma, tumores gástricos e pancreáticos (40).

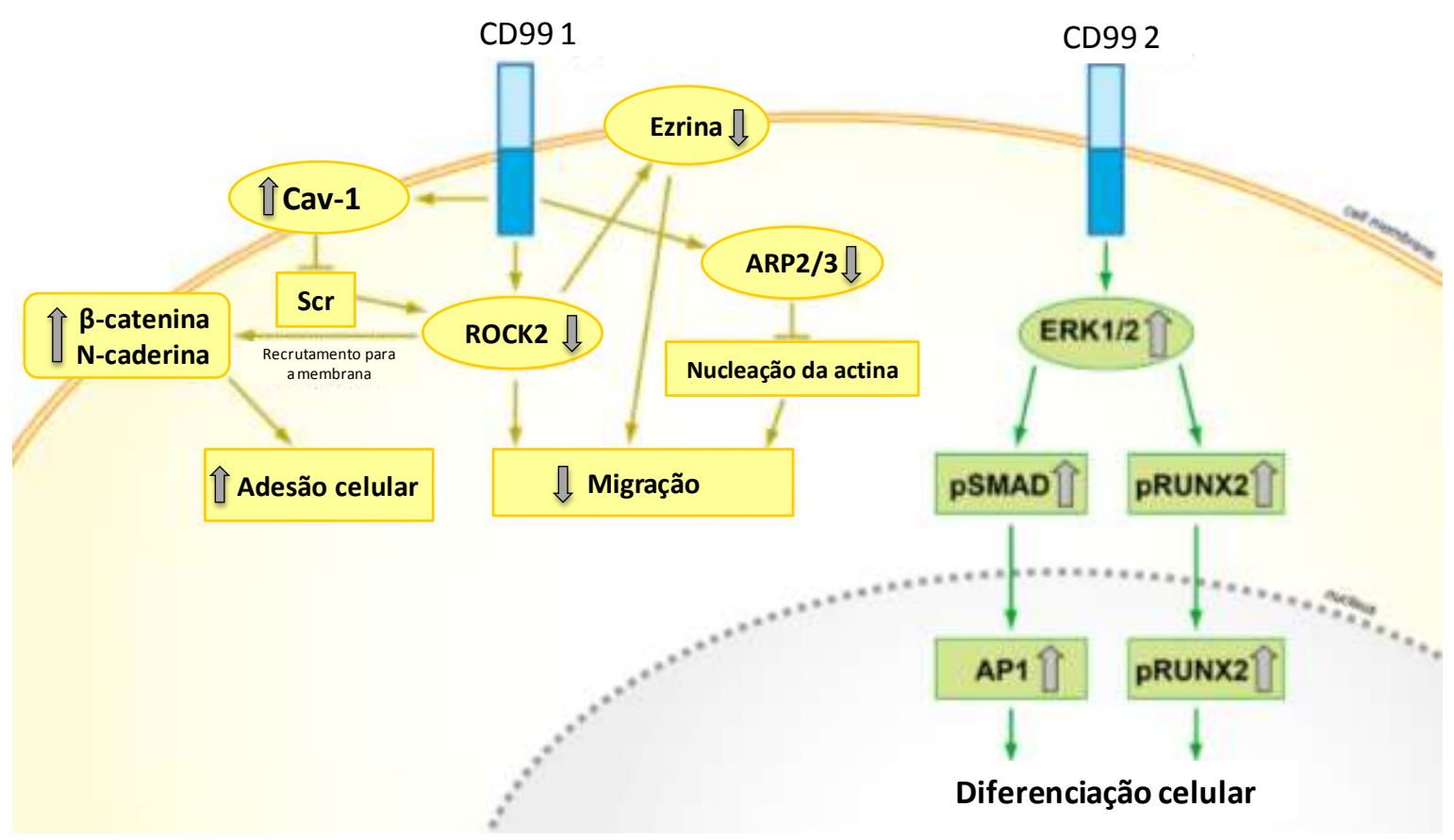

Figura 5. Representação esquemática dos efeitos funcionais da superexpressão de CD99 em células de osteossarcoma. CD991 inibe o eixo c-Src/ROCK2, que leva à inibição de ezrina, recrutamento de $\mathrm{N}$-caderina e $\beta$-catenina para a membrana plasmática e regulação negativa ARP2/3, aumentando assim a adesão celular e reduzindo a migração. CD992 regula a sinalização ERK1/2 e promove a atividade dos principais fatores transcricionais osteogênicos AP1 e RUNX2, que reativa a diferenciação celular. Adaptado de Manara et al. (2018). 
Nas células tumorais MCF-7, CD99 regulou de forma negativa a tumorigenicidade e metástase mediada por FAK (quinase de adesão focal). Nesse modelo CD99 inativa a integrina $\beta 1$ através da desfosforilação de FAK e o CD98 exerce um efeito oposto sobre a sua regulação. A ativação de CD98 facilita a formação dos complexos PKC $\alpha$-sintenina-FAK e IPPAkt1-sintenina que, por sua vez, modulam a via de sinalização ativada pela integrina $\beta 1$ levando a formação das adesões focais. A ativação de CD99 recruta a proteína SHP2 que desfosforila FAK, inibindo a formação do complexo FAK-talina e talina-integrina $\beta 1$, resultando na diminuição da adesão célula-matriz extracelular (62). Lee at al. desenvolveram peptídeos agonistas do CD99 que foram capazes de ativar a proteína quinase A (PKA) e recrutar a proteína SHP2. Uma vez que SHP2 foi ativada por PKA, ela induziu a fosforilação de ERK1/2 através da via de sinalização HRAS/RAF1/MEK. Subsequente a isso, FAK foi desfosforilada nos resíduos Y397 e S910, através da tirosina fosfatase intracelular PTPN12 e peptidil-prolil cis/trans PIN1. Esse estudo sugere que o ligante agonista de CD99 pode suprimir a atividade da integrina $\beta 1$ através da via de sinalização PKA/SHP2/ERK1/2/PTPN12/FAK $(63,64)$.

\subsection{CD99 E O PAPEL NOS ASTROCITOMAS}

O estudo de CD99 resultou do interesse do nosso grupo em investigar genes com alta expressão em placenta e astrocitomas, que poderiam contribuir para o estabelecimento e manutenção do fenótipo maligno tumoral, além de possivelmente ser um marcador tumoral e/ou um potencial alvo terapêutico (21).

A expressão de CD99 foi maior nos astrocitomas de diferentes graus de malignidade em relação às amostras controle não tumorais de tecido cerebral (Figura 6A). Estes dados representam a expressão de CD99 total, não distinguindo as isoformas. A expressão gênica diferencial nos astrocitomas foi ainda confirmada pela análise da proteína por western blot (Figura 6B e 6C). A imunohistoquímica revelou acentuada marcação de CD99 na membrana plasmática nas linhagens U87MG e A172, semelhante àquela observada nas amostras de GBM (21). 
A

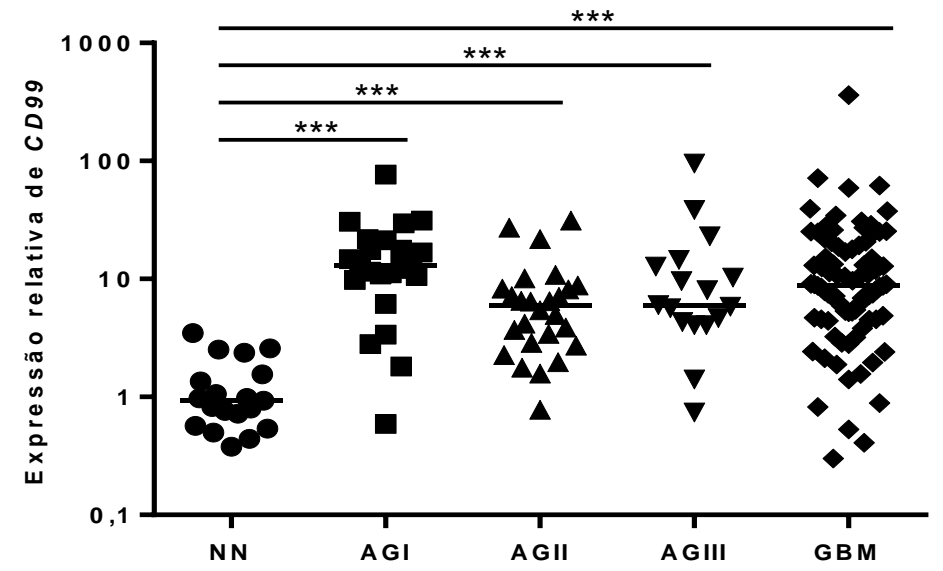

B

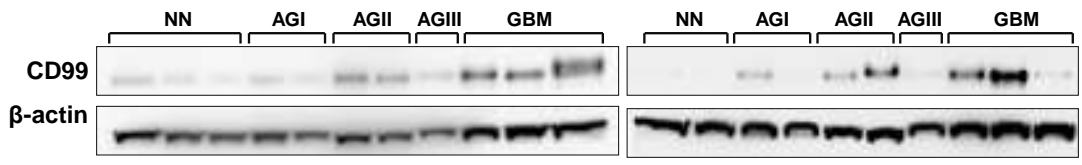

C

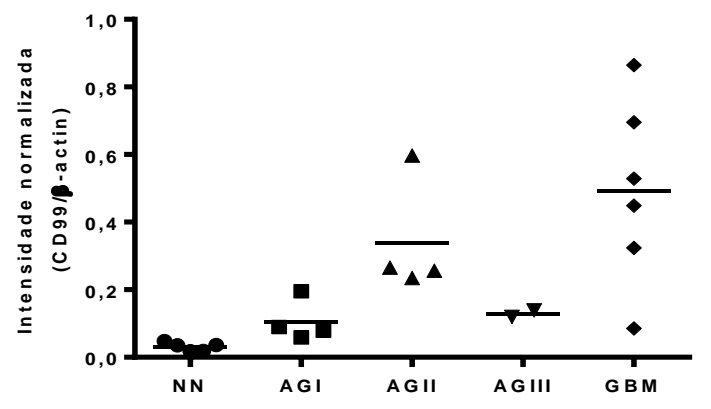

Figura 6. Análise de expressão do gene e da proteína CD99 em astrocitomas. (A) Expressão relativa do gene CD99 em astrocitomas de diferentes graus de malignidade (AGI, AGII, AGIII e GBM) em relação aos tecidos cerebrais não tumorais (NN). A barra horizontal indica a média de cada grupo. (B) Expressão da proteína CD99 em astrocitomas de diferentes graus de malignidade em relação aos tecidos cerebrais não tumorais. (C) Densitometria de CD99 relativa proteína $\beta$-actina. As linhas horizontais indicam a média de cada grupo. Adaptado de Urias et al. (2014).

CD99 foi uma das 31 proteínas de membrana com alta expressão em gliomas identificada em um estudo de microarray que buscou identificar potenciais alvos terapêuticos nestes tumores (46). Em um estudo de meta-análise com dados de expressão de microarrays de astrocitomas, CD99 foi identificado entre os 10 genes com alta expressão que poderiam influenciar no desenvolvimento de GBM (48).

Seol e colaboradores superexpressaram CD99 na linhagem de GBM U87MG e observaram um aumento da adesão celular, invasão e migração, além do aumento da atividade de Rac e diminuição atividade de Rho, em vias de sinalização independente de PI3K/Akt, ERK1/2 e JNK. Neste mesmo estudo foi demonstradauma interação de CD99 com 
as proteínas calpaína-1 e proteínas chaperonas 14-3-3, que possivelmente regulam a atividade do citoesqueleto através de Rac e Rho (47).

\subsection{CD99 COMO ALVO TERAPÊUTICO}

CD99 foi proposto como um dos antígenos associados ao tumor como candidatos a imunoterapia por apresentar alta expressão gênica e protéica em um estudo com duas linhagens de GBM (U343 e U87MG) (65).

A ativação de CD99 com o anticorpo agonista 0662 em sarcoma de Ewing inibiu significativamente o crescimento das linhagens celulares de sarcoma de Ewing in vivo e in vitro por meio da indução da apoptose, reduzindo o potencial maligno nestas células (52). Estudos estruturais identificaram o epítopo de ligação do anticorpo 0662 no resíduo de fenilalanina da posição 68, uma região importante para desencadear sinais biológicos mediante a ativação de CD99 (25). A administração simultânea do anticorpo 0662 e doxorrubicina promoveu efeito sinérgico na inibição do crescimento tumoral in vitro, enquanto que a combinação dos dois agentes foi efetiva para inibiro crescimento tumoral e metástases in vivo (33).

O desenvolvimento de um anticorpo recombinante bivalente anti-CD99 humano ( $d A b d$ C7) com especificidade pelas linhagens celulares de sarcoma de Ewing, apresentou pouca ou quase nenhuma especificidade por células não-tumorais (66). A ativação do CD99 pelo anticorpo bivalente $\mathrm{C7}$ dAbd induziu uma rápida e massiva morte celular nas células de sarcoma de Ewing por meio da degradação da proteína MDM2 e reativação de p53, além de potencializar o efeito citotóxico da doxorrubicina (53). A produção do anticorpo bivalente C7 dAb através da expressão em bactéria permitiu a obtenção em larga escala, mais rápida e com menor custo (67). Após purificação do anticorpo a atividade anti-proliferativa e próapoptótica, independente de caspase, foram confirmadas em linhagens de sarcoma de Ewing.

Recentemente, foi descrita uma pequena molécula, clofarabina, já aprovada pelo FDA para tratar linfoma, capaz de ligar na porção extracelular de CD99, inibindo as propriedades biológicas nas linhagens celulares do sarcoma de Ewing tanto in vitro e in vivo, 
sugerindo assim um uso direcionado de uma droga já desenvolvida e em uso para o tratamento de pacientes com outro tipo de neoplasia (68). O mecanismo de ação dessa droga consiste em parar a replicação de DNA, inibição do reparo do DNA e indução da quebra da cadeia de DNA e apoptose. A clofarabina inibiu seletivamente o crescimento celular de culturas de células de sarcoma de Ewing com valores de IC50 30 vezes menor em comparação com linhagens de GBM, osteosarcoma, tumores de mama, pulmão, próstata e rim. Além disso, a clofarabina diminuiu significativamente o crescimento do tumor em três modelos xenográficos de sarcoma de Ewing (68). 


\section{JUSTIFICATIVA}

Este estudo analisou o transcriptoma da linhagem U87MG silenciada para o gene CD99 para um melhor conhecimento a respeito das vias de sinalização moduladas por CD99 em GBM. A partir destes resultados foram realizados experimentos funcionais in vitro e in vivo para comprovação do papel do CD99 na regulação do desenvolvimento e crescimento do GBM. 


\section{OBJETIVOS}

O objetivo do presente projeto é caracterizar a expressão das isoformas 1 e 2 de CD99 e estudar o papel funcional do CD99 através de silenciamento permanente da expressão gênica na linhagem de GBM humano U87MG. Foram desenvolvidas, especificamente, as seguintes etapas:

1. Análise a expressão das isoformas de CD99 em astrocitomas de diferentes graus de malignidade e amostras de tecido cerebral não tumoral e na linhagem U87MG;

2. Sequenciamento e análise do transcriptoma da linhagem de GBM humano U87MG silenciadas para a expressão de CD99 com siRNA para identificação de processos e vias de sinalização nos quais CD99 pode estar envolvido;

3. Silenciamento da expressão gênica de CD99 por shRNA na linhagem celular U87MG a fim de realizar os ensaios funcionais de validação dos dados de transcriptoma in vitro;

4. Análise da capacidade de crescimento tumoral e o efeito proliferativo da linhagem U87MG silenciada in vivo. 


\section{MATERIAIS E MÉTODOS}

\subsection{CASUÍSTICA}

As amostras de astrocitomas de diferentes graus foram coletadas durante o procedimento cirúrgico e imediatamente congeladas em nitrogênio líquido após ressecção pelo grupo de Tumores Encefálicos e Metástases da Divisão de Clínica Neurocirúrgica do Instituto Central do Departamento de Neurologia do Hospital das Clínicas da Faculdade de Medicina da Universidade de São Paulo (HC-FMUSP). As amostras de tecido não neoplásico foram coletadas do lobo temporal de paciente com epilepsia durante procedimento cirúrgico realizado pelo grupo de Epilepsia. A casuística deste projeto consistiu em 19 amostras de tecido cerebral não-neoplásico, 22 astrocitomas grau I, 26 astrocitomas grau II, 17astrocitomas grau III e 84 de glioblastoma. Todos os tecidos utilizados no presente estudo possuem confirmação histopatológica da Divisão de Anatomia Patológica do HC-FMUSP, de acordo com a classificação da OMS, e fazem parte do biorrepositório de amostras coletadas durante o Projeto Genoma Clínico, aprovado pela Comissão Nacional de Ética em Pesquisa (CONEP) e pela Comissão de Ética para Análise de Projetos de Pesquisa (CAPPesq) do HCFMUSP, sob o número de protocolo 830/01. Os consentimentos pós-informados foram obtidos de todos os pacientes com tumor e epilepsia ou seus responsáveis legais.

\subsection{LINHAGEM CELULAR}

As linhagens comerciais estabelecidas de GBM humano U87MG e HEK293T foram cultivadas em monocamada e mantidas em meio DMEM, suplementado com $10 \%$ de soro fetal bovino (SFB) e antibióticos (estreptomicina e penicilina). As células foram mantidas em incubadora a $37^{\circ} \mathrm{C}$ com $5 \%$ de $\mathrm{CO}_{2}$ e desagregadas com tripsina/EDTA, centrifugadas a 2000 rpm por 10 minutos e ressuspensas em DMEM para replaqueamento. O azul de Tripan foi utilizado para avaliar a concentração e viabilidade das células em contador automático Countess (Thermo Fisher Scientific). 


\subsection{ANIMAIS}

Foram utilizados 70 camundongos Balb/c Nude fêmeas de 8 a 10 semanas de idade, provenientes do Biotério Central da FMUSP, mantidos em condições padronizadas (temperatura $23^{\circ} \mathrm{C}$ a $25^{\circ} \mathrm{C}$, ciclo de 12 horas claro/escuro), água e dieta ad libitum. Todos os experimentos foram conduzidos de acordo com os padrões éticos e a realização do projeto foi aprovada pelo Comitê de Ética para Análise de Projetos de Pesquisa (CAPPesq) do HCFMUSP sob o número de protocolo 830/01 e Comissão de Ética no Uso de Animais (CEUA) do Biotério Central da FMUSP sob o número de registro 122/15. As amostras tumorais congeladas foram analisadas em criocortes de $4 \mu \mathrm{m}$ corados com hematoxilina e eosina para verificação da qualidade. Porções de tecidos não tumorais (tecido normal, necrose) foram dissecados previamente à extração de RNA total, realizada com RNeasy Mini Kit (Qiagen), para garantir uma porcentagem maior que $80 \%$ de tecido tumoral. Para extração do RNA total de culturas de células, as células foram lisadas em tampão do kit. As concentrações e pureza dos RNAs extraídos foram determinadas através de leitura em espectrofotômetro por leitura a 260 e $280 \mathrm{~nm}$. Razões A260/A280 maiores que 1,8 foram consideradas de pureza satisfatória. As amostras foram estocadas a $-80^{\circ} \mathrm{C}$ até sua utilização para a síntese de DNA complementar (cDNA).

\subsection{SÍNTESE DE DNA COMPLEMENTAR POR TRANSCRIÇÃO REVERSA}

O procedimento para a obtenção cDNA foi realizado inicialmente com digestão do RNA total com DNase para eliminar qualquer contaminação com DNA genômico. A transcrição foi realizada com transcriptase reversa SuperScript III, inibidor de RNase (RNaseOUT), oligonucleotídeos randômicos e oligodT, de acordo com recomendações do fabricante (Thermo Fisher Scientific). O cDNA obtido foi tratado com $1 U$ de RNase H (USB) a $37^{\circ} \mathrm{C}$ por 30 minutos e $72^{\circ} \mathrm{C}$ por 10 minutos para eliminar eventuais híbridos formados. Em seguida foi diluído em tampão Tris-EDTA (TE) e armazenado a $-20^{\circ} \mathrm{C}$ para subsequentes análises de expressão gênica. 


\subsection{ANÁLISE DE EXPRESSÃO GÊNICA POR PCR EM TEMPO REAL}

O nível de expressão da linhagem celular foi analisado por PCR em tempo real quantitativo (qRT-PCR). As reações foram realizadas pelo método de incorporação de SYBR Green, em aparelho ABI 7500 (Applied Biosystems). Os oligonucleotídeos foram desenhados em exons diferentes, para evitar amplificação de possível DNA contaminante, e sintetizados pela MWG Biotech. As reações foram realizadas em duplicatas em um volume final de reação de $10 \mu \mathrm{L}$, contendo $5 \mu \mathrm{L}$ de Power Sybr Green PCR Master Mix (Applied Biosystems), $2,5 \mu \mathrm{L}$ de cDNA e 2,5 $\mu \mathrm{L}$ de oligonucleotídeos em concentração previamente padronizada. As condições de amplificação foram: incubação a $50^{\circ} \mathrm{C}$ por 5 minutos, desnaturação inicial a $95^{\circ} \mathrm{C}$ por 10 minutos, 40 ciclos de $95^{\circ} \mathrm{C}$ por 15 segundos (desnaturação) e $60^{\circ} \mathrm{C}$ por 60 segundos (anelamento dos oligonucleotídeos e extensão).

O valor de expressão do gene foi normalizado com um gene de referência como controle interno, o HPRT nos experimentos celulares. No caso de expressão dos tecidos, a média geométrica de três genes de referência foi utilizada, HPRT, GUSB e BCRP. A amplificação de produto único foi confirmada através da análise de sua curva de dissociação. Os produtos da PCR também foram analisados em eletroforese em gel de agarose, corados com Gel Red (Biotium), para confirmação da amplificação do tamanho correto do produto. A eficiência de amplificação [E=10(-1/slope)-1)] foi calculada utilizando-se diluições seriadas de cDNA. A equação $2^{-\Delta C t}$ foi aplicada no cálculo da expressão gênica para $E=100 \pm 10 \%$, onde $\Delta \mathrm{Ct}$ = média do $\mathrm{Ct} C D 99$ - média do $\mathrm{Ct}$ do gene normalizador (HPRT para os experimentos celulares e média de HPRT, GUSB e BCRP para amostras biológicas)(69).

As informações sobre os oligonucleotídeos e tamanho dos produtos de qRT-PCR de todos os genes estão apresentadas na Tabela 1. 
Tabela 1. Tamanho do produto e sequência dos oligonucleotídeos utilizados para as reações de PCR quantitativo em tempo real

\begin{tabular}{|c|c|c|c|}
\hline Gene & $\begin{array}{l}\text { Tamanho do } \\
\text { produto }(\mathrm{pb})\end{array}$ & Orientação & Primer (5'- 3') \\
\hline CD99 & 113 & $\begin{array}{c}\text { Senso } \\
\text { Antisenso }\end{array}$ & $\begin{array}{c}\text { GATTTATCCGATGCCCTTCCT } \\
\text { TTTTCTCCATCAACAACAGCATCT }\end{array}$ \\
\hline $\begin{array}{c}\text { CD99 } \\
\text { isoforma } 1 \\
\end{array}$ & 106 & $\begin{array}{c}\text { Senso } \\
\text { Antisenso }\end{array}$ & $\begin{array}{l}\text { GATTGTGGGGGCTGTCGT } \\
\text { CACCTCCCCTTGTTCTGCATT }\end{array}$ \\
\hline $\begin{array}{c}\text { CD99 } \\
\text { isoforma } 2\end{array}$ & 108 & $\begin{array}{c}\text { Senso } \\
\text { Antisenso }\end{array}$ & $\begin{array}{c}\text { GATTGTGGGGGCTGTCGT } \\
\text { TCCCTAGGTCTTCAGCCATCATT }\end{array}$ \\
\hline GUSB & 101 & $\begin{array}{c}\text { Senso } \\
\text { Antisenso }\end{array}$ & $\begin{array}{l}\text { GAAAATACGTGGTTGGAGAGCTCATT } \\
\text { CCGAGTGAAGATCCCCTTTTTA }\end{array}$ \\
\hline HPRT & 118 & $\begin{array}{c}\text { Senso } \\
\text { Antisenso }\end{array}$ & $\begin{array}{l}\text { TGAGGATTTGGAAAGGGTGT } \\
\text { GAGCACACAGAGGGCTACAA }\end{array}$ \\
\hline$B C R P$ & 67 & $\begin{array}{c}\text { Senso } \\
\text { Antisenso }\end{array}$ & $\begin{array}{l}\text { CCTTCGACGTCAATAACAAGGAT } \\
\text { CCTGCGATGGCGTTCAC }\end{array}$ \\
\hline
\end{tabular}

\subsection{SILENCIAMENTO POR RNA DE INTERFERÊNCIA PEQUENO (SIRNA)}

A transfeç̧ão transitória foi realizada em $1 \times 10^{5}$ células em placas de seis poços com Lipofectamine RNAiMAX (Life Technologies) e siRNA para CD99 (RNA dupla fita de 27 mers) sintetizado pela IDT (Integrated DNA Technologies). Como controle experimental, foi realizada transfeç̧ão com um oligonucleotídeo sem homologia com genes humanos (NonTargeting Control - NTC). A concentração final de oligonucletídeos utilizada foi de 10 nM. Uma vez concluído cada experimento, foi realizado extração de RNA. A eficiência do silenciamento foi determinada pelo nível de redução da expressão de CD99 nas linhagens silenciadas em comparação ao controle NTC por qRT-PCR por 2, 4 e 7 dias após transfecção. Western blot foi realizado no dia 2.

\subsection{ANÁLISE DO TRANSCRIPTOMA (RNA-SEQ)}

\subsubsection{Análise de genes diferencialmente expressos de células U87MG após silenciamento com SiRNA}

O preparo da biblioteca de cDNA foi realizado a partir de $1 \mu \mathrm{g}$ de RNA total extraído da linhagem U87MG silenciada por siRNA e NTC (non target control) de duplicatas 
experimentais. O silenciamento por siRNA foi realizado no trabalho anterior do laboratório (21).

A construção da biblioteca foi realizada com kit TruSeq Stranded Total RNA (Illumina). A partir da amostra total de RNA foi feita a depleção do RNA ribossômico citoplasmático e mitocondrial com esferas magnéticas Ribo-Zero Gold. O RNA foi fragmentando por meio de cátions divalentes e transcrito para a primeira fita de cDNA com transcriptase reversa e oligonucleotídeos randômicos. A síntese da segunda fita de cDNA foi realizada com DNA polimerase. Aos fragmentos de cDNA foram adicionados adaptadores e índices com sequências únicas para cada amostra. As bibliotecas foram enriquecidas por PCR e quantificadas por qRT-PCR (Kapa Library Quantification Kit, Kapa Biosystems). O tamanho médio foi determinado no equipamento Bioanalyzer 2100 (Agilent Technologies). O sequenciamento das bibliotecas de RNA-seq foi realizado em sequenciadorHiSeq 2500 (Illumina), que faz parte da Rede PREMiUM de equipamentos multiusuários (SELA Sequenciamento em Larga Escala) da FMUSP. A análise foi realizada com a ajuda de Antonio Marcondes Lerário, colaborador da Universidade de Michigan, de acordo com os seguintes passos:

1. Alinhamento dos dados: os dados brutos (arquivos .FASTQ) de sequenciamento foram alinhados à versão hg38 do genoma humano através do software STAR (70). Ao final desta etapa, foram gerados dois tipos de arquivos .BAM: um deles com as sequências de leituraalinhadas às coordenadas genômicas e o outro às do transcriptoma. Os dados referentes às coordenadas do transcriptoma (conjunto de genes e numeração dos exons, bem como suas coordenadas) foram obtidos do portal do Ensembl.

2. Quantificação dos dados de expressão gênica: após gerados os arquivos .BAM, foi feita a quantificação da expressão de cada gene através do software STAR(71). Foram geradas planilhas individuais para cada amostra, contendo os dados de expressão brutos (medida em contagens por gene) e os dados normalizados segundo dois diferentes métodos: RPKM e COM (72). Além disso, foi gerada uma planilha baseada nos dados em contagens, em que as linhas correspondem a cada gene do transcriptoma e as colunas a cada uma das amostras. 
3. Análise estatística: para a análise de expressão diferencial, foi utilizado o framework limma-voom, disponível no portal Bioconductor (73). Os dados brutos (planilha com as contagens geradas na etapa anterior) foram inicialmente log-transformados e normalizados. Posteriormente, a análise estatística (expressão diferencial entre os grupos) foi realizada através de modelos lineares e aplicação de estatística $t$ moderada.

4. Controle de qualidade: Os arquivos .FASTQ foram submetidos à análise de controle de qualidade realizada pelo software FASTQC. Além disso, a análise de qualidade incluiu para cada amostra uma estimativa do número de genes detectados, o nível de contaminação por RNA ribossômico, a relação entre transcritos intrônicos e exônicos, bem como o número total de sequências alinhadas, entre outros. Esta análise é feita com a ferramenta RNASeqC (74).

A análise final dos resultados do RNA-seq (diferença de expressão das células silenciadas por siRNA em relação ao controle NTC) foi realizada através do banco de dados DAVID (https://david.ncifcrf.gov/).

\subsubsection{Análise de dados do TCGA}

Os dados de expressão deRNAseq de casos de GBM do TCGA (The Cancer Genome Atlas) foram baixados do portal Genomic Data Commons (https://portal.gdc.cancer.gov/) e normalizados pelo programa DEseq (75).

\subsection{GERAÇÃO DA LINHAGEM U87MG SILENCIADA PARA CD99 POR SHRNA (SHORT HAIRPIN RNA)}

\subsubsection{Titulação da concentração de puromicina}

Antes de iniciar o ensaio de silenciamento por shRNA na linhagem U87MG, foi realizada a otimização da concentração do antibiótico puromicina necessária para a seleção dos clones positivos após a transdução das células com as partículas lentivirais. Um total de $1 \times 10^{5}$ células foi semeado em placas de 6 poços. Após 24 horas foi adicionada puromicina 
nas seguintes concentrações: $0,25,0,5,1,2$ e $5 \mu \mathrm{g} / \mathrm{mL}$. As células foram examinadas a cada 2 dias. Ao final de 5 dias, a menor concentração que causou morte completa das células foi considerada ideal para a seleção das células transduzidas.

\subsubsection{Obtenção dos plasmídeos}

CD99 foi silenciado na linhagem U87MG com dois vetores lentivirais comerciais (MISSION shRNA Library, Sigma-Aldrich), com duas sequências diferentes, clones TRCN0000057506 e TRCN0000057503,nomeados shCD99 1 e shCD99 2, respectivamente. Como controle foi utilizado o vetor lentiviral scrambled SHC016 (MISSION shRNA Control Vector), com uma sequência aleatória sem homologia a nenhum gene humano. O vetor no qual estão inseridas as sequências de shRNA de CD99 e controle, pLKO.1-puro, possui um gene que confere resistência ao antibiótico puromicina, utilizado para a seleção das células transduzidas. As sequências dos shRNAs são apresentadas na Tabela 2.

Tabela 2. Sequências dos shRNAs controle e do gene CD99

\begin{tabular}{ll}
\hline Abreviatura & Sequências (5'-3') \\
\hline Scrambled & CCGGGCGCGATAGCGCTAATAATTTCTCGAGAAATTATTAGCGCTATCGCGCTTTTT \\
\hline shCD99 1 & CCGGGCGTTTCAGGTGGAGAAGGAACTCGAGTTCCTTCTCCACCTGAAACGCTTTTTG \\
\hline shCD99 2 & CCGGCGGATGGTGGTTTCGATTTATCTCGAGATAAATCGAAACCACCATCCGTTTTTG \\
\hline
\end{tabular}

Primeiramente foram produzidos os plasmídeos com as sequências dos shRNAs do CD99 ou controle. Para tanto, as bactérias contendo os vetores plasmideais do CD99, do controle, do capsídeo (pCMV delta R 8.2, Addgene) e das proteínas virais (pCMV-VSV-G, Addgene) foram crescidas em meio LB líquido na presença de ampicilina.

Para a produção de partículas lentivirais contendo gene da proteína fluorescente vermelha TurboFP635, foram utilizados os vetores estruturais para a produção das partículas lentivirais pMDL (vetor codificante para as sequências gag e pol), pREV (vetor codificante para a proteína Rev, responsável pela exportação do RNA viral para o citoplasma), pVSVG (vetor codificante para a proteína VSVG do envelope viral). Todos os vetores foram cedidos pelo Dr. InderVerma (Salk Institute for Biological Studies, CA, EUA). O vetor pTurboFP635 é 
comercial e contém gene de resistência a kanamicina (Evrogen).

Todos os DNAs plasmideais foram extraídos utilizando o Plasmid Midi Kit (Qiagen).

\subsubsection{Produção das partículas lentivirais}

A produção do vírus e a transdução da linhagem celular U87MG foram realizadas em laboratório com nível de biossegurança NB-2 do Laboratório de Virologia, LIM52, do Departamento de Doenças Infecciosas e Parasitárias do Instituto de Medicina Tropical da USP, CQB: 0217/06. A manipulação do lentivírus foi realizada em cabine de biossegurança classe 2 com a utilização de EPIs adequados.

As partículas lentivirais contendo os vetores para silenciamento foram produzidas em células empacotadoras na linhagem HEK293T. Um total de $2 \times 10^{6}$ células foram semeadas em placa de $10 \mathrm{~cm}$ na presença de meio de cultura DMEM contendo $10 \%$ de SFB, $25 \mathrm{mM}$ de glicose e sem antibióticos. A cotransfecção das células com os plasmídeos de interesse (shCD99 1 e 2, ou controle), mais o pCMV delta R 8.2 e pCMV-VSV-G, foi realizada utilizando o reagente de transfecção FuGENE HD (Promega). Após 72 horas de incubação em estufa de $\mathrm{CO}_{2}$ as partículas virais produzidas e secretadas no meio de cultura foram coletadas através da centrifugação do sobrenadante e filtradas em filtro de 0,4 $\mu \mathrm{m}$.

Para a produção de partículas lentivirais contendo o gene do TurboFP635, 1×106 células foram semeadas em placa de $35 \mathrm{~mm}$ na presença de meio de cultura DMEM contendo $10 \%$ de SFB, 25 mM de glicose e sem antibióticos. A transfecção das células HEK293T com o plasmídeo de interesse (pTurboFP635) e os plasmídeos para a expressão das proteínas que compõem a partícula lentiviral foi realizada utilizando o reagente Lipofectamina 2000 (Thermo Fisher Scientific). Após 5 horas do início da transfecção, o meio de cultura foi substituído por $2 \mathrm{~mL}$ de DMEM contendo 10\% SFB HyClone (Thermo Fisher Scientific) e antibióticos. O sobrenadante contendo as partículas lentivirais secretadas no meio de cultura das células HEK293T foi coletado a cada 24 horas até o período final de 72 horas de incubação, filtrado em filtro de $0,45 \mu \mathrm{m}$ para a retirada de restos celulares, aliquotado e congelado a $-70^{\circ} \mathrm{C}$. 


\subsubsection{Titulação das partículas lentivirais}

A multiplicidade de infecção (MOI) refere-se ao número de partículas lentivirais que infectam uma célula. A fim de determinar a quantidade de sobrenadante lentiviral necessária para uma transdução eficiente foram testadas MOls de 1, 2 e 5. Para tanto, $1 \times 10^{5}$ células da linhagem U87MG foram semeadas em placa de 6 poços. 0 meio de cultura foi substituído por DMEM contendo diferentes volumes de sobrenadante viral e $8 \mu \mathrm{g} / \mathrm{mL}$ de polibreno (Sigma-Aldrich). Um poço com células sem vírus e com puromicina foi utilizado como controle positivo de seleção. Outro controle negativo do ensaio foi realizado com células sem transdução e puromicina.

Após 24 horas da transdução foi iniciada a seleção com puromicina. Foram realizadas as contagens das células vivas para cada volume de sobrenadante lentiviral testado e para as células do controle (sem vírus e puromicina). A infectividade viral foi calculada considerando que a quantidade de células vivas do controle equivale a 100\%, segundo o cálculo a seguir para definir a porcentagem de células vivas para cada volume de sobrenadante lentiviral $(x)$ :

\section{$X(\%$ de células vivas/sobrenadante viral $)=100 \times n^{\circ}$ de células vivas para cada vol. de sobrenadante $\mathrm{n}^{\circ}$ de células do controle (sem vírus e sem puro)}

Em seguida, foi calculado o volume de sobrenadante lentiviral equivalente a $\mathrm{MOI}$ de 1, através de um gráfico no qual a porcentagem de células vivas fica no eixo y e o volume de sobrenadante lentiviral no eixo $x$. Na equação da reta o valor de y foi substituído por $50 \%$ de células vivas ( $\mathrm{MOI}$ de 1 corresponde a $50 \%$ de células infectadas) e o valor de $\mathrm{x}$ indica um volume de sobrenadante lentiviral correspondente a $\mathrm{MOI}$ de 1 . Para testar $\mathrm{MOI}$ de 2 e 5 foi feita a multiplicação do volume obtido $(x)$ por 2 e 5.

\subsubsection{Transdução da linhagem U87MG}

Foram semeadas $1 \times 10^{5}$ células da linhagem U87MG em placa de 6 poços e transduzidas com volumes de shCD99 1 e shCD99 2 correspondentes às MOls de 1, 2 e 5 na presença de polibreno. Após 24 horas, o meio com o sobrenadante lentiviral foi substituído 
por meio de cultura contendo puromicina. O silenciamento de CD99 foi verificado por qRTPCR e Western blot.

Para a produção de células U87MG expressando a proteína TurboFP635, foram cultivadas $1 \times 10^{4}$ células por poço em uma placa de 96 poços e após 24 horas de incubação, foram adicionados $50 \mu \mathrm{L}$ de suspensão lentiviral. As populações geradas apresentaram cerca de 97\% de células com expressão positiva para a proteína TurboFP635 conforme confirmado por citometria de fluxo no equipamento FACSAria (BD Biociences).

\subsubsection{Expressão da proteína por Western blot}

A lise das células foi realizada com tampão RIPA e coquetel de inibidores de proteases (Sigma-Aldrich). As concentrações de proteína total foram determinadas em triplicatas pelo método de BCA, utilizando o kit Pierce BCA Protein Assay, segundo recomendações do fabricante (Thermo Fisher Scientific). A leitura foi realizada a $570 \mathrm{~nm}$ utilizando um leitor de placa Multiskan EX (Labsystens Uniscience). As concentrações das amostras foram determinadas com base na curva padrão de albumina bovina. Um total de $30 \mu \mathrm{g}$ de proteína de cada amostra foi submetido à eletroforese em gel de poliacrilamida com gradiente $4-12 \%$ (Thermo Fisher Scientific) em tampão de eletroforese 1x NuPAGE MOPS SDS 20x (Thermo Fisher Scientific). As bandas protéicas foram transferidas para uma membrana de nitrocelulose através do sistema iBLOT (iBlot Dry Blotting System, Thermo Fisher Scientific). Foi então realizada incubação com os anticorpos primários monoclonais de camundongo anti-CD99 (clone DN16, Abcam) na diluição de 1:1.000 e anti- $\beta$-actina (clone AC-74, Sigma-Aldrich) na diluição de 1:20.000 como controle de quantidade de proteína total. O anticorpo secundário utilizado foi o anti-lgG de camundongo conjugado com peroxidase (HRP) na diluição de 1:1.000 (Sigma-Aldrich). As proteínas foram reveladas através de um sistema de detecção de quimioluminescência utilizando o reagente $\mathrm{ECL}$ (Western Lightning Chemiluminescence Reagent Plus, Perkin Elmer). A detecção das proteínas de interesse na membrana foi realizada no aparelho ImageQuant LAS4000 (GE Healthcare). 


\subsection{ENSAIO DE FERIDA EM MONOCAMADA}

A influência do CD99 na migração na linhagem U87MG silenciada por shRNA foi investigada in vitro por meio de um ensaio de ferida em monocamada. Um total de $2 \times 10^{5}$ células/poço das células silenciadas e seus respectivos controles (scrambled) foram cultivados em placas de 24 poços previamente cobertos com poli-L-Lisina, na presença de meio DMEM suplementado com $10 \%$ de SFB, até atingirem a confluência de monocamada. 0 meio de cultura foi removido e com auxílio de uma ponteira de micropipeta de $200 \mu \mathrm{L}$ foi realizada uma descontinuidade na monocamada, criando uma área livre de células ("ferida"). Os poços foram lavados com PBS para a remoção das células soltas e em seguida foi adicionado meio de cultura com $1 \%$ de SFB, para diminuir a proliferação celular. 0 fechamento das "feridas" foi registrado em diferentes tempos (0, 6, 12 e 24 horas), em dois ensaios independentes e quadruplicatas para cada condição. Pontos de referência foram demarcados no fundo de cada poço da placa para localizar os campos correspondentes às áreas livres de células analisadas para aquisição de imagens nos diferentes intervalos de tempo.

Paralelamente, um ensaio em tempo real foi realizado no microscópio de fluorescência invertido Axiovert 200 motorizado (Zeiss) e o fechamento da ferida foi registrado a cada 3 até o tempo final de 24 horas. 0 ensaio foi realizado em duplicatas e foram fotografados 3 campos diferentes de cada poço.

As áreas livres de células foram inicialmente calculadas como porcentagem da área livre de células no tempo 0 e arbitrariamente marcada como $100 \%$. Em seguida a porcentagem de área livre foi calculada pelo Image J (76). A porcentagem de área invadida nos diferentes tempos foi determinada pela diferença da área no tempo zero (100\%) menos a área livre.

\subsection{ENSAIO DE INVASÃO CELULAR}

O papel do CD99 na invasão foi avaliado por meio da habilidade da linhagem celular silenciada atravessar uma membrana com poros de $8 \mu \mathrm{m}$ de diâmetro utilizando-se o kit 
BioCoat Matrigel Invasion Chambers (BD Biosciences). As células foram desagregadas com tripsina e um total de $2,5 \times 10^{4}$ células foram cultivadas em $500 \mu \mathrm{L}$ de meio de DMEM com $1 \%$ de SFB na parte superior dos insertos. Um volume de $750 \mu \mathrm{L}$ de DMEM com $10 \%$ de SFB foi adicionado na parte inferior do inserto para agir como quimioatraente. Os insertos foram incubados por 18 horas a $37^{\circ} \mathrm{C}$ sob atmosfera de $5 \%$ de $\mathrm{CO}_{2}$. Após este período, as células que não invadiram o matrigel foram removidas da superfície da membrana com o auxílio de um bastão com algodão. As células que atravessaram os poros foram fixadas com paraformaldeído $4 \%$, coradas com cristal violeta $0,2 \%$ em $20 \%$ de metanol e analisadas por microscopia de luz (aumento de 10x). A quantificação foi realizada por contagem do total de células de cada um dos insertos das duplicatas experimentais. Os ensaios foram repetidos em dois experimentos independentes.

\subsection{ENSAIO DE ADESÃO}

A capacidade adesiva das células U87MG do controle (scrambled) e shCD991 e 2 foram comparadas. Inicialmente as células foram incubadas durante 2 horas em DMEM com $1 \%$ de SFB. Foram semeadas $5 \times 10^{4}$ de células por poço em uma placa de 96 poços e mantidas a $37^{\circ} \mathrm{C}$ sob atmosfera de $5 \% \mathrm{CO}_{2}$ por 3 horas. As células não aderentes foram removidas com3lavagens com PBS. As células aderidas foram quantificadas adicionando-se uma mistura de DMEM com 10\% do PrestoBlue (Thermo Fisher Scientific) e incubando-se em estufa por 2 horas. A leitura foi realizada no equipamento GloMax (Promega) a $535 \mathrm{~nm}$ de excitação e $560 \mathrm{~nm}$ de emissão. Os valores da fluorescência são diretamente proporcionais à quantidade de células viáveis aderidas à placa. Foram realizados dois experimentos independentes em sextuplicatas.

\subsection{ENSAIO DE PROLIFERAÇÃO IN VITRO}

O ensaio de proliferação foi realizado com o reagente Prestoblue (Thermo Fisher Scientific). A linhagem U87MG shCD99 1 e 2 e seus controles (scrambled 1 e 2) foram semeadas na quantidade de $1 \times 10^{4}$ células/poço em $200 \mu \mathrm{L}$ de DMEM com 10\% de SFB em 
uma placa de 96 poços em octuplicatas. As células foram incubadas em estufa a $37^{\circ} \mathrm{C}$ nos tempos 0 (3 horas - tempo mínimo para as células aderirem), 2, 5 e 7 dias. Nos tempos determinados o meio foi substituído por uma mistura de DMEM contendo $10 \%$ do PrestoBlue em cada poço e a placa incubada na estufa por 2 horas. Em seguida a leitura foi realizada no equipamento GloMax (Promega) a $535 \mathrm{~nm}$ de excitação e $560 \mathrm{~nm}$ de emissão. Os valores da fluorescência são diretamente proporcionais à quantidade de células viáveis que proliferaram no poço.

\subsection{IMUNOFLUORESCÊNCIA}

Foram plaqueadas $2 \times 10^{4}$ células da linhagem U87MG em lamínulas previamente cobertas com Poli-L-Lisina (Sigma-Aldrich) e fixadas por 1 hora e 30 minutos com paraformaldeído $4 \%$ em tampão fosfato tamponado (PBS) 1x a $4^{\circ} \mathrm{C}$. As células foram lavadas com PBS 3 vezes por 5 minutos e, em seguida, permeabilizadas com 0,1\% de NP-40 (Abcam) diluído em PBS por 30 minutos a $37^{\circ} \mathrm{C}$ e lavadas 2 vezes com PBS por 5 minutos. Os sítios inespecíficos foram bloqueados incubando-se as células com $4 \%$ de soro de cabra (SigmaAldrich) por 30 minutos a $37^{\circ} \mathrm{C}$, seguida de 2 lavagens de 5 minutos com PBS. As células foram incubadas com o anticorpo primário anti-CD99 conjugado com FITC (1:50, Thermo Fisher Scientific) ou faloidina marcada com Alexa Fluor 488 (1:50, Thermo Fisher Scientific) diluídos em solução de bloqueio em câmara úmida por 48 horas a $4^{\circ} \mathrm{C}$. As células foram lavadas 3 vezes com PBS por 5 minutos e os núcleos foram marcados através da adição do corante DAPI (diamidino-2-fenil-indole, Thermo Fisher Scientific) na proporção de 1:1000 e incubação por 3 minutos. Foram realizadas 3 lavagens com PBS por 5 minutos. Controles negativos incluem a reação completa, com ausência do anticorpo primário. A documentação e análise das lâminas foram realizadas no sistema confocal LSM510 Meta/UV (Carl Zeiss).

\subsection{ENSAIO DE CRESCIMENTO TUMORAL IN VIVO}

As células U87MG silenciadas para a expressão de CD99 (shCD99 1 e shCD99 2) e seus controles foram analisadas para o crescimento in vivo. Um total de 20 animais foram 
divididos em 4 grupos experimentais. O grupo scrambled 1 (3 animais/grupo), shCD99 1 (3 animais/grupo), scrambled 2 (6 animais/grupo) e shCD99 2 (6 animais/grupo).

\subsubsection{Preparo celular}

As células foram mantidas em meio de cultura DMEM com alta glicose ( $25 \mathrm{nM}$ ) e $10 \%$ de SFB até atingirem confluência de 70-80\%. No momento do experimento as células foram desagregadas com $2 \mathrm{~mL}$ de tripsina. Após adicionar DMEM sem soro até completar $10 \mathrm{~mL}$, as células foram contadas e a viabilidade determinada, sendo utilizadas para o experimento células com viabilidade acima de 95\%. Em seguida as células foram centrifugadas a $1000 \mathrm{rpm}$ por 5 minutos a $4^{\circ} \mathrm{C}$ duas vezes. $\mathrm{O}$ sobrenadante foi aspirado e o pellet foi ressuspenso no volume apropriado de meio livre de soro para obter uma concentração de trabalho final de $1 \times 10^{5}$ células em $3 \mu \mathrm{L}$. As células foram mantidas em gelo até o momento da injeção.

\subsubsection{Implantação das células tumorais}

Os animais foram anestesiados com mistura de quetamina e xilazina $(100 \mathrm{mg} / \mathrm{kg}$ e 10 $\mathrm{mg} / \mathrm{kg}$ ) via intraperitoneal. Após foram posicionados em aparelho de estereotaxia para pequenos animais (Kopf Instruments). Em seguida, o couro cabeludo foi preparado por limpeza com solução de clorexidina. Nos olhos foi aplicada solução salina 0,9\% para manter a umidade durante o procedimento cirúrgico. Usando um bisturi estéril foi realizada uma incisão sagital completa de aproximadamente $1 \mathrm{~cm}$ sobre o osso parieto-occiptal. A superfície exposta do crânio foi limpa utilizando um cotonete embebido em solução de peróxido de hidrogênio 3\%. O ponto bregma foi exposto nesse momento. Antes da injeção das células tumorais, uma agulha de calibre 25 foi usada para perfurar o crânio $2 \mathrm{~mm}$ a direita do bregma e $1 \mathrm{~mm}$ anterior à sutura coronal.

A seringa de Hamilton (modelo $701 \mathrm{SN}$, volume $10 \mu \mathrm{L}$, calibre $23 \mathrm{~s}$ ) foi carregada com o volume de $3 \mu \mathrm{L}$ de células homogeneizadas com o auxílio de um microinjetor (Kopf Instruments). A utilização do microinjetor garantiu precisão do volume injetado, além da profundidade exata para a inoculação das células no lobo frontal direito. A seringa foi posicionada de forma perpendicular ao crânio em cima do furo criado anteriormente e 
lentamente, por 5 minutos, foi injetada a suspensão de células. A seringa foi, então, removida vagarosamentepara evitar refluxo das células.

Foi realizada assepsia do crânio com peróxido de hidrogênio $3 \%$ e o orifício foi fechado com cera de osso. O couro cabeludo foi suturado com fio reabsorvível e limpo com solução de clorexidina. Ao final do procedimento, foi administrado tramadol ( $20 \mathrm{mg} / \mathrm{Kg}$ ) por via intraperitoneal a cada 12 horas por mais 3 dias. Durante a cirurgia e recuperação póscirúrgica, os animais foram mantidos em cima de bolsas aquecidas a $37^{\circ} \mathrm{C}$ para evitar a hipotermia. Os animais foram monitorados pós-cirurgia até voltarem a andar e iniciar suas atividades normais.

\subsubsection{Monitoramento do crescimento tumoral por fluorescência}

As imagens dos camundongos expressando a proteína fluorescente vermelha foram geradas usando o sistema in vivo Image System IVIS Spectrum (PerkinElmer Inc) com excitação de $605 \mathrm{~nm}$ e emissão de $660 \mathrm{~nm}$. Uma série de imagens foi adquirida até a obtenção da maior intensidade de sinal (mensuração em counts). A quantificação foi realizada definindo a região fluorescente de interesse (ROI) utilizando o programa Living Image 4.3.1. A partir do ROI, e para cada imagem, a intensidade de fluorescência média foi calculada após subtração de fundo e utilizada para a confecção da curva de crescimento tumoral. As diferenças entre as curvas de sobrevida foram comparadas utilizando o test de log-rank. Os animais foram monitorados periodicamente e, quando observado perda de peso maior do que $20 \%$ e/ou alteração motora, foram sacrificados.

\subsection{ANÁLISES ESTATÍSTICAS}

As análises estatísticas foram feitas no programa GraphPad Prism, versão 7. Foram realizados testes de normalidade de Kolmogorov-Smirnov para a determinação da distribuição dos dados. Valores de $p<0,05$ foram considerados significativos. Para a análise de diferença na expressão das isoformas 1 e 2 de CD99 nos diferentes graus de astrocitomas e tecido cerebral não tumoral foi utilizado o teste de Kruskal-Walis. A expressão de CD99 
entre os diferentes tipos moleculares de GBM foi também realizada pelo teste de KruskallWallis. A comparação entre dois grupos foi realizada pelo teste de Dunn.

O resultado de quantificação da expressão de RNA mensageiro do CD99 na linhagem U87MG silenciada comparada com o controle scrambled foi analisado por teste t de Student.

Os resultados do ensaio de ferida em monocamada foram analisados por two-way ANOVA, seguido por teste Bonferroni. Para o ensaio de migração em tempo real, proliferação celular e crescimento tumoral in vivo foram realizadas análises de regressão não-linear.

Para os ensaios de invasão e adesão foi utilizado o teste de Mann-Whitney para avaliar a diferença estatística entre as células controle e silenciadas.

As diferenças das intensidades de fluorescência foram analisadas com o teste $t$ de Student não pareado.

Para a curva de crescimento do modelo animal foi feita uma curva de regressão nãolinear. Aanálise de sobrevida foi realizada como teste de log-rank. 


\section{RESULTADOS}

\subsection{ANÁLISE DA EXPRESSÃO DAS ISOFORMAS DE CD99 NA LINHAGEM U87MG}

A avaliação dos níveis expressão de RNA mensageiro das isoformas 1 e 2 de CD99 por qRT-PCR mostraram expressão predominante da isoforma 1 na linhagem U87MG (Figura 7A). A expressão de CD99 foi avaliada também por Western blot (Figura 8B). Os dados confirmam os resultados de expressão gênica. O anticorpo anti-CD99 (DN16 - Abcam) utilizado reconhece ambas isoformas de CD99, mas foi observada a presença apenas da isoforma 1 de peso molecular de $32 \mathrm{kDa}$.

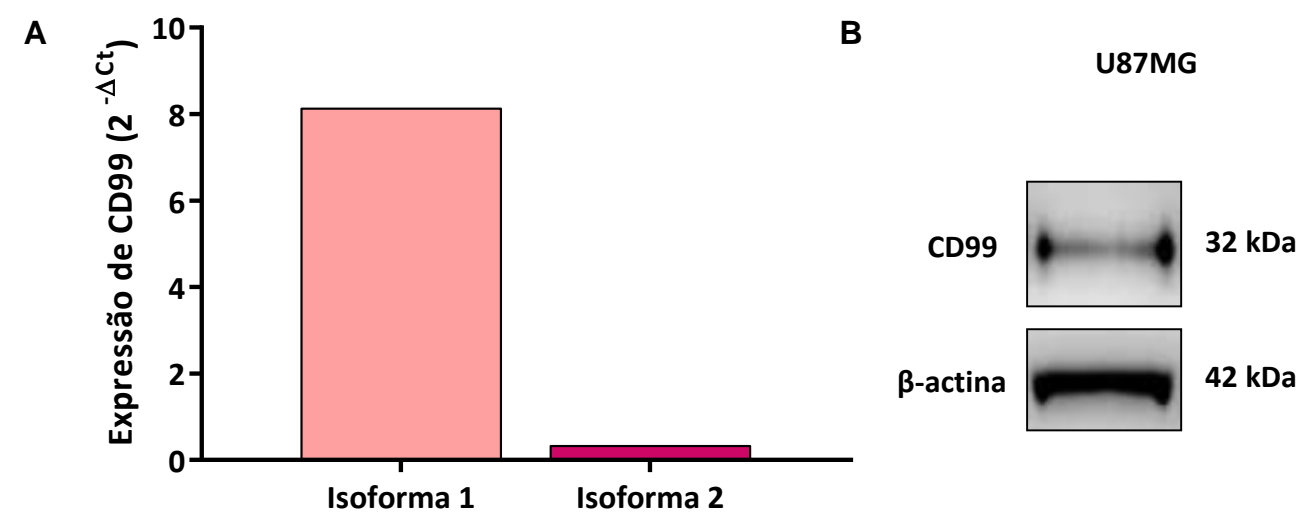

Figura 7. (A) Expressão das isoformas 1 e 2 de CD99 na linhagem U87MG. O HPRT foi utilizado como gene de referência. Os resultados foram expressos como média de 2 experimentos independentes. (B) Western blot representativo mostrando a expressão de CD99 na linhagem U87MG. $\beta$-actina foi utilizada como controle de quantidade de proteína total.

\subsection{ANÁLISE DA EXPRESSÃO GÊNICA DE CD99 EM ASTROCITOMAS E SUBTIPOS MOLECULARES DE GBM}

\subsubsection{Expressão das isoformas de CD99 em astrocitomas de diferentes grau de malignidade}

A análise da expressão das isoformas 1 e 2 de CD99 em diferentes graus de astrocitomas (I-IV) está de acordo com a expressão observada na linhagem celular U87MG, com predomínio da isoforma 1. Os níveis de expressão da isoforma 1 de CD99 são maiores 
em amostras de astrocitomas quando comparados ao tecido não neoplásico (NN) em comparação com a isoforma 2 (Figura 8). Além disto, há uma diferença estatística $(p<0,0001)$. A expressão da proteína CD99 é maior em amostras de GBM quando comparada ao tecido NN.

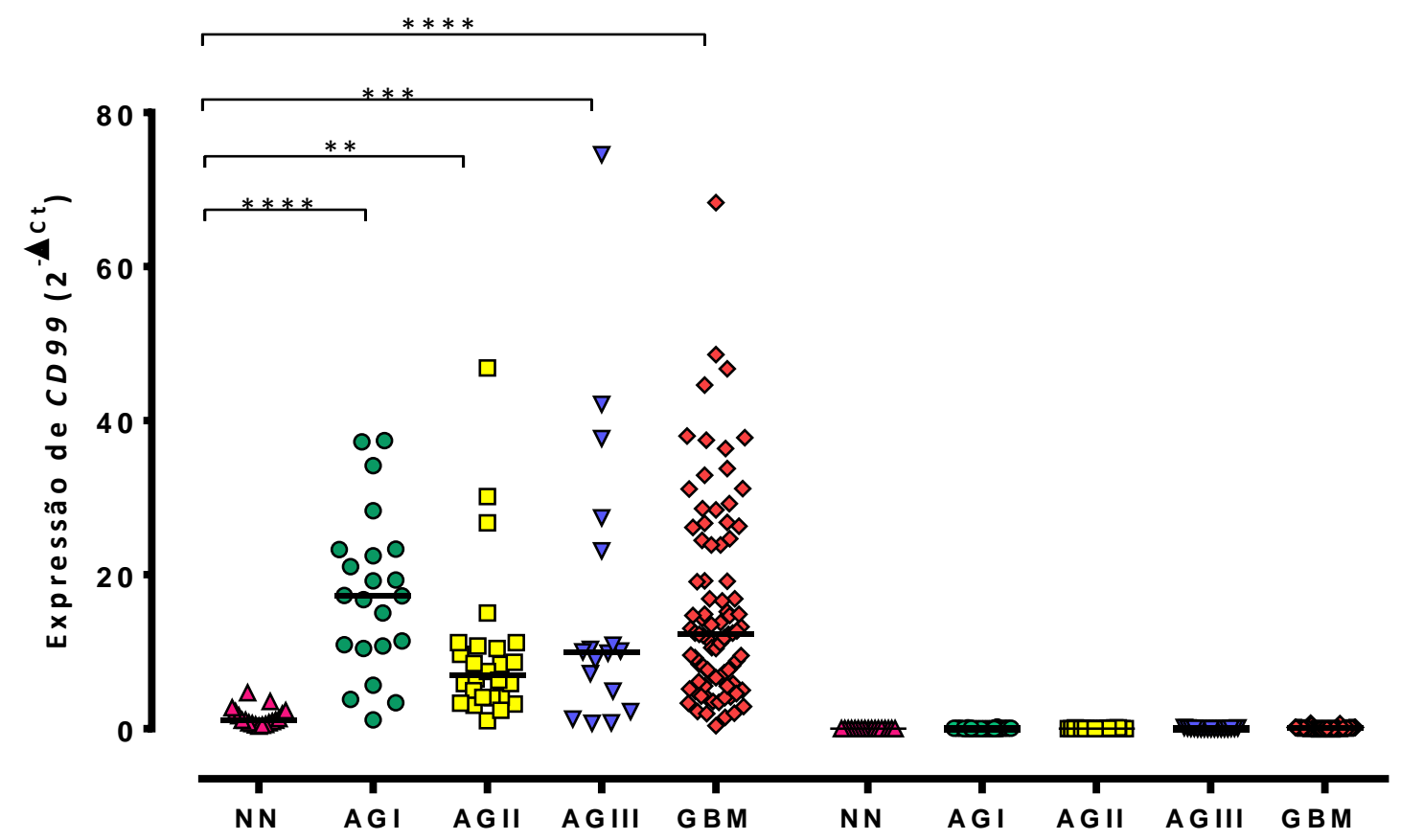

Figura 8. Expressão das isoformas 1 e 2 de CD99 em 22 amostras de astrocitoma pilocítico (AGI), 26 astrocitomas de baixo grau (AGII), 17 astrocitomas anaplásico (AGIII), 84 GBM e 19 amostras de tecido não neoplásico (NN). Os valores de expressão de CD99 foram calculados com base na média geométrica dos níveis de expressão de HPRT, BCRP e GUSB de cada amostra. A barra horizontal indica a mediana de cada grupo. A diferença foi significativa entre os grupos analisados para a isoforma 1 de CD99 ( $p<0,0001$, teste de Kruskal-Wallis). As diferenças foram significativas entre os grupos de astrocitomas e NN: Teste de Dunn: ${ }^{* * *} \mathrm{p}<0,0001,{ }^{* * *} \mathrm{p}=0,0003,{ }^{* *} \mathrm{p}=0,016$.

De acordo com os nossos resultados, o silenciamento do CD99 terá como alvo a isoforma 1.

\subsubsection{Expressão de CD99 em subtipos moleculares de GBM}

A análise de expressão de CD99 nos subtipos moleculares casos de GBMs, composta de 37 casos clássicos, 14 mesenquimais e 14 proneurais (77), mostrou uma menor expressão no subtipo proneural, embora sem significância estatística (Figura 9A). Uma análise in silico de dados de RNAseq de uma maior casuísitica de GBMs do TCGA, com 38 subtipos clássicos, 
53 mesenquimais e 29 proneurais, confirmaram uma maior expressão de CD99 em subtipos clássicos e mesenquimais ( $p=0,0031)$ (Figura 9B).

A

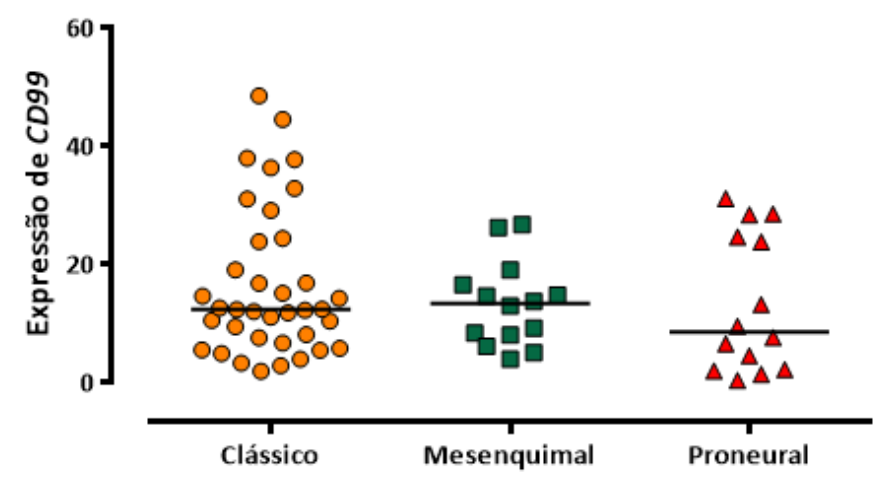

B

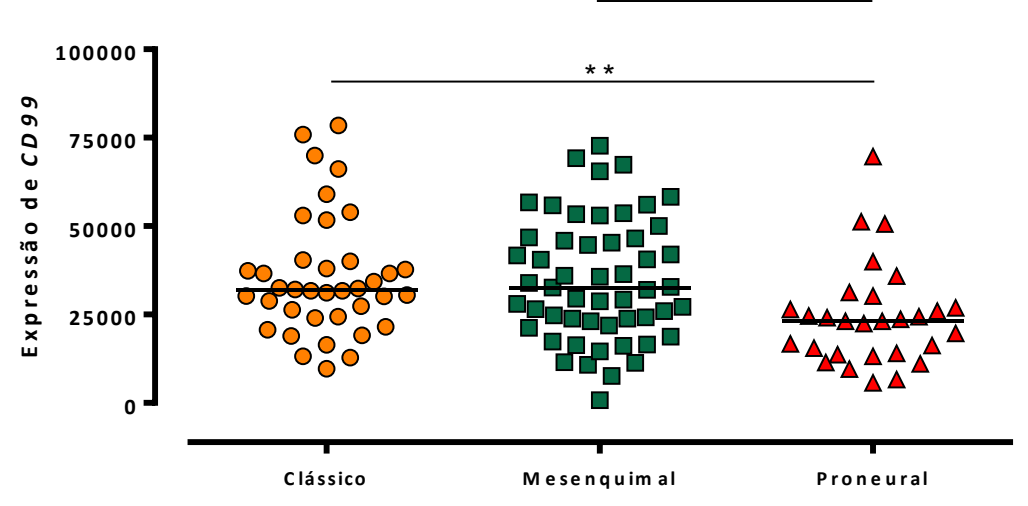

Figura 9. Expressão de CD99em diferentes subtipos moleculares de GBM. (A) Expressão gênica determinada por qRT-PCR na casuística do laboratório e apresentada na Figura 8. (B) Expressão gênica determinada por RNAseq da casuística do TCGA. A diferença entre os grupos foi significativa para os casos do TGCA. Teste de Kruskal-Wallis: $p=0,0031$. A barra horizontal indica a mediana de cada grupo.As diferenças foram significativas entre os subtipos mesenquimal e proneural e mesenquimal e clássico. Teste de Dunn: ${ }^{* *} p<0,01$.

\subsection{ANÁLISE DO TRANSCRIPTOMA DA LINHAGEM U87MG SILENCIADAS POR SIRNA}

Foi realizada análise do transcriptoma da linhagem celular U87MG por RNA-seq após silenciamento com siRNA para CD99 e comparada ao controle NTC. O silenciamento do gene CD99 e da proteína foram confirmados por RT-qPCR e Western blot, segundo trabalho previamente publicado (21). A Figura 10 mostra os resultados de uma curva de tempo de expressão de CD99. Após 2 dias, houve uma inibição da expressão ao nível de gene e 
proteína de quase $100 \%$. A análise do transcriptoma foi realizada nestas células e comparada com o controle.

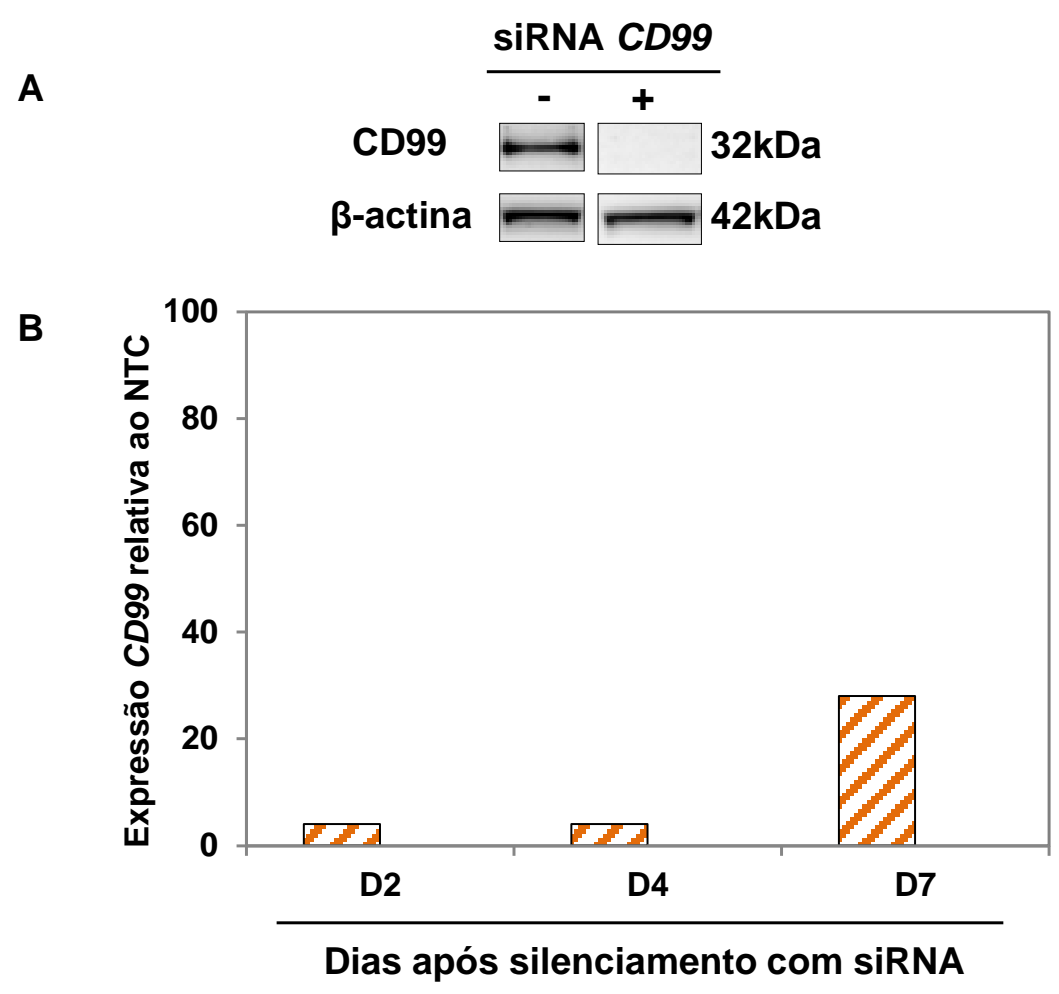

Figura 10. Análise de expressão de CD99 após silenciamento de CD99 por siRNA da linhagem U87MG. (A) Western blot das células U87MG controle NTC (-) e silenciada (+) com siRNA2 dias após transfecção com siRNA (adaptado de Urias et al., 2014). A $\beta$-actina foi utilizada como controle de quantidade de proteína total. (B) Expressão de CD99 em relação ao controle NTC nos dias 2 (D2), 4 (D4) e 7 (D7) após silenciamento com siRNA.

A análise da expressão diferencial da linhagem U87MG silenciada para CD99 e NTC resultou em 2.670 genes, apresentando diferenças de expressão estatística com $p \leq 0,01$ e $\log _{2}$ fold-change variando de $\leq-1$ a $\geq 1$. CD99 foi um dos genes com maior diminuição de expressão em relação ao controle (17,51 vezes) confirmando a eficiência do silenciamento do CD99. CD99 foi descrito como uma proteína que participa na adesão e migração de várias células tumorais. Para determinar as vias de sinalização que são potencialmente reguladas por CD99 em GBM, a análise dos dados do transcriptoma (genes diferencialmente expressos em células silenciadas por siRNA comparados ao controle NTC) foi realizada através do banco de dados DAVID para enriquecimento funcional e das vias de sinalização. 
A análise de enriquecimento pelo algoritmo DAVID mostrou que o cluster enriquecido no GO Terms está relacionado à adesão celular, principalmente célula-célula. 0 segundo está mais relacionado à atividade de proteínas quinases (Figura 11).

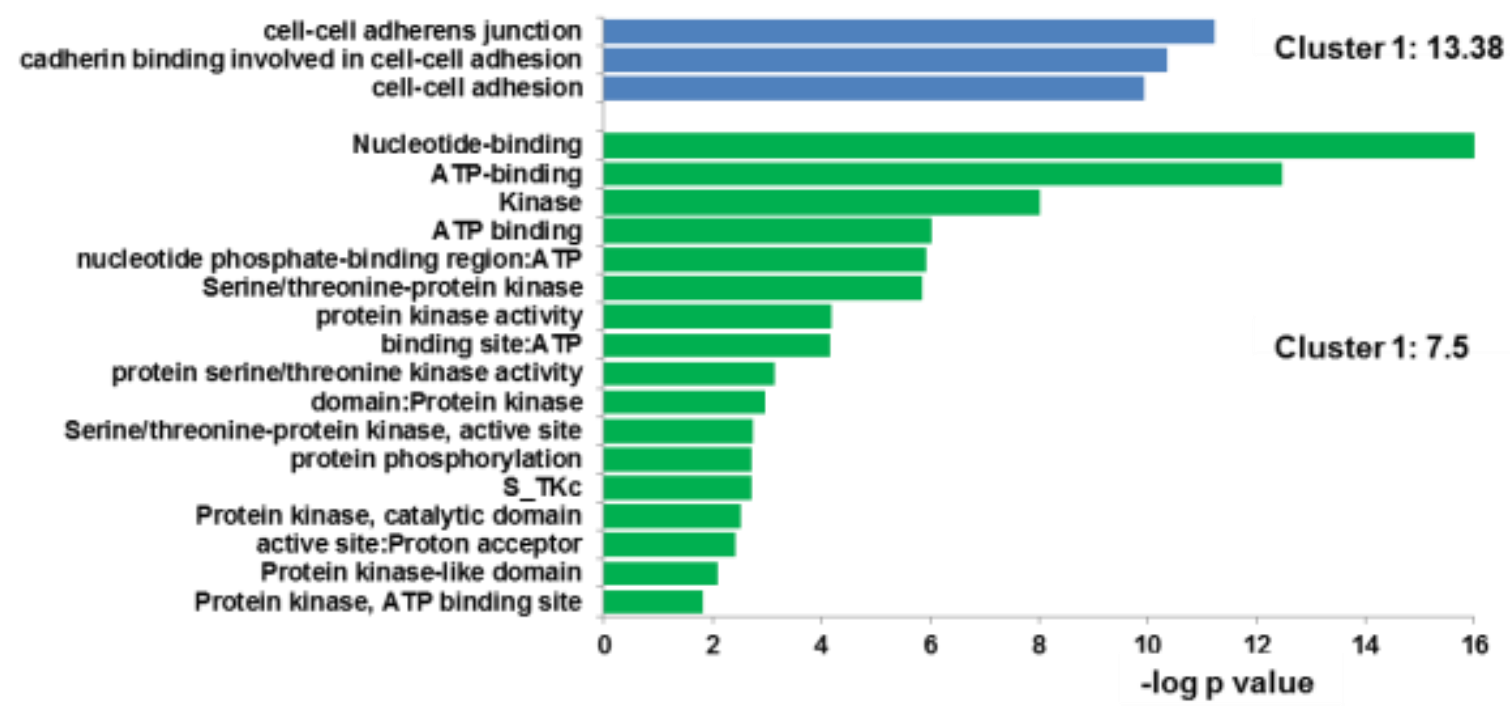

Figura 11. Análise do transcriptoma da linhagem celular U87MG knockdown paraCD99 por siRNA. Os dois clusters mais enriquecidos do GO Terms (Gene Onthology Term Enrichment) determinados pela análise de clusteres de genes diferencialmente expressos após o knockdown de $\operatorname{CD99}(p \leq 0,01)$ no banco de dados do DAVID (https://david.ncifcrf.gov/).

Os valores de RPKM foram transformados em escores-z para visualização no mapa de calor (78). Foram analisados, além do CD99, genes que codificam proteínasde membrana, matriz extracelular, fibras de estresse, adesão focal e de filopodio e lamelipodio. Um mapa de calor e as diferenças na expressão (fold-change) destes genes selecionados são apresentados nas Figuras 12A e 12B, respectivamente. Entre as proteínas de matriz, OPN (osteopontina) e LAMA5 (laminina 5) tiveram sua expressão dimuída, enquanto FN1 (fibronectina 1), THBS1 (trombospondina 1) e COL5A2 (cadeia alfa ( $\alpha$ ) 2 (VI) do colágeno tipo V) apresentaram aumento de expressão quando o CD99 foi silenciado. Os genes que codificam proteínas transmembrana, que interagem com proteínas de matriz extracelular, como CD44 e algumas subunidades de integrinas (ITGB8, ITGA2, ITGAV e ITGA5), também aumentaram a expressão nas células controle em relação às silenciadas. 

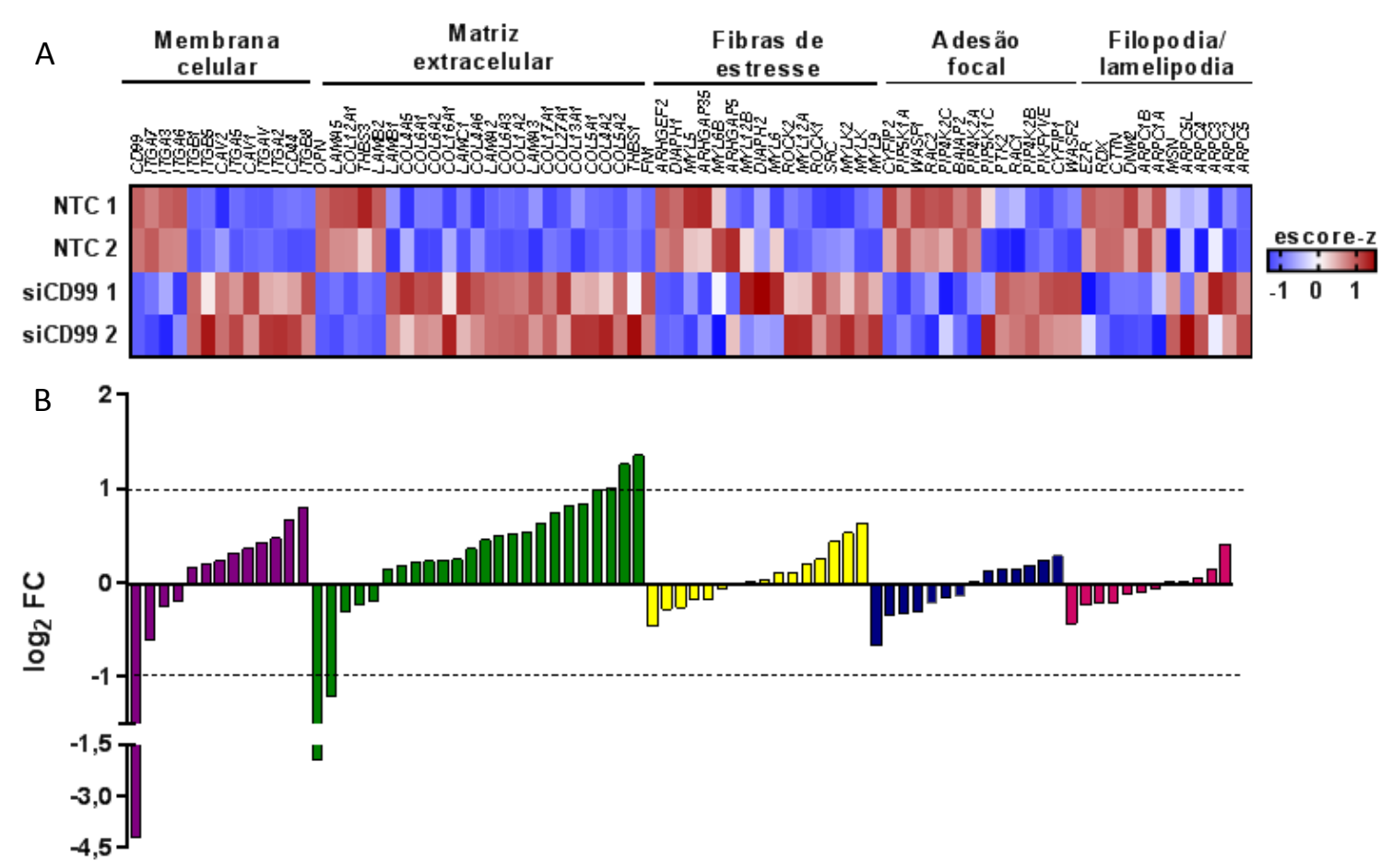

Figura 12. Análise do transcriptoma da linhagem celular U87MG knockdown paraCD99 por siRNA. (A) Mapa de calor representando a expressão de genes que codificam proteínas de membrana, matriz extracelular, fibras de estresse, adesão focal e filopódio/lamelipódio. Os valores de RPKM das duplicatas experimentais foram normalizados pelo escore-z. (B) $O \log 2$ da diferença de expressão (FC) dos genes representados no mapa de calor, mostrando o silenciamento de CD99 com siRNA de mais de 17 vezes.

Com base nos resultados de transcriptoma de genes possivelmente regulados por CD99, foram selecionados para validação as vias de adesão, migração, invasão e proliferação celular. Além dos ensaios in vitro, foram também realizados ensaios de crescimento in vivo.

\subsection{SILENCIAMENTO DA LINHAGEM U87MG POR SHRNA}

Como o efeito do silenciamento por siRNA é transitório (Figura 10), as células U87MG foram silenciadas com shRNA com a finalidade de se obter células com silenciamento permanente do gene para os estudos funcionais, uma vez que muitos ensaios foram realizados por períodos mais longos, especialmente os experimentos in vivo. Foram utilizados dois construtos diferentes de shRNA de CD99 e os controles. As partículas lentivirais foram produzidas e utilizadas para as transduções. 


\subsubsection{Determinação da MOI (Multiplicidade de Infecção)}

Inicialmente foi determinada a menor concentração de puromicina que levava a morte da linhagem U87MG: $5 \mu \mathrm{g} / \mathrm{mL}$. A fim de determinar a quantidade efetiva de vírus para obtenção de um silenciamento adequado inicialmente foi realizado o cálculo do volume de sobrenadante lentiviral correspondente a MOI de 1. Para isso, determinou-se a porcentagem de células vivas para a linhagem celular com base no controle do experimento (célula sem vírus e sem puromicina). Os gráficos a seguir mostram a relação da porcentagem de células vivas com diferentes volumes de sobrenadante lentiviral para o shCD99 1 e shCD99 2 e os controles (Figura 13). A partir dessa relação foi obtida a equação da reta.

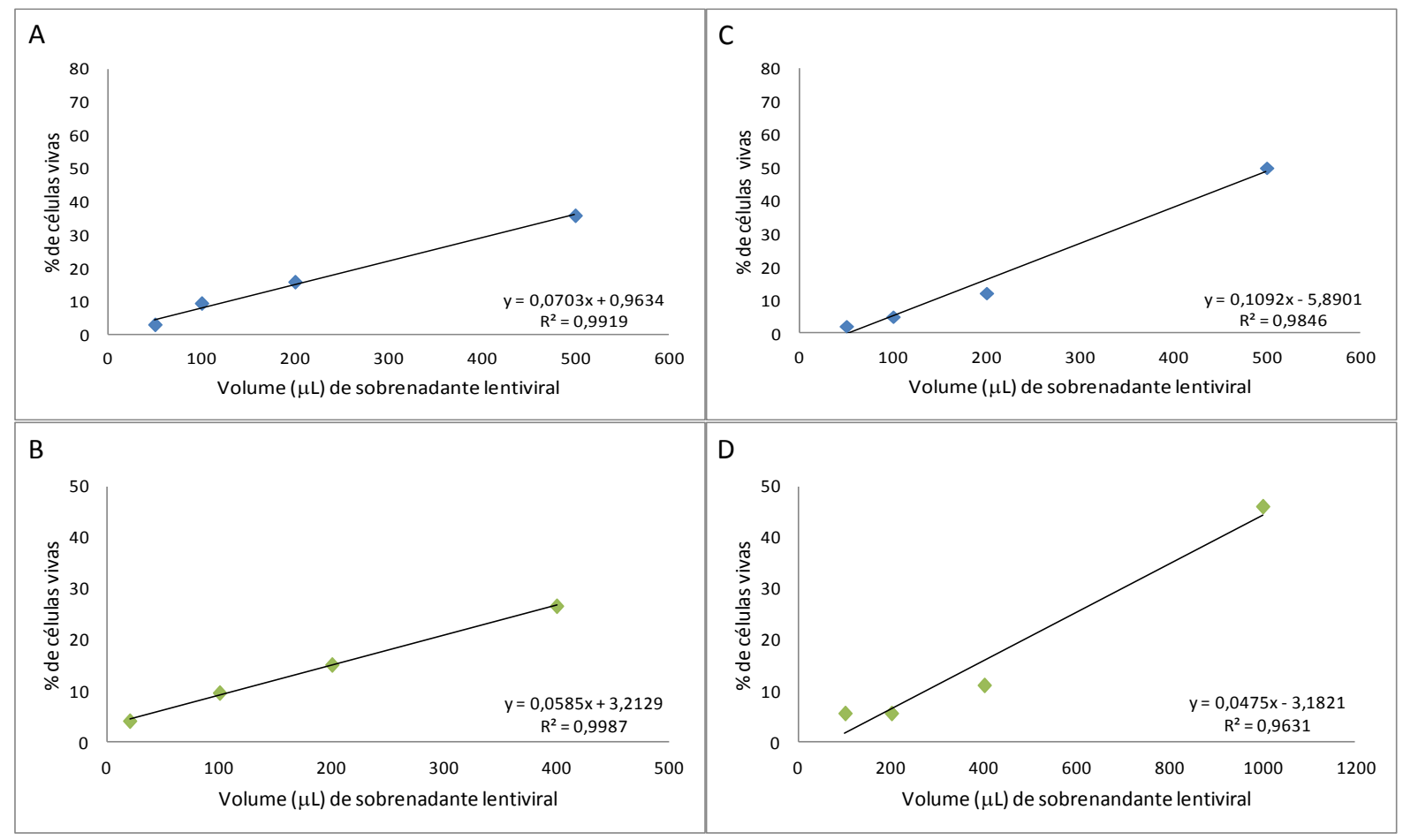

Figura 13. Análise de células vivas da linhagem U87MG após transdução com partículas lentivirais. Relação entre porcentagem de células vivas e volume de sobrenadante lentiviral da linhagem U87MG transduzida com os shCD99 1 (A), shCD99 2 (B), controle 1 (C) e controle 2 (D). Os gráficos representam a relação entre os volumes de sobrenadante lentiviral e a porcentagem de células vivas em cada volume testado em relação aos controlessem vírus e sem puromicina em ambos os construtos. As equações das retas estão apresentadas em cada gráfico. 
Para calcular o volume de sobrenadante lentiviral (valor de $\mathrm{x}$ ) correspondente a $\mathrm{MOI}$ de 1 para $1 \times 10^{5}$ células, foi feita a substituição de y por 50 (valor que equivale a $50 \%$ das células vivas infectadas) nas duas linhagens transduzidas com os shCD99 1, 2 e o scrambled (Tabela 3).

Tabela 3. Volumes correspondentes a MOI de 1 para a linhagem U87MG transduzida com shCD99 1, shCD99 2 e scrambled

\begin{tabular}{|c|c|}
\hline $\begin{array}{l}\text { Linhagem celular transduzida } \\
\qquad\left(1 \times 10^{5} \text { células }\right)\end{array}$ & $\begin{array}{c}\text { Volume }(\mu \mathrm{L}) \text { de vírus } \\
\text { correspondente a MOI de } 1\end{array}$ \\
\hline U87MG shCD99 1 & 698 \\
\hline U87MG scrambled 1 & 512 \\
\hline U87MG shCD99 2 & 799,78 \\
\hline U87MG scrambled 2 & 986 \\
\hline
\end{tabular}

Foram então testadas as MOls de 1, 2 e 5 . Após seleção com puromicina foi observado que as MOls mais eficientes para silenciar o CD99 foi MOI de 5 para o shCD99 1 e MOI de 1 para o shCD99 2. O scrambled foi transduzido com as MOls correspondentes.

\subsubsection{Validação do silenciamento na linhagem U87MG}

A validação do silenciamento na linhagem U87MG foi realizada inicialmente por qRTPCR. Na Figura 14A é possível observar que a expressão do CD99 para U87MG diminuiu em $80 \%$ e $97 \%$ comparados aos controles. O silenciamento também foi validado por análise da expressão da proteína através de Western blot para ambos shRNAs (Figuras 14B). Os resultados de Western blot confirmaram o silenciamento de CD99 em relação ao scrambled. 


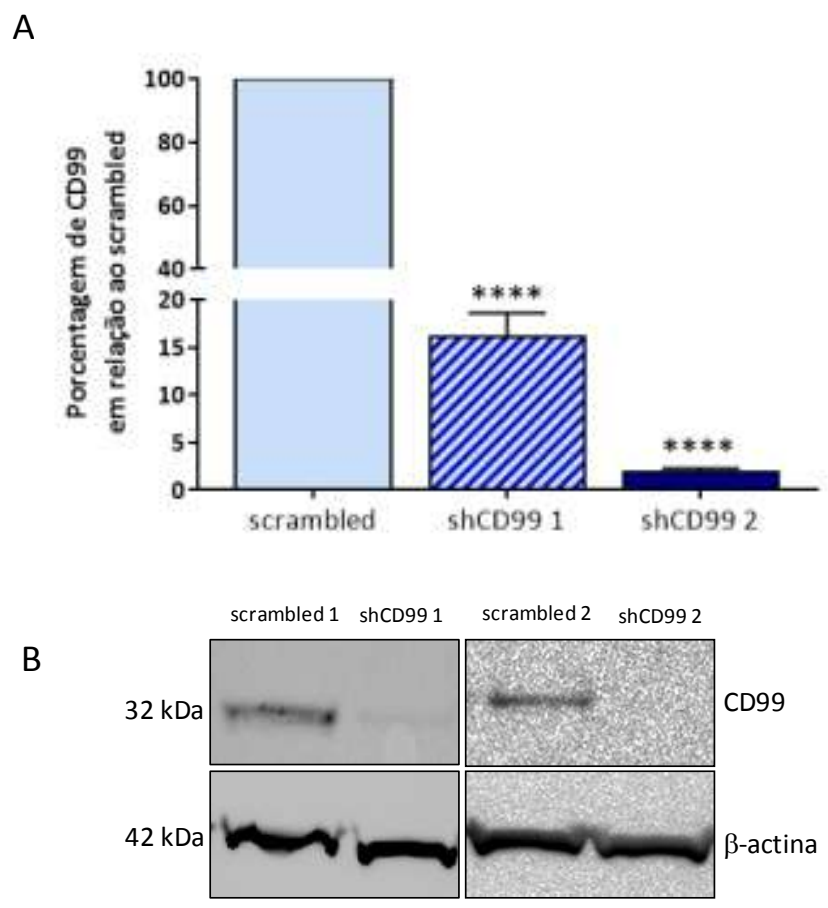

Figura 14. Silenciamento da expressão de CD99 por shRNA na linhagem U87MG. (A) Expressão de CD99 nas células silenciadas com shCD99 1 e shCD99 2 em relação ao controle (scrambled). $O$ gene $H P R T$ foi utilizado como gene de referência. Os resultados foram expressos como média \pm erro padrão da média de três experimentos independentes. Teste t não-pareado: $* * * * p<0,0001$. (B) Western blot referente à expressão da proteína CD99 na linhagem U87MG shCD99 1 e shCD99 2 e respectivos controles (scrambled 1 e 2). A $\beta$-actina foi utilizada como controle de quantidade de proteína total.

\subsection{ANÁLISES FUNCIONAIS IN VITRO DE CD99}

Os ensaios para a determinação do papel de CD99 em GBM foram selecionados com base na análise do transcriptoma. Foram realizadas análises do efeito do silenciamento de CD99 nas células U87MG in vitro, conforme descritas a seguir.

\subsubsection{Ensaio de ferida em monocamada}

O papel da expressão de CD99 na migração da célula U87MG foi analisado pelo ensaio de ferida em monocamada. As células silenciadas com ambos os construtos apresentaram uma redução da atividade migratória quando comparadas aos controles $(p<0,05)$ (Figura 15). As células silenciadas com shCD99 2 apresentaram menor migração em relação ao controle já em 6 horas $(p=0,022)$. As diferenças ficaram mais evidentes nos 
tempos maiores, de 18 e 24 horas $(p<0,0001)$ entre os dois grupos silenciados em relação aos controles.

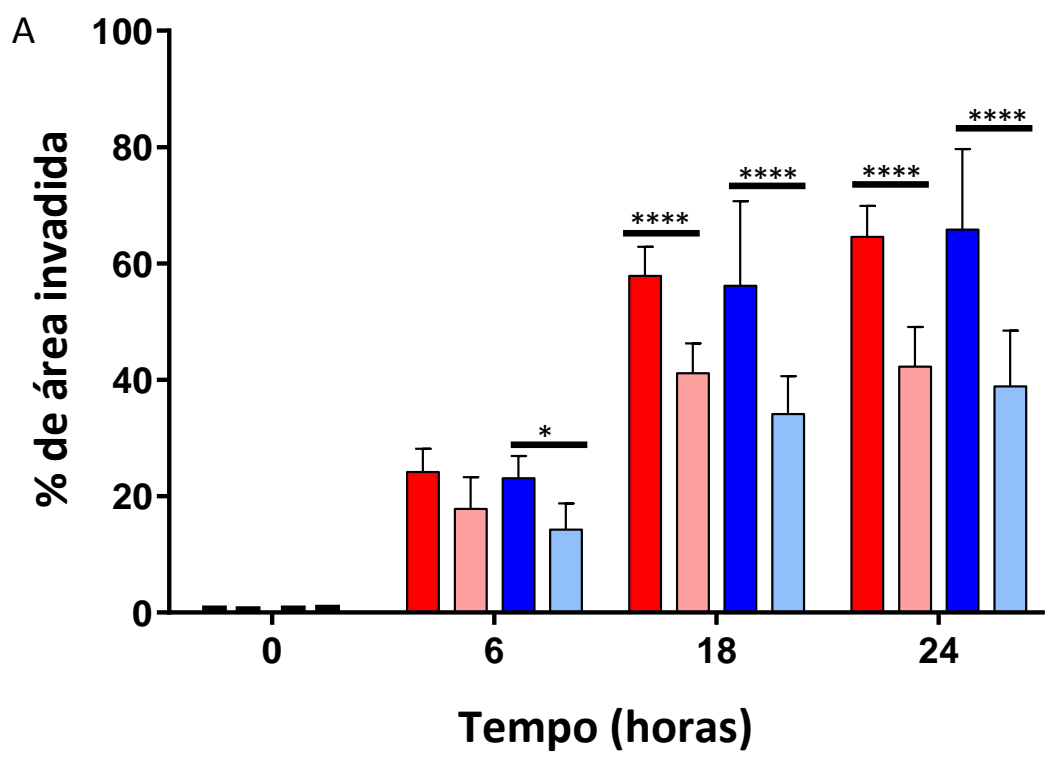

U87 scrambled 1

B
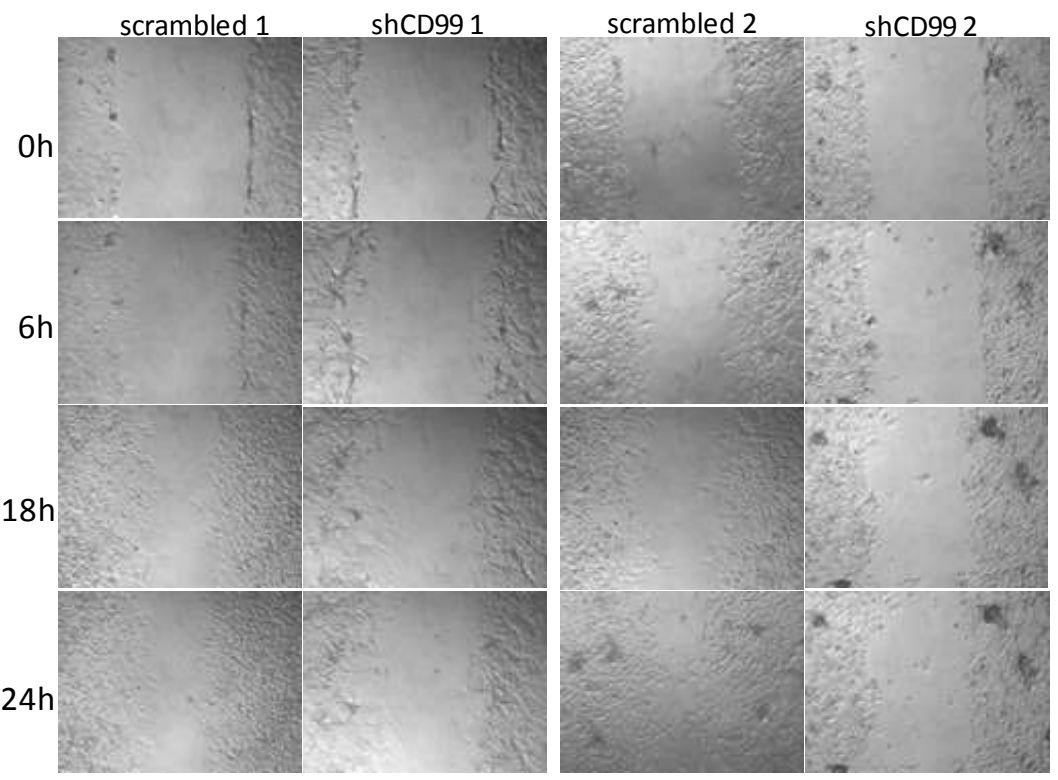

Figura 15. Papel de CD99 na migração da linhagem U87MG. (A) Ensaio de ferida em monocamada das células silenciadas com shCD99 1 e shCD99 2 mostrando atividade migratória reduzida quando comparadas ao controle (scrambled). O gráfico representa a área livre ocupada pelas células nos tempos 0, 6, 18 e 24 horas apósrealizada a ferida. Os resultados foram expressos como média \pm erro padrão da média (quadruplicatas) de dois experimentos independentes. Os asteriscos indicam diferenças estatisticamente significantes da área invadida pelas células silenciadas em relação aos controles. Análise de variância ANOVA, seguida por teste de Bonferroni: ${ }^{*} p=0,022,{ }^{* * * *} p<0,0001$. 
(B) Fotomicrografias representativas do fechamento da ferida nos tempos 0, 6, 18 e 24 horas. Aumento de 10x.

Outro ensaio de migração, monitorado e com menores intervalos de tempo, foi realizado a seguir. Nesta análise foram registradas imagens a cada 3 horas até o tempo final de 24 horas. A Figura 16 mostra um gráfico de tempo de monitoramento em relação à porcentagem da área invadida pelas células. É possível observar que as células silenciadas com ambos os shCD99 apresentam uma diminuição da migração em relação aos controles a partir de 6 horas. A análise estatística mostrou que houve diminuição significativa da migração $(p<0,0001)$ para as células silenciadas com os ambos os construtos. Semelhantemente ao que foi observado anteriormente, houve um maior efeito da diminuição da migração para a linhagem U87MG shCD99 2 comparada a com a U87MG shCD99 1.

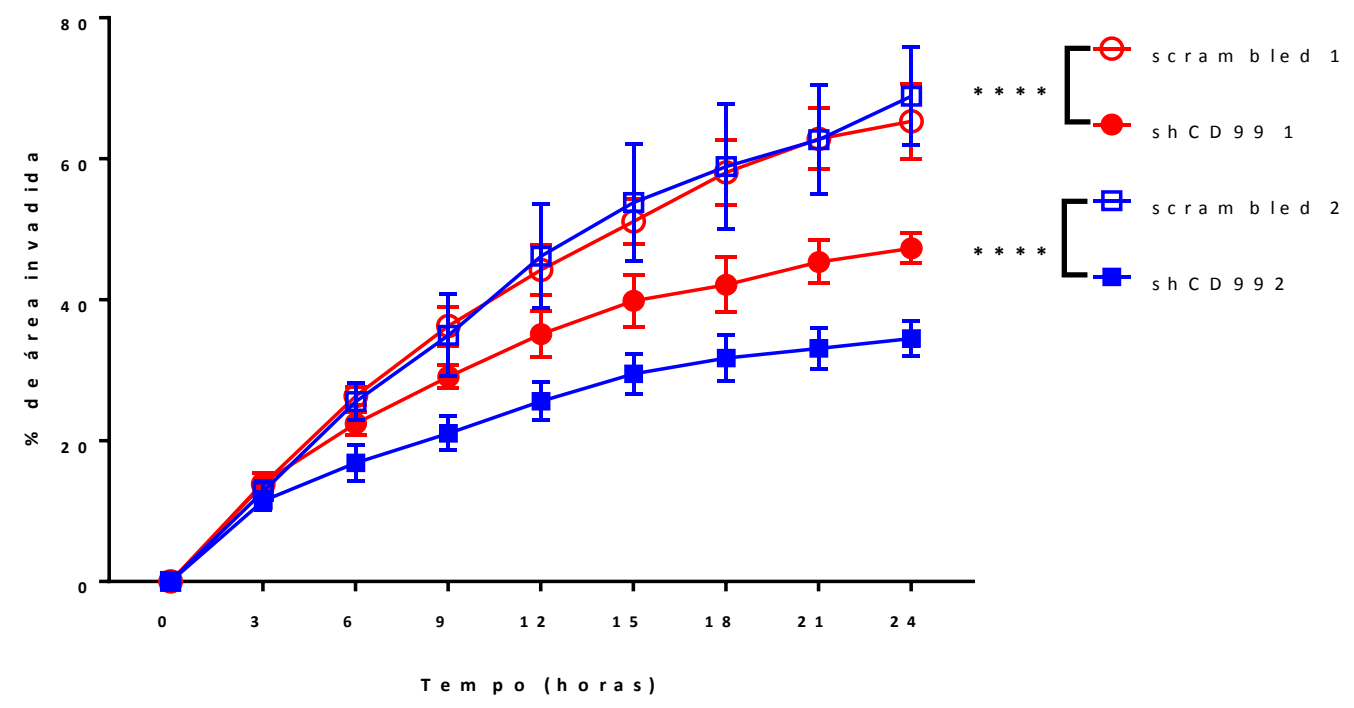

Figura 16. Papel de CD99 na migração da linhagem U87MG em ensaio de monitorado. O ensaio de ferida em monocamada mostrando o papel de CD99 na migração da linhagem U87MG foi realizado por análises nos tempos de 0, 3, 6, 9, 12, 15, 18, 21 e 24 horas. As células silenciadas com shCD99 1 (círculo fechado vermelho) e shCD99 2 (quadrado fechado azul) apresentaram atividade migratória reduzida quando comparadas aos respectivos controles, scrambled 1 (círculo aberto vermelho) e scrambled 2 (quadrado aberto azul). O resultado foi expresso como média \pm erro padrão (sextuplicatas). Os asteriscos indicam diferença estatisticamente significante das células silenciadas para CD99 em relação ao scrambled nos diferentes tempos.Análise de regressão não-linear:**** $p<0,0001$. 


\subsubsection{Ensaio de invasão celular}

A análise do papel de CD99 na invasão celular foi realizada em um ensaio em insertos com matrigel. Os resultados dos ensaios realizados em duplicatas estão apresentados na Figura 17A. Houve diminuição significativa da capacidade de invasão das células U87MG em relação aos controles, com 47\% e45\% com silenciamento com shCD99 1 e shCD99 2, respectivamente $(p=0,029)$. É interessante observar que houve diminuição da invasão nos dois construtos e que a porcentagem de células que invadiram foi semelhante entre os construtos. Os dados corroboram com o resultado de migração mostrando que o CD99 parece importante não só para o processo migratório, mas também para o processo invasivo na linhagem de GBM.

A

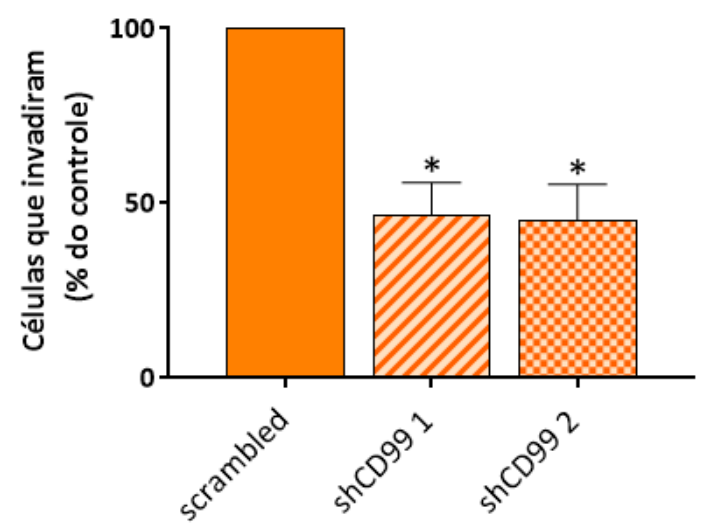

B

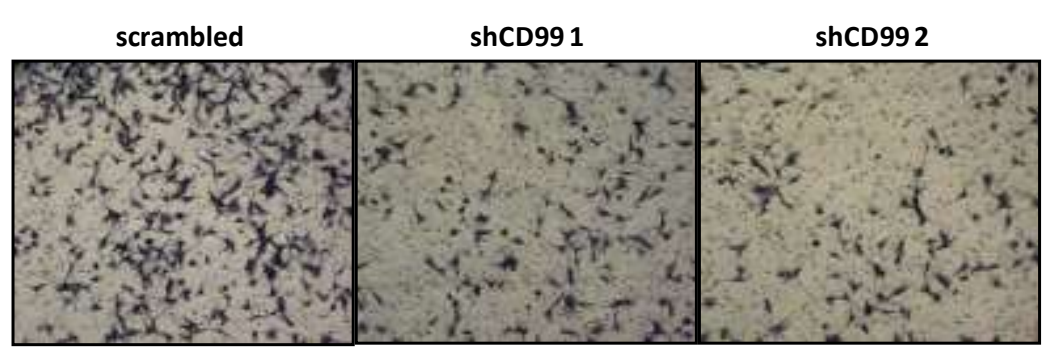

Figura 17. Papel de CD99 na invasão da linhagem U87MG. (A) A análise do comportamento invasivo da linhagem U87MG foi realizada nos controles scrambled e após silenciamento por shCD99 1 e 2. 0 gráfico representa a porcentagem do total de células silenciadas que migraram por inserto em relação ao controle. (B) Imagens de campos representativos mostrando as células que atravessaram os insertos após fixadas e coradas com cristal violeta. Aumento de 10x. Teste de Mann-Whitney: * $p=0,029$ para ambas as análises. 


\subsubsection{Ensaio de adesão celular}

Como a adesão celular influencia a mobilidade das células, foram realizados ensaios de capacidade de adesão de células U87MG após silenciamento de CD99. A Figura 18 mostra a quantidade de U87MG aderidas à placa.

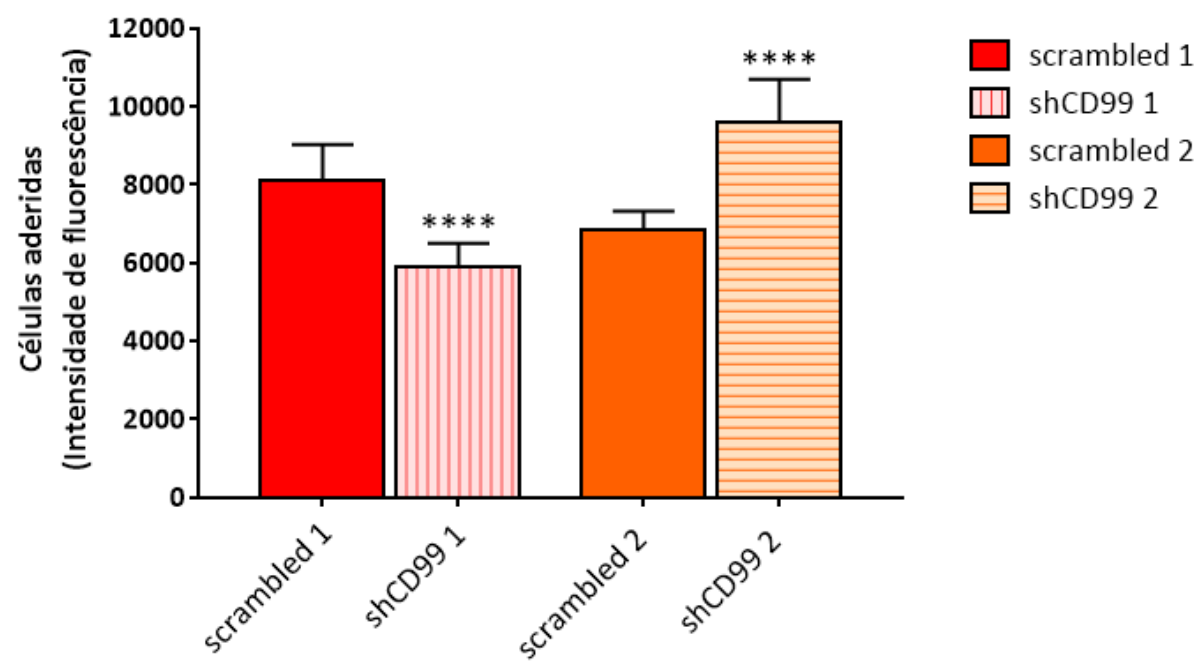

Figura 18. Papel do CD99 na adesão celular da linhagem U87MG. A adesão das células foi avaliada após 3 horas de adesão à placa e a viabilidade celular foi analisada com o reagente PrestoBlue. 0 gráfico expressa a média de sextuplicatas de dois ensaios independentes. Teste de MannWhitney: ${ }^{* *} \mathrm{p}<0,001 ; * * * * \mathrm{p}<0,0001$.

Enquanto as células U87MG silenciadas com shCD99 1 aderiram menos em relação ao seu controle $(p<0,0001)$, observou-se um aumento significativo da adesão de células silenciadas com shCD99 2 quando comparadas com o grupo controle $(p<0,0001)$. Esse resultado pode ser explicado pela diferença nos níveis de silenciamento entre os dois construtos, lembrando que na linhagem U87MG shCD99 1 ainda resta 20\% da expressão de CD99.

\subsubsection{Ensaio de proliferação celular}

Os resultados da proliferação celular das células U87MG silenciadas para o CD99 estão apresentados na Figura 19 para ambos osshRNAs utilizados. Observa-se uma diminuição significativa $(p<0,0001)$ da proliferação entre as células shCD99 1 e o respectivo 
controle nos dias 5 e 7 (Figura 19A). De maneira semelhante, houve diminuição significativa $(p<0,0001)$ da proliferação no shCD99 2 quando comparado ao seu controle nos tempos 5 e 7 dias (Figura 19B).
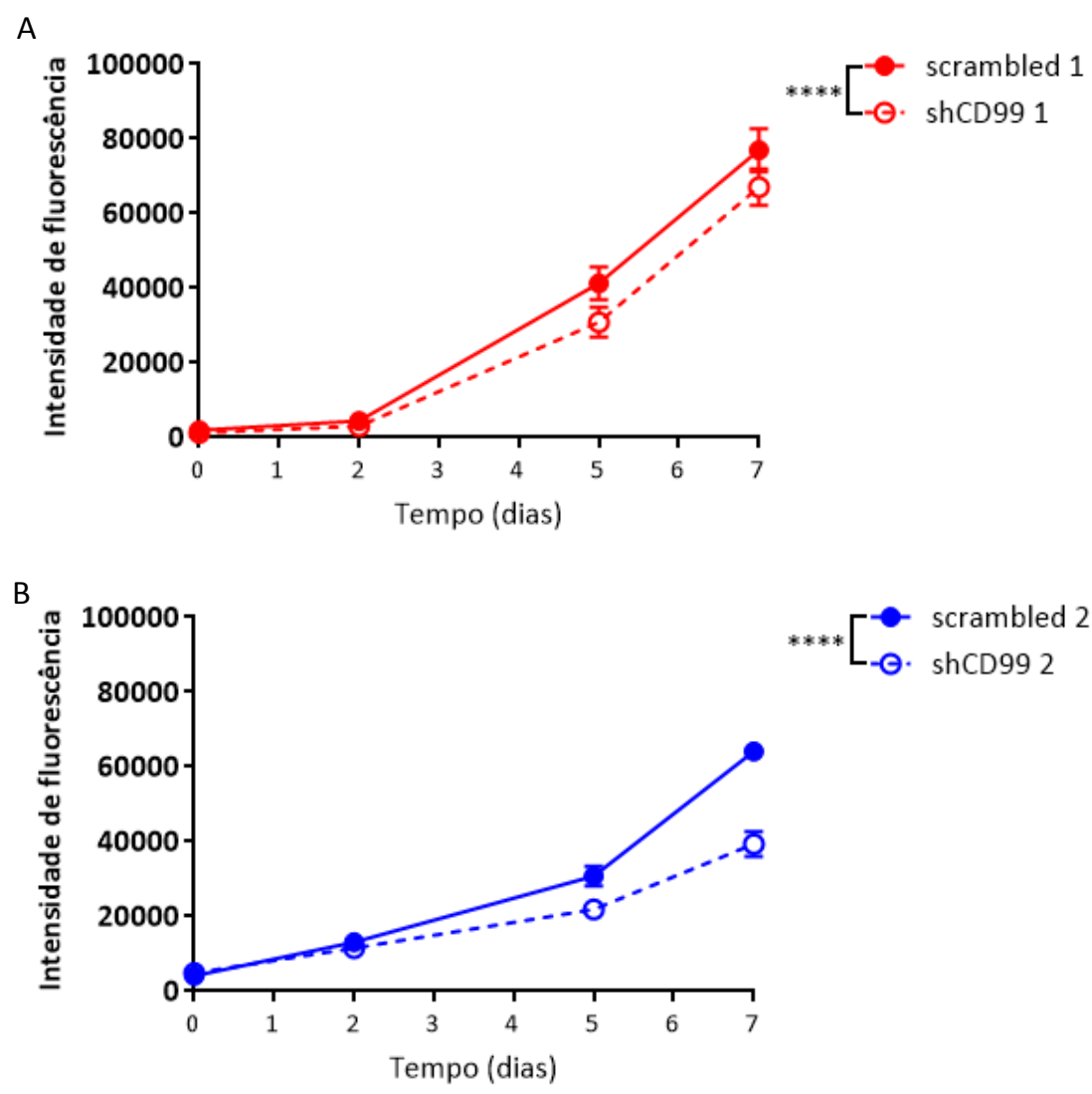

Figura 19. Curva de proliferação da linhagem U87MG shCD99 1 (A) e shCD99 2(B). O resultado representa dois experimentos independentes e foi expresso como média \pm erro padrão (sextuplicata). $\mathrm{O}$ asterisco indica diferença estatisticamente significante das células silenciadas para CD99 em relação ao scrambled nos diferentes tempos. Análise de regressão não-linear: $* * * * \mathrm{p}<0,0001$.

\subsection{IMUNOFLUORESCÊNCIA}

\subsubsection{Localização de CD99 na linhagem U87MG}

A Figura 20 mostra a localização predominantemente de CD99 na membrana das células U87MG, com marcação acentuada nas projeções da membrana, estruturas de contato focal, que lembram os lamelipódios e filopódios. 


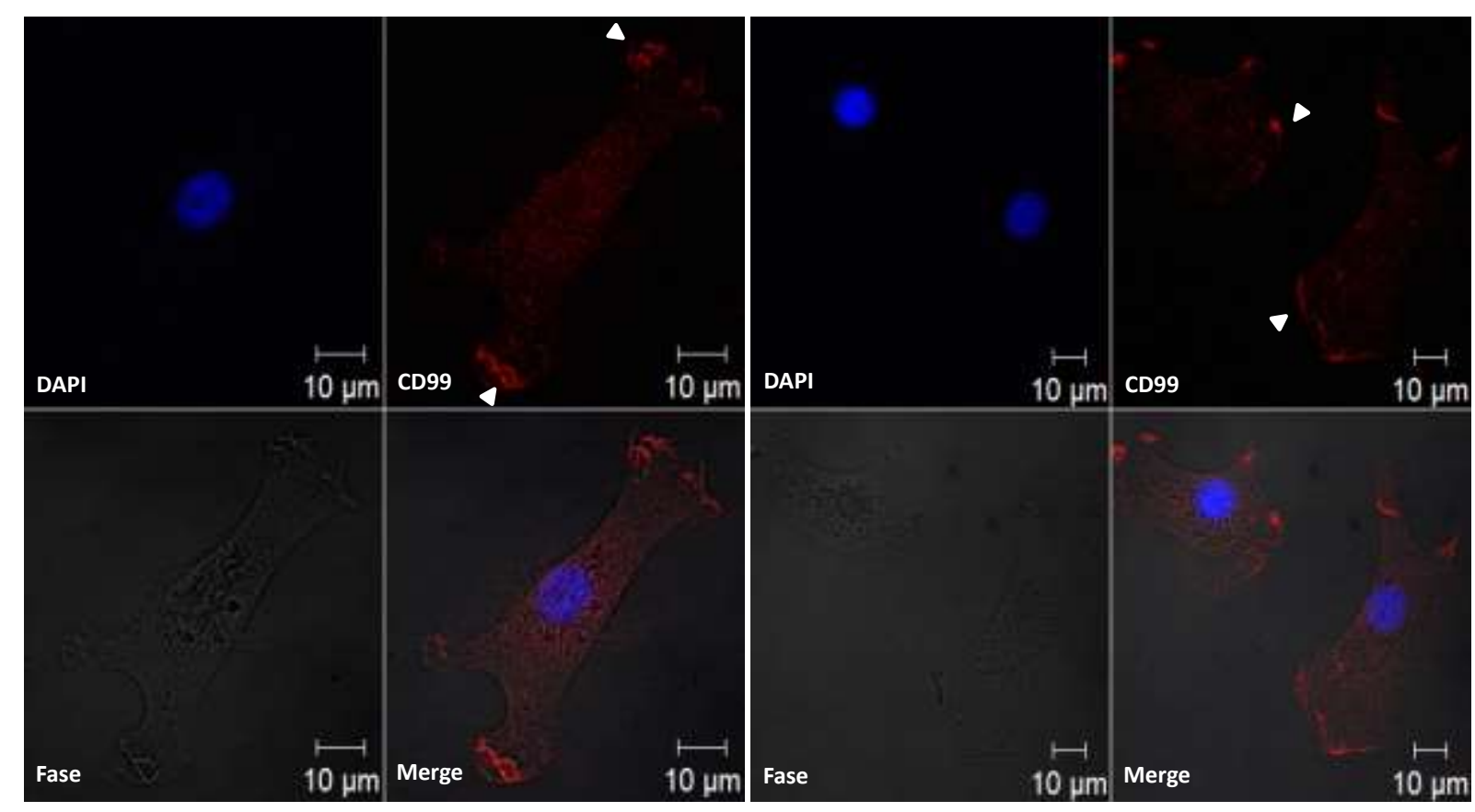

Figura 20. Expressão e localização da proteína CD99 na linhagem U87MG. Fotomicrografias representativas da expressão e localização da proteína CD99 na membrana e nos lamelipódios. Anticorpo anti-CD99 conjugado com FITC (vermelho) e núcleo corado com DAPI (azul). As imagens foram analisadas por microscopia confocal utilizando-se objetiva de 40x (zoom de 3x e 2x).

Alterações na reorganização do citoesqueleto das células U87MG silenciadas por shRNA foram analisadas através da comarcação de CD99 com filamentos de actina.

\subsubsection{Alterações docitoesqueleto}

A Figura 21 ( $\mathrm{A}$ e C) mostra co-marcação dosfilamentos de actina/faloidina e CD99 nos controles (scrambled 1 e 2) na região de contato célula-célula e nos lamelipódios/filopódios. As células silenciadas (Figura 21B e 21D) não apresentaram marcação para o CD99, como já esperado, além de apresentar alteração da morfologia quando comparada aos controles. Além disto, a distribuição da actina parece mais homogênea nas células silenciadas com o shCD99 1, enquanto que nas que foram silenciadas com o shCD99 2 apresentaram as bandas de actina mais desorganizadas. 


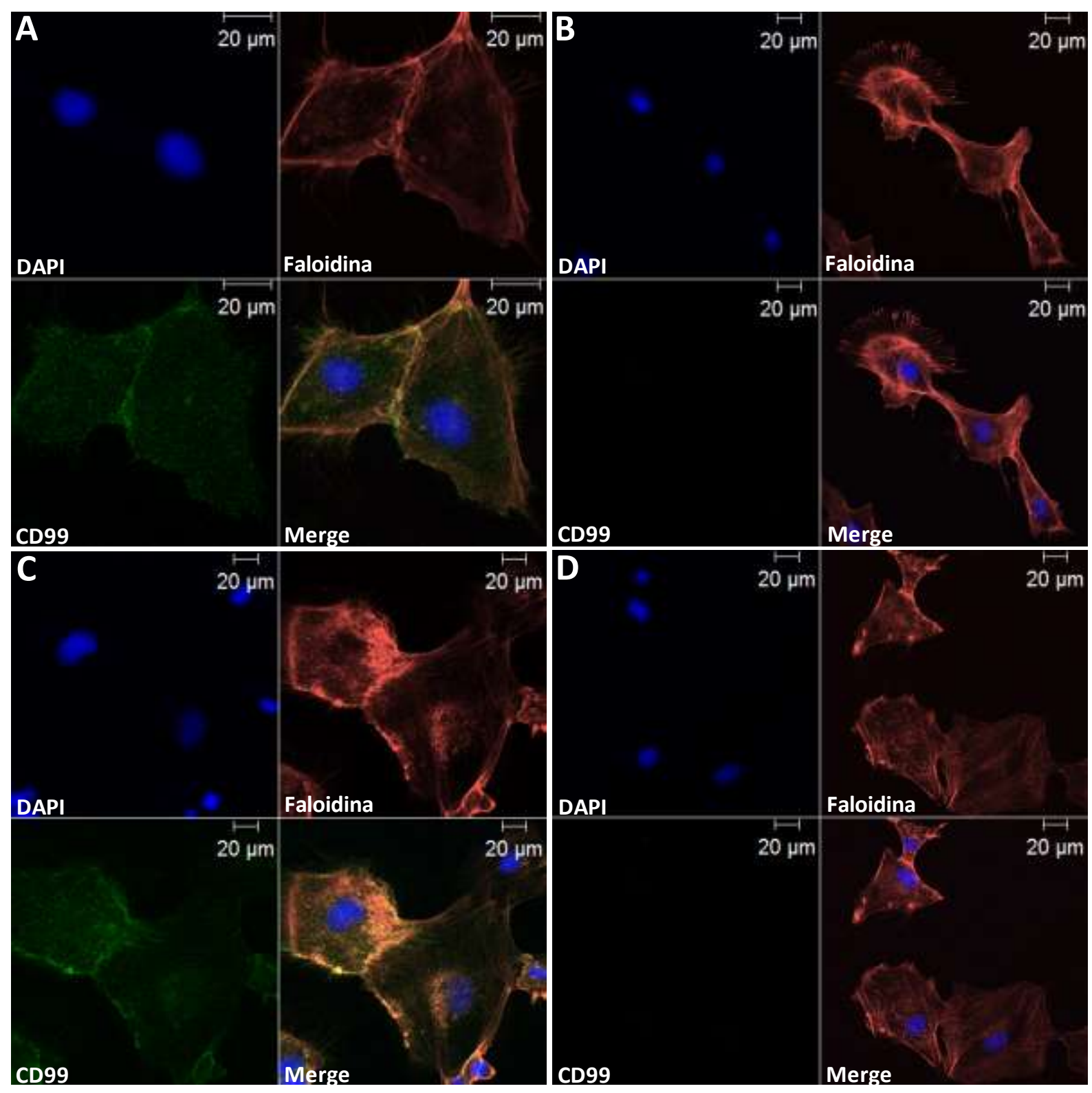

Figura 21. Co-localização de CD99 e faloidina nas células U87MG silenciadas para CD99 e controles. Fotos representativas da imunofluorescência mostrando a co-localização de CD99 (verde) e faloidina (vermelho) na linhagem U87MG silenciada shCD99 1 e shCD99 2 e seus controles. Os núcleos foram corados com DAPI (azul). As imagens foram analisadas por microscopia confocal utilizando-se objetiva de 40x.

\subsection{MODELO ORTOTÓPICO}

Após os ensaios para análise da função de CD99 in vitro, o crescimento das células silenciadas com shCD99 1 e shCD992 e seus respectivos controles foi analisado em modelo animal ortotópico, por inoculação das células por estereotaxia. Para estas análises, as células 
foram inicialmente transduzidas com lentivírus para produção de proteína fluorescente, a fim de possibilitar o monitoramento dos animais por análise de imagens não invasiva de progressão do crescimento tumoral.

As células U87MG nas quatro diferentes condições (dois shRNAs e dois controles) foram transduzidascom vetor lentiviral para expressão da proteína fluorescente (TurboFP635). A eficiência de transdução foi confirmada por citometria de fluxo, que mostrou mais de $95 \%$ das células expressando a proteína fluorescente.

Foi injetado um total de $1 \times 10^{5}$ células em um volume de $3 \mu \mathrm{L}$ por estereotaxia com auxílio de microinjetor no lobo frontal direito. Os animais foram monitorados por imagem não invasiva através da leitura de fluorescência no cérebro.

A Figura 22A é a imagem representativa do crescimento tumoral das células U87MG TurboFP635 silenciada com shCD991 em 6 camundongos nude, sendo 3 animais para controles e 3 para o shCD99 1, nos dias 14, 30, 45 e 60 após a injeção das células. A Figura 22B mostra o gráfico representativo do crescimento do tumoral em diferentes tempos. Pode-se observar um aumento da intensidade de fluorescência com o tempo nos camundongos que receberam as células controle, enquanto que a intensidade de fluorescência diminuiu nos animais que foram injetadas as células silenciadas com o shCD99 1. A Figura 22C mostra que umamenor sobrevida dos animais controle do grupo 1 em relação ao grupo de animais com as células silenciadas para a expressão de CD99. Os animais que receberam as células silenciadas foram sacrificados aos 60 dias após cirurgia para finalização do experimento, apesar de não apresentarem perda de peso e/ou alterações comportamentais. 


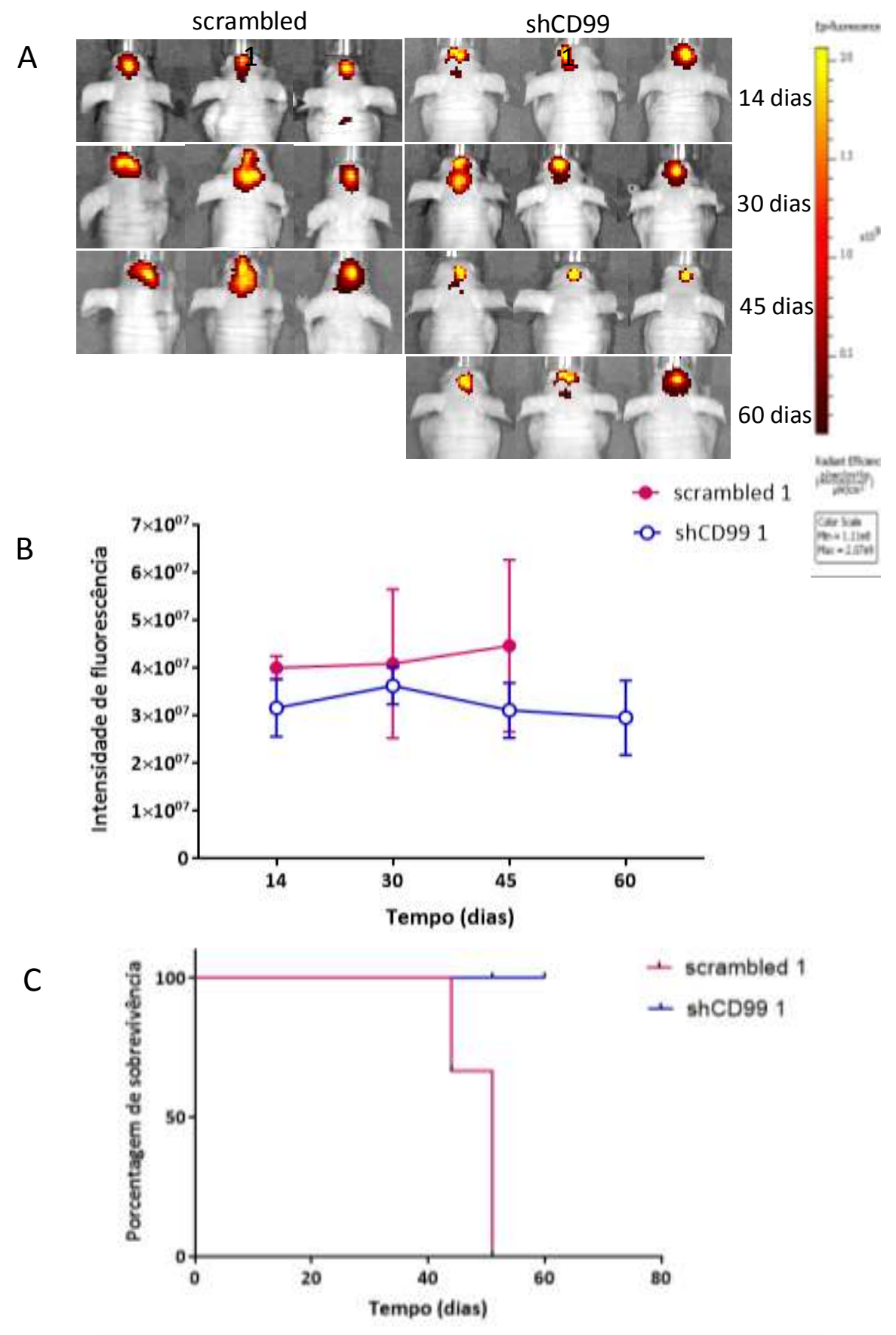

Figura 22. Efeito do silenciamentocom shCD99 1 no crescimento tumoral da linhagem U87MG no modelo ortotópico in vivo. (A) O crescimento ortotópico da linhagem U87MG TurboFP635 foi monitorado em tempo real (IVIS - in vivo Image System) mostrando a expressão da proteína TurboFP635 no scrambled 1 e shCD99 1 implantada no lobo frontal dos camundongos nude nos dias 14, 30 e 45 e 60. (B) Média da intensidade de fluorescência do cérebro dos animais nos dias 14, 30 e 45 e 60 dias após a injeção das células U87MG TurboFP635. Os resultados foram expressos como média \pm erro padrão ( 3 animais/grupo). (C) A análise de sobrevida mostra um aumento da sobrevida dos animais que receberam a linhagem U87MG shCD99 1 em relação ao seu controle (scrambled 1). 
A Figura 23A mostra o crescimento tumoral da linhagem U87MG TurboFP635 silenciada com shCD99 2. A imagem é representativa de 6 animais por grupo, sendo cada grupo composto por 6 do grupo controle e 6 do shCD99 2. A Figura 23B mostra o crescimento tumoral nos dias 7, 14, 21, 30, 45 e 60 após a inoculação das células U87MG. Semelhante ao shCD99 1 foi observado um aumento da intensidade de fluorescência nos camundongos que receberam as células controle ao longo do período monitorado, enquanto que a intensidade de fluorescência nos animais que receberam as células silenciadas para o shCD99 2 diminuiu. A análise de regressão não-linear mostrou que houve diferença significativa entre controle e shCD99 2 nos dias 14 e 21 após a cirurgia $(p<0,0001)$. A Figura $23 \mathrm{C}$ representa as curvas de sobrevida e mostra que os animais do grupo que receberam as células sem expressão de CD99 apresentaram maior sobrevida que os do grupo controle $(p<0,03)$. Os animais que receberam as células silenciadas foram sacrificados aos 60 dias após cirurgia para finalização do experimento e não apresentaram alterações fisiológicas nem comportamentais até o dia do sacrifício.

Os dados corroboram os resultados obtidos de diminuição da proliferação in vitro com as células U87MG silenciadas, sendo que a célula silenciada com shCD99 2, de forma semelhante ao modelo in vivo, teve a proliferação reduzida de forma mais acentuada quando comparada ao shCD99 1. 
A
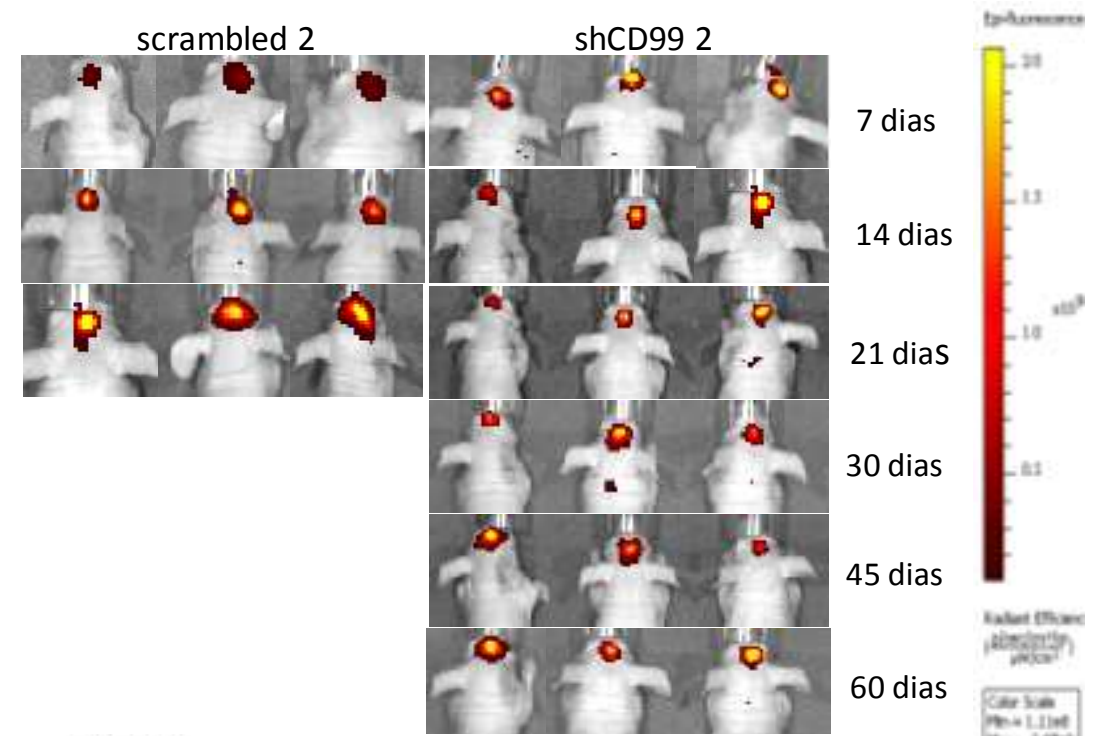

B

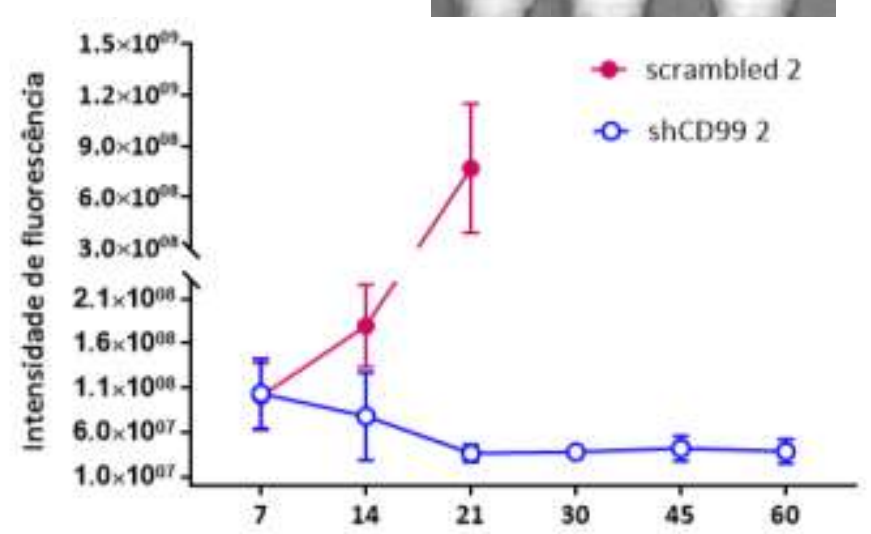

C

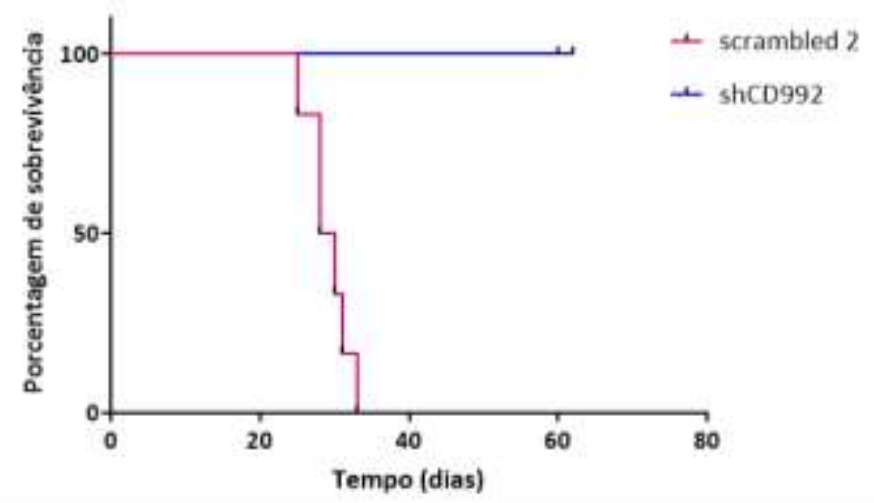

Figura 23. Efeito do silenciamento com shCD992 no crescimento tumoral da linhagem U87MG no modelo ortotópico in vivo. (A) O crescimento ortotópico da linhagem U87MG TurboFP635 foi monitorado em tempo real (IVIS - in vivo Image System) mostrando a expressão da proteína TurboFP635 no scrambled 2 e shCD99 2 implantada no lobo frontal dos camundongos nude. (B) Média da intensidade de fluorescência do cérebro doa animais nos dias 7, 14, 21, 30 e 45 e 60 dias após a injeção das células U87MG TurboFP635. Houve diminuição significativa do crescimento tumoral das células U87MG shCD99 2 em relação ao controle (regressão não-linear: $p<0,0001$ ). 0 resultado foi expresso como média \pm erro padrão (6 animais/grupo). (C) Análise de sobrevida mostra um aumento significativo da sobrevida dos animais que receberam a linhagem U87MG shCD99 2 em relação ao seu controle (scrambled 2). Teste de log-rank: $p<0,03$. 


\section{DISCUSSÃO}

O CD99 é um antígeno altamente expresso no GBM e é alvo para desenvolvimento da vacina sintética com múltiplos péptidos ou imunoterapia celular dendrítica. O papel funcional do CD99 em tumores ainda não foi completamente elucidado. O ligante para CD99 ainda não foi identificado e a maior parte do conhecimento sobre suas funções vem da ativação de CD99 por anticorpos monoclonais agonistas em células hematopoiéticas e tumorais $(25,29,31,79)$. Portanto, o conhecimento a respeito das vias de sinalização moduladas pelo CD99 no GBM é escasso e necessário para o entendimento de sua função em GBMs e outros tipos de tumores nos quais atua como oncogene.

Um estudo anterior de nosso laboratório analisou a expressão de CD99 em 150 amostras de astrocitomas de diferentes graus de malignidade e demonstrou uma alta expressão do gene e da proteína nas amostras tumorais quando comparados ao tecido cerebral não-neoplásico. Embora a diferença nos níveis de expressão gênica entre os diferentes graus de astrocitomas não tenha sido significativa, a localização da proteína foi diferente, primeiramente porque nos astrocitomas de maior grau de malignidade (graus III e GBM) a marcação foi predominante no citoplasma e membrana plasmática e nos astrocitomas de menor grau (I e II) e tecido não-neoplásico, CD99 localizou-se predominantemente no núcleo (21).

No presente estudo, foi demonstrado que a isoforma 1 de CD99 é a molécula que desempenha um papel importante na malignidade tumoral do GBM. Além disto, as análises funcionais com o silenciamento do gene corroboram este dado. As análises de transcriptoma das células U87MG silenciadas através de siRNA mostraram que a diminuição da expressão de CD99 afetou a expressão de genes envolvidos na adesão celular e regulação de proteínas da matriz extracelular. Foram realizados experimentos funcionais in vitro, ensaios de imunofluorescência e de crescimento in vivo com U87MG silenciadas para a expressão de CD99 por shRNA. 


\subsection{EXPRESSÃO DE ISOFORMAS CD99}

A análise de expressão das isoformas 1 e 2 de CD99 na linhagem celular U87MG mostrou uma expressão predominante da isoforma 1. A expressão da isoforma 2 é muito baixa a nível de expressão gênica e proteica. O anticorpo anti-CD99 utilizado (clone DN16) reconhece as duas isoformas do CD99, mas apenas a isoforma 1 com $32 \mathrm{kDa}$ de peso molecular, foi detectada por Western blot. A análise dos níveis de expressão de ambas as isoformas de CD99 também foi realizada em amostras de astrocitomas de diferentes graus de malignidade. Os resultados corroboram com a expressão observada na linhagem celular U87MG. Existe uma expressão predominante da isoforma 1 de CD99 nos casos de astrocitomas quando comparado ao tecido cerebral não tumoral. Nossos dados confirmam os resultados já observados anteriormente (65). A expressão da proteína CD99 é maior nas amostras tumorais quando comparada ao tecido NN, como já observado em nosso trabalho anterior $(21,80)$.

A isoforma 1 de CD99 é essencial na adesão de linfócitos mediada pela integrina LFA1, enquanto que a isoforma 2 inibe a adesão espontânea dessas células através da via LFAI/ICAM $(25,80)$. Nos tumores, as isoformas de CD99 regulam diferentes funções na malignidade tumoral, afetando negativamente os processos biológicos. No osteossarcoma, a isoforma 1 desempenha um papel na modulação da malignidade do câncer atuando como um potente supressor de migração e metástase através da repressão c-Src $(23,60)$. Por outro lado, a transfecção da isoforma 2 de CD99 em uma linhagem de câncer de mama levou a uma capacidade superior de migração em comparação com o controle, embora essa diferença não tenha sido observada nas mesmas células transfectadas com a isoforma 1 (32, 58). Além disso, a expressão de CD99 está associada à progressão tumoral no sarcoma de Ewing e leucemia linfoblástica aguda $(50,81)$, enquanto que no osteossarcoma $(37,82)$ e linfoma de Hodgking (83) CD99 tem baixa expressão e atua como um supressor de tumor. Em nosso modelo de astrocitomas, a isoforma 1 de CD99 desempenha um papel importante, apresentando alta expressão nos GBMs. Portanto, o silenciamento do CD99 foi direcionado para a isoforma 1 utilizando a linhagem celular de GBM U87MG. 


\subsection{ANÁLISE DO RNA-SEQ, VIAS DE SINALIZAÇÃO MODULADAS POR CD99}

Os dados de expressão gênica da linhagem celular U87MG silenciada para a expressão de CD99 por siRNA gerados pelo RNAseq foram analisados em relação ao controle (NTC) na base de dados DAVID. Entre os processos mais enriquecidos estavam os relacionados à junção aderente célula-célula e adesão celular, o que está de acordo com o papel de CD99 já descrito anteriormente nos diferentes tipos de tumores. A hipótese do presente trabalho é que CD99 pode modular a via de sinalização de integrina "de dentro

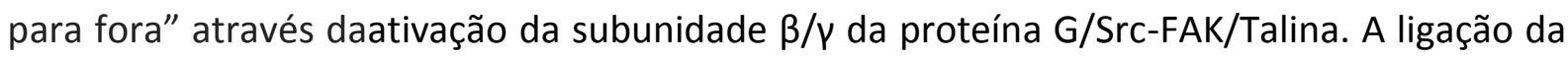
talina às caudas citoplasmáticas de cadeia $\beta 3$ da integrina induz mudanças conformacionais em seus domínios extracelulares, aumentando a afinidade da integrina pelos ligantes (84). Outra possibilidade é que CD99 ativa caveolina-1 via cadeias V e $\alpha 5$ de integrina, e caveolina1 , então, ativa FAK. Uma vez que o FAK é ativada, vinculina ativa a $\alpha$-actina, promovendo, assim, a adesão celular e a formação de fibras de estresse. Além disso, FAK pode ativar o CDC42/RAC que regula a polimerização da actina mediada por Arp2/3 e consequente orientação da migração celular $(85,86)$.

Recentemente, foi descrita outra via em um modelo de tumor de mama, em que os ligantes agonistas derivados de CD99 inibem a ativação da integrina 1 mediada por fibronectina através da via de sinalização SHP2/ERK/PTPN12/FAK (64). A supressão da atividade da integrina $\beta 1$ pela ativação do CD99 pode ocorrer através da desfosforilação de FAK em no resíduo de tirosina 397 (62).

Portanto, os dados do transcriptoma e os achados de estudos anteriores sugerem que os alvos de matriz extracelular juntamente com antígenos associados a tumores, incluindo CD99 e integrinas, participam de uma via de sinalização intermediada por FAK e cSrc. De fato, a análise do transcriptoma de genes envolvidos na adesão focal e regulação das vias do citoesqueleto de actina mostrou a regulação negativa da expressão daqueles relacionados à formação de fibras de estresse como RhoGap (ARHGAP5 e ARHGAP35), DIAPH1, e MLC (MYL5, MYL6B e MYL12B). Similarmente, a regulação negativa de vários genes que codificam proteínas envolvidas na via de FAK, como pequena GTPase 2da família Rac (RAC2), proteína 2 citoplasmática queinterage com FMR1 (CYFIP2), membro 1 da família 
de proteínas WAS (WASF1), proteína 2 associada a BAI1 (BAIAP2) e subunidades 1A e 1B do complexo de proteínas 2/3 relacionada a actina (ARPC1A e ARPC1B), que foram relacionadas à formação de filopódios e lamelipódios e regulam os filamentos de actina, que são essenciais para direcionar a migração celular.

Além disso, os genes que codificam ezrina $(E Z R)$, radixina $(R D X)$ e moesina $(M S N)$ foram regulados negativamente quando CD99 foi silenciado. Estes genes são membros altamente homólogos da superfamília FERM (ezrina, radixina, moesina), essenciais para a ligação do citoesqueleto de actina à membrana celular e organizadores chave de domínios de membrana especializados como filopódio e lamelipódio (87). A diminuição da expressão pode levar a uma maior desorganizaçãodo citoesqueleto de actina, levando auma redução da migração celular. Da mesma forma, genes que codificam a dinamina 2 (DNM2) e a cortactina (CTTN) também foram negativamente reguladas com a diminuição da expressão de CD99. Essas proteínas participam da migração celular devido a estabilização dos feixes de F-actina nos filopódios (88).

\subsection{INFLUÊNCIA DE CD99 SOBRE MIGRAÇÃO, INVASÃO E ADESÃO CELULAR}

A regulação da adesão e migração celular é essencial para o processo metastático. Embora as células tumorais apresentem um amplo espectro de mecanismos de invasão e migração, dois modelos clássicos são bem descritos:

- migração mesenquimal semelhante à de fibroblastos, realizada por células alongadas que possuem fibras de estresse e dependentes de proteólise celular,

- migração ameboide, realizada por células redondas com alta tensão cortical e baixa adesão à matriz extracelular $(89,90)$.

Embora esses modelos de migração possam ser facilmente separados in vitro, as evidências sugerem que não são mutuamente exclusivos e que as células podem alterar de um tipo para outro em resposta a mudanças no microambiente do tumor. GBMs usam um modo mesenquimal de migração e invasão $(91,92)$. No entanto, as células de GBM U87MG que superexpressam o CD99 apresentaram uma maior proporção de migração ameboide com alta tensão cortical e baixa adesão à matrix extracelular do que nas células controle 
(47). Os ensaios funcionais com células U87MG silenciadas demonstraram que a diminuição da expressão de CD99 resultou em diminuição da migração e invasão. Uma menor motilidade celular após o silenciamento do CD99 em células de GBM pode estar relacionada à desregulação da formação de fibras de estresse, adesão focal e particularmente à desregulação da formação de filopódios e lamelipódios de acordo com o conjunto de genes identificados pela análise do transcriptoma (Figura 24). De fato, a superexpressão da isoforma 1 em linhagens celulares de osteossarcoma modulou de forma semelhante a expressão de genes essenciais para remodelamemto do citoesqueleto de actina e a invasão celular por $A R P 2$ e $A R P C 1 A$ do complexo $\operatorname{Arp2} / 3(33,60)$. Esses estudos prévios corroboram os presentes resultados da análise do transcriptoma que uma disfunção do complexo Arp2/3 é um nó importante para a regulação da motilidade celular.

Nossos dados corroboram com o resultado obtido por Seol e colaboradores, que mostraram que a superexpressão de CD99 em células U87MG aumentou a taxa de migração e invasão em comparação ao controle, enquanto que em outras duas linhagens celulares de GBM, T98 e SNB19, o silenciamento CD99 por siRNA resultou em uma diminuição da migração e invasão (47). Semelhantemente, em um modelo diferente de células tumorais, o silenciamento da isoforma 2 de CD99 inibiu a capacidade invasiva de células de câncer de mama (32). Um efeito contrário foi observado em células de osteossarcoma, nas quais a superexpressão da isoforma 1 diminuiu a migração $(33,37,60)$.

A adesão celular é um processo complexo que envolve muitas interações moleculares, incluindo a ligação ligante-receptor, mudanças nos fluxos através de vias de sinalização intracelular e modulação do remodelamento do citoesqueleto. Consequentemente, os ensaios de adesão não só analisam os contatos entre uma célula e proteínas de adesão extracelulares, mas também fornecem informações sobre outros eventos celulares importantes $(93,94)$. Nesse contexto os ensaios funcionais com U87MG silenciada para CD99 por shRNA também mostraram a importante alteração da capacidade de adesão celular, sugerindo que esta função nas células U87MG é dependente da quantidade de CD99 expressa nas células. O silenciamento quase completo de CD99 (97\% knockdown com shCD99 2) apresentou um número maior de células aderidas em relação ao controle, em contraste às células silenciadas com ao shCD99 1, que ainda apresentou $20 \%$ 
de CD99 expresso. Essa diferença pode ser explicada pelo estímulo distinto para produzir os componentes da matriz extracelular e consequente ativação de vias de sinalização distintas. Nesse contexto, a análise do transcriptoma mostrou o aumento da expressão de fibronectina com o silenciamento do CD99. As células apresentam uma organização diferente da actina do citoesqueleto em resposta a diferentes concentrações de fibronectina. Baixas concentrações de fibronectina resultam em poucas adesões altamente dinâmicas, enquanto os padrões de polimerização de actina são menos organizados. Por outro lado, altas concentrações de fibronectina resultam em adesões e actina abundantes, mas menos dinâmicas. Concentrações médias de fibronectina resultam em altas taxas de migração, aderências moderadas e taxa de actina muito dinâmica (95).

É importante avaliar a capacidade de CD99 para controlar o remodelamento do citoesqueleto celular, pois este é o primeiro passo na migração celular. CD99 foi capaz de promover a reorganização do citoesqueleto nas células de sarcoma de Ewing $(26,82,96)$. Este fenômeno, observado por imunofluorescência e microscopia de ultrassom, resultou na formação de junções adesivas e adesões focais observadas após a ativação de células com um anticorpo agonista anti-CD99 (26).

As observações anteriores são consistentes com os presentes resultados da análise dos dados do transcriptoma da linhagem U87MG silenciada por siRNA para o CD99. Os achados da imunofluorescência e da ultrassonografia após a ativação das células do sarcoma de Ewing com um anticorpo anti-CD99 agonista também reforçam que CD99 é capaz de controlar o remodelamento do citoesqueleto celular e formar junções aderentes e adesões focais(96). A localização de CD99 por imunofluorescência mostrou uma marcação de membrana celular em regiões de contato celulares (filopódios e/ou lamelipódios) em células U87MG. Por outro lado, não foi observada imunomarcação para CD99 nas células U87MG silenciadas por shRNA, confirmando a ausência de expressão causada pelo shRNA. Curiosamente, nestas células foram observadas alterações morfológicas marcantes, caracterizadas por redução da superfície celular predominantemente na periferia das células silencidadas com shCD991 e com feixes de F-actina esparsos na superfície das células silenciadas com shCD99 2. Corroborando nossos dados, um estudo avaliou a imuno-colocalização de CD99 em osteoblastos sugerindo um possível papel na diferenciação celular. 
Os autores mostraram uma marcação intensa de CD99 em lamelipódios, além de colocalização em estruturas de adesão (37). Na linhagem celular de sarcoma de Ewing, houve acúmulo de actina nos locais de adesão celular (junções e adesões focais) após a ativação de CD99 com um anticorpo agonista (26). Essas descrições reforçam a diferença entre a força de adesão entre as células silenciadas com ambos os shRNAs. As células U87MG shCD991 com baixa resistência à adesão possuem somente aderências focais periféricas que estão frequentemente associadas a feixes grossos de F-actina periféricos (97). Já as células U87MG shCD992, com uma maior força de adesão, apresentam adesões focais com poucas marcações e menores, distribuídas por toda a superfície ventral da célula e conectadas a muitos feixes de F-actina que abrangem toda a célula e o aumento da força de adesão é mediado pelo aumento da participação da integrina na matriz extracelular $(98,99)$. 

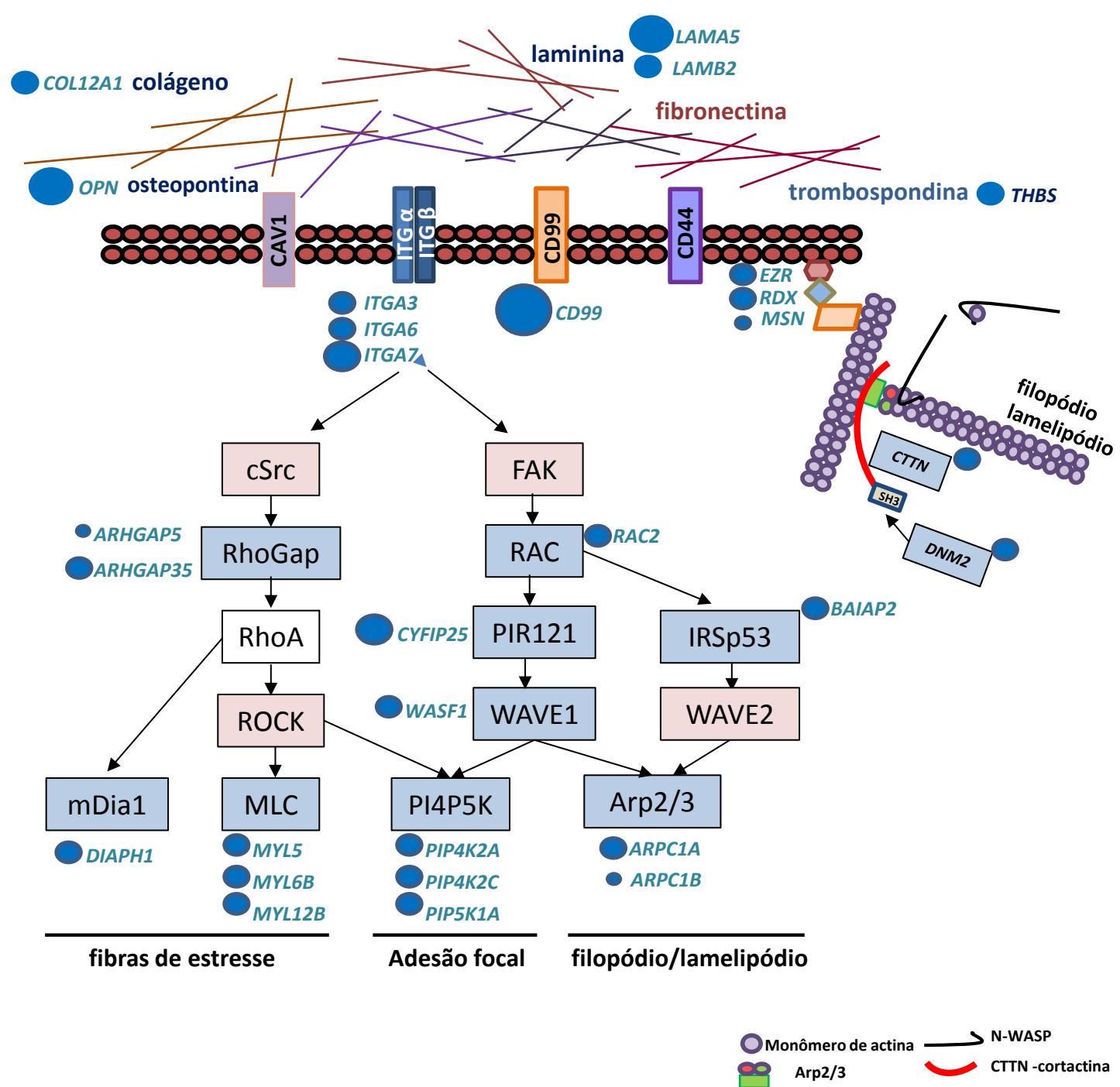

Figura 24. Representação esquemática de vias de sinalização de adesão focal e regulação do citoesqueleto de actina, mostrando a membrana plasmática e os alvos da matriz extracelular, e vias de de c-Src e FAK com correspondentes alvos intermediários envolvidos na formação de fibras de estresse, adesão focal e formação de fillopódios e lamelipódios. O símbolo da proteína ou de um complexo é representado por um retângulo azul quando diminui a expressão, ou um retângulo rosa quando aumenta, de acordo com a análise do transcriptoma do siCD99 da linhagem U87MG. Os genes específicos com menor expressão de cada grupo são anotados ao lado do retângulo correspondente, e o tamanho dos círculos azuis é proporcional à variação da alteração de expressão (siCD99/NTC). Abaixo da membrana plasmática, no lado direito, o complexo ERM (ezrina/radixina/moesina) está representado conectado ao polímero de actina e o sítio de ramificação da actina, o complexo Arp2/3 - cortactina (CTTN) - NWASP - dinamina 2 (DMN2) estão representados naformação de filopódios e lamelipódios. Todos os componentes foram regulados negativamente quando o CD99 foi silenciado, demonstrando o seu papel na redução da migração celular. 


\subsection{CD99 MODULA A PROLIFERAÇÃO CELULAR IN VITRO E IN VIVO}

O ensaio de proliferação in vitro mostrou uma diminuição da proliferação das células U87MG silenciadas para o CD99. Na sequência, o modelo ortotópico realizado com estas células mostrou diminuição da proliferação nas células silenciadas com os dois shRNAs, sendo mais acentuada a diminuição da proliferação na linhagem U87MG silenciada com o shCD992. Houve também um aumento da sobrevida dos animais em ambos os grupos de animais inoculados com as células silenciadas em relaçãos aos seus grupos controles. $\mathrm{Na}$ literatura existem poucos estudos que abordaram o papel do CD99 na regulação da proliferação dos tumores. Um modelo xenográfico que visava demonstrar o efeito do silenciamento do CD99 nas células de sarcoma de Ewing resultou em uma diminuição do crescimento tumoral e do tamanho do tumor. A inibição do crescimento celular induzida pelo silenciamento de CD99 foi devido a um bloqueio na fase G2 / M do ciclo celular e aumento da apoptose (27).

No tumor de mama não houve correlação da expressão de CD99 com a proliferação celular. A expressão de CD99 associou-se a uma baixa expressão de ciclina D1. Um alto nível de ciclina D1 está relacionado a uma alta taxa proliferativa e mau prognóstico em certos tipos de câncer (59).

\subsection{EXPRESSÃO DE CD99NOS SUBTIPOS MOLECULARES DE GBM}

Na análise da expressão de CD99 nos casos de GBM do TCGA, foi observado uma expressão maior no subtipo mesenquimal e clássico, cujos pacientes apresentam prognóstico mais agressivo do que os com o subtipo proneural. Interessantemente, o modelo celular utilizado da linhagem celular de GBM, U87MG, é do subtipo mesenquimal, pois possui mutação de NF1, segundo o COSMIC - Catalogue of Somatic Mutation in Cancer(https://cancer.sanger.ac.uk/cell lines). Isto reforça nossos dados de análises funcionais, que mostraram que uma menor expressão de CD99 levou a uma menor proliferação, migração e invasão das células. 


\subsection{CONSIDERAÇÕES FINAIS}

Estratégias terapêuticas para inibir ou diminuir a ação de CD99 pode melhorar a ressecabilidade do tumor e reduzir a probabilidade de recorrência tumoral. Desta forma, um melhor conhecimento dos mecanismos que levam CD99 a modificar a dinâmica do citoesqueleto pode identificar alvos terapêuticos para melhorar o prognóstico dos pacientes com GBM. 


\section{CONCLUSÕES}

- A isoforma 1 de CD99 é expressa na linhagem U87MG e nas amostras de astrocitomas quando e tecido cerebral não-neoplásico. A isoforma 2 apresenta expressão muito baixa ao nível de transcrito e não foi detectada ao nível de proteína;

- Os dados de RNA-seq das linhagens U87MG silenciadas por siRNA mostraram que o CD99 está envolvido nas interações de adesão célula-célula e célula-matriz via integrinas e remodelamento do citoesqueleto;

- Os ensaios funcionais in vitro após silenciamento do CD99 por shRNA na linhagem U87MG mostraram uma diminuição da migração, invasão adesão celular e proliferação celular, além da estrutura do citoesqueleto;

- CD99 está mais presente nos complexos de adesão focal e co-localiza com faloidina indicando a participação na reestruturação do citoesqueleto da célula;

- As células U87MG silenciadas para a expressão de CD99 injetadas no cérebro de camundongos apresentaram menor capacidade proliferativa e levaram a um aumento de sobrevida dos animais, quando comparados aos controles. 


\section{REFERÊNCIAS}

1. Louis DN, Ohgaki H, Wiestler OD, Cavenee WK, Burger PC, Jouvet A, et al. The 2007 WHO classification of tumours of the central nervous system (vol 114, pg 97, 2007). Acta Neuropathologica. 2007;114(5):547-.

2. Dolecek TA, Propp JM, Stroup NE, Kruchko C. CBTRUS Statistical Report: Primary Brain and Central Nervous System Tumors Diagnosed in the United States in 20052009. Neuro-Oncology. 2012;14:v1-v49.

3. Ostrom QT, Gittleman H, Liao P, Rouse C, Chen YW, Dowling J, et al. CBTRUS Statistical Report: Primary Brain and Central Nervous System Tumors Diagnosed in the United States in 20072011. Neuro-Oncology. 2014;16:1-63.

4. Ostrom QT, Gittleman H, Farah P, Ondracek A, Chen YW, Wolinsky Y, et al. CBTRUS Statistical Report: Primary Brain and Central Nervous System Tumors Diagnosed in the United States in 20062010. Neuro-Oncology. 2013;15:1-56.

5. Louis DN, Perry A, Reifenberger G, von Deimling A, Figarella-Branger D, Cavenee WK, et al. The 2016 World Health Organization Classification of Tumors of the Central Nervous System: a summary. Acta Neuropathologica. 2016;131(6):803-20.

6. Wesseling $\mathrm{P}$, van den Bent $\mathrm{M}$, Perry A. Oligodendroglioma: pathology, molecular mechanisms and markers. Acta Neuropathologica. 2015;129(6):809-27.

7. Reis GF, Tihan T. Therapeutic Targets in Pilocytic Astrocytoma Based on Genetic Analysis. Seminars in Pediatric Neurology. 2015;22(1):23-7.

8. Bar EE, Lin A, Tihan T, Burger PC, Eberhart CG. Frequent gains at chromosome 7q34 involving BRAF in pilocytic astrocytoma. Journal of Neuropathology and Experimental Neurology. 2008;67(9):878-87.

9. Ichimura K, Narita $Y$, Hawkins CE. Diffusely infiltrating astrocytomas: pathology, molecular mechanisms and markers. Acta Neuropathologica. 2015;129(6):789-808.

10. Furnari FB, Fenton T, Bachoo RM, Mukasa A, Stommel JM, Stegh A, et al. Malignant astrocytic glioma: genetics, biology, and paths to treatment. Genes \& Development. 2007;21(21):2683-710.

11. Binder DC, Davis AA, Wainwright DA. Immunotherapy for cancer in the central nervous system: Current and future directions. Oncoimmunology. 2016;5(2).

12. Walker C, Baborie A, Crooks D, Wilkins S, Jenkinson MD. Biology, genetics and imaging of glial cell tumours. British Journal of Radiology. 2011;84:S90-S106.

13. Ohgaki H, Kleihues P. Genetic alterations and signaling pathways in the evolution of gliomas. Cancer Science. 2009;100(12):2235-41.

14. Ceccarelli M, Barthel FP, Malta TM, Sabedot TS, Salama SR, Murray BA, et al. Molecular Profiling Reveals Biologically Discrete Subsets and Pathways of Progression in Diffuse Glioma. Cell. 2016;164(3):550-63.

15. Ostrom QT, Gittleman H, Liao P, Vecchione-Koval T, Wolinsky $Y$, Kruchko $C$, et al. CBTRUS Statistical Report: Primary brain and other central nervous system tumors diagnosed in the United States in 2010-2014. Neuro-Oncology. 2017;19:V1-V88.

16. Soomro SH, Ting LR, Qing YY, Ren M. Molecular biology of glioblastoma: Classification and mutational locations. Journal of the Pakistan Medical Association. 2017;67(9):1410-4.

17. Veliz I, Loo Y, Castillo O, Karachaliou N, Nigro O, Rosell R. Advances and challenges in the molecular biology and treatment of glioblastoma-is there any hope for the future? Annals of Translational Medicine. 2015;3(1).

18. Ohgaki $\mathrm{H}$, Kleihues P. The Definition of Primary and Secondary Glioblastoma. Clinical Cancer Research. 2013;19(4):764-72. 
19. Verhaak RG, Hoadley KA, Purdom E, Wang V, Qi Y, Wilkerson MD, et al. An integrated genomic analysis identifies clinically relevant subtypes of glioblastoma characterized by abnormalities in PDGFRA, IDH1, EGFR and NF1. Cancer Cell. 2010;17(1):98.

20. Weathers S-PS, Gilbert MR. Toward Personalized Targeted Therapeutics: An Overview. Neurotherapeutics. 2017;14(2):256-64.

21. Urias U, Marie SKN, Uno M, da Silva R, Evagelinellis MM, Caballero OL, et al. CD99 is upregulated in placenta and astrocytomas with a differential subcellular distribution according to the malignancy stage. Journal of Neuro-Oncology. 2014;119(1):59-70.

22. Wingett D, Forcier K, Nielson CP. A role for CD99 in T cell activation. Cellular Immunology. 1999;193(1):17-23.

23. Alberti I, Bernard G, Rouquette-Jadanian AK, Pelassy C, Pourtein M, Aussel C, et al. CD99 isoform expression dictates T-cell functional outcomes. Faseb Journal. 2002;16(12):1946-+.

24. Lee JH, Kim SH, Wang LH, Choi YL, Kim YC, Kim JH, et al. Clinical significance of CD99 downregulation in gastric adenocarcinoma. Clinical Cancer Research. 2007;13(9):2584-91.

25. Hahn JH, Kim MK, Choi EY, Kim SH, Sohn HW, Ham DI, et al. CD99 (MIC2) regulates the LFA1/ICAM-1-mediated adhesion of lymphocytes, and its gene encodes both positive and negative regulators of cellular adhesion. Journal of Immunology. 1997;159(5):2250-8.

26. Cerisano V, Aalto Y, Perdichizzi S, Bernard G, Manara MC, Benini S, et al. Molecular mechanisms of CD99-induced caspase-independent cell death and cell-cell adhesion in Ewing's sarcoma cells: actin and zyxin as key intracellular mediators. Oncogene. 2004;23(33):5664-74.

27. Rocchi A, Manara MC, Sciandra M, Zambelli D, Nardi F, Nicoletti G, et al. CD99 inhibits neural differentiation of human Ewing sarcoma cells and thereby contributes to oncogenesis. Journal of Clinical Investigation. 2010;120(3):668-80.

28. Manara MC, Pasello M, Scotlandi K. CD99: A Cell Surface Protein with an Oncojanus Role in Tumors. Genes (Basel). 2018;9(3).

29. Bernard G, Breittmayer JP, deMatteis M, Trampont P, Hofman P, Senik A, et al. Apoptosis of immature thymocytes mediated by E2/CD99. Journal of Immunology. 1997;158(6):2543-50.

30. Husak Z, Printz D, Schumich A, Potschger U, Dworzak MN. Death induction by CD99 ligation in TEL/AML1-positive acute lymphoblastic leukemia and normal B cell precursors. Journal of Leukocyte Biology. 2010;88(2):405-12.

31. Bernard G, Raimondi V, Alberti I, Pourtein M, Widjenes J, Ticchioni M, et al. CD99 (E2) upregulates alpha 4 beta 1-dependent $T$ cell adhesion to inflamed vascular endothelium under flow conditions. European Journal of Immunology. 2000;30(10):3061-5.

32. Byun HJ, Hong IK, Kim E, Jin YJ, Jeoung DI, Hahn JH, et al. A splice variant of CD99 increases motility and MMP-9 expression of human breast cancer cells through the AKT-, ERK-, and JNKdependent AP-1 activation signaling pathways. Journal of Biological Chemistry. 2006;281(46):3483347.

33. Scotlandi K, Zuntini M, Manara MC, Sciandra M, Rocchi A, Benini S, et al. CD99 isoforms dictate opposite functions in tumour malignancy and metastases by activating or repressing c-Src kinase activity. Oncogene. 2007;26(46):6604-18.

34. Kim HY, Kim YM, Shin YK, Park SH, Lee W. Solution structure of the cytoplasmic domain of human CD99 type I. Molecules and Cells. 2004;18(1):24-9.

35. Choi FY, Park WS, Jung KC, Kim SH, Kim YY, Lee WJ, et al. Engagement of CD99 induces upregulation of TCR and MHC class I and II molecules on the surface of human thymocytes. Journal of Immunology. 1998;161(2):749-54.

36. Pata S, Otáhal P, Brdička T, Laopajon W, Mahasongkram K, Kasinrerk W. Association of CD99 short and long forms with MHC class I, MHC class II and tetraspanin CD81 and recruitment into immunological synapses. BMC Res Notes. 42011. p. 293. 
37. Manara MC, Bernard G, Lollini PL, Nanni P, Zuntini M, Landuzzi L, et al. CD99 acts as an oncosuppressor in osteosarcoma. Molecular Biology of the Cell. 2006;17(4):1910-21.

38. Choi YL, Xuan YH, Shin YK, Chae SW, Kook MC, Sung RH, et al. An immunohistochemical study of the expression of adhesion molecules in gallbladder lesions. Journal of Histochemistry \& Cytochemistry. 2004;52(5):591-601.

39. Ramsay $A D$, Bates $A W$, Williams $S$, Sebire NJ. Variable antigen expression in hepatoblastomas. Applied Immunohistochemistry \& Molecular Morphology. 2008;16(2):140-7.

40. Edlund K, Lindskog C, Saito A, Berglund A, Ponten F, Goransson-Kultima H, et al. CD99 is a novel prognostic stromal marker in non-small cell lung cancer. International Journal of Cancer. 2012;131(10):2264-73.

41. Li L, Li JS, Hao CY, Zhang CJ, Mu K, Wang Y, et al. Immunohistochemical evaluation of solid pseudopapillary tumors of the pancreas: The expression pattern of CD99 is highly unique. Cancer Letters. 2011;310(1):9-14.

42. Guo Y, Yuan F, Deng H, Wang HF, Jin XL, Xiao JC. Paranuclear Dot-like Immunostaining for CD99: A Unique Staining Pattern for Diagnosing Solid-Pseudopapillary Neoplasm of the Pancreas. American Journal of Surgical Pathology. 2011;35(6):799-806.

43. Rajagopalan A, Browning D, Salama S. CD99 expression in Merkel cell carcinoma: a case series with an unusual paranuclear dot-like staining pattern. Journal of Cutaneous Pathology. 2013;40(1):19-24.

44. Kommoss F, Oliva E, Bittinger F, Kirkpatrick CJ, Amin MB, Bhan AK, et al. Inhibin-alpha, CD99, HEA125, PLAP and chromogranin immunoreactivity in testicular neoplasms and the androgen insensitivity syndrome. Human Pathology. 2000;31(9):1055-61.

45. Folpe AL, McKenney JK, Bridge JA, Weiss SW. Sclerosing rhabdomyosarcoma in adults Report of four cases of a hyalinizing, matrix-rich variant of rhabdomyosarcoma that may be confused with osteosarcoma, chondrosarcoma, or angiosarcoma. American Journal of Surgical Pathology. 2002;26(9):1175-83.

46. Persson O, Krogh M, Saal LH, Englund E, Liu J, Parsons R, et al. Microarray analysis of gliomas reveals chromosomal position-associated gene expression patterns and identifies potential immunotherapy targets. Journal of Neuro-Oncology. 2007;85(1):11-24.

47. Seol HJ, Chang JH, Yamamoto J, Romagnuolo R, Suh Y, Weeks A, et al. Overexpression of CD99 Increases the Migration and Invasiveness of Human Malignant Glioma Cells. Genes Cancer. 32012. p. 535-49.

48. Kunkle BW, Yoo C, Roy D. Reverse Engineering of Modified Genes by Bayesian Network Analysis Defines Molecular Determinants Critical to the Development of Glioblastoma. Plos One. 2013;8(5).

49. Milanezi F, Pereira EM, Ferreira FV, Leitao D, Schmitt FC. CD99/MIC-2 surface protein expression in breast carcinomas. Histopathology. 2001;39(6):578-83.

50. Dworzak MN, Fritsch G, Fleischer C, Printz D, Froschl G, Buchinger P, et al. CD99 (MIC2) expression in paediatric $B$-lineage leukaemia lymphoma reflects maturation-associated patterns of normal B-lymphopoiesis. British Journal of Haematology. 1999;105(3):690-5.

51. Buxton D, Bacchi CE, Gualco G, Weiss LM, Zuppan CW, Rowsell EH, et al. Frequent Expression of CD99 in Anaplastic Large Cell Lymphoma A Clinicopathologic and Immunohistochemical Study of 160 Cases. American Journal of Clinical Pathology. 2009;131(4):574-9.

52. Scotlandi K, Baldini N, Cerisano V, Manara MC, Benini S, Serra M, et al. CD99 engagement: An effective therapeutic strategy for Ewing tumors. Cancer Research. 2000;60(18):5134-42.

53. Guerzoni C, Fiori V, Terracciano M, Manara MC, Moricoli D, Pasello M, et al. CD99 Triggering in Ewing Sarcoma Delivers a Lethal Signal through p53 Pathway Reactivation and Cooperates with Doxorubicin. Clinical Cancer Research. 2015;21(1):146-56. 
54. Manara MC, Terracciano M, Mancarella C, Sciandra M, Guerzoni C, Pasello M, et al. CD99 triggering induces methuosis of Ewing sarcoma cells through IGF-1R/RAS/Rac1 signaling. Oncotarget. 2016;7(48):79925-42.

55. Overmeyer JH, Kaul A, Johnson EE, Maltese WA. Active Ras triggers death in glioblastoma cells through hyperstimulation of macropinocytosis. Molecular Cancer Research. 2008;6(6):965-77.

56. Toomey EC, Schiffman JD, Lessnick SL. Recent advances in the molecular pathogenesis of Ewing's sarcoma. Oncogene. 2010;29(32):4504-16.

57. Ventura S, Aryee DNT, Felicetti F, De Feo A, Mancarella C, Manara MC, et al. CD99 regulates neural differentiation of Ewing sarcoma cells through miR-34a-Notch-mediated control of NF-kappa B signaling. Oncogene. 2016;35(30):3944-54.

58. Lee HJ, Kim E, Jee B, Hahn JH, Han K, Jung KC, et al. Functional involvement of src and focal adhesion kinase in a CD99 splice variant-induced motility of human breast cancer cells. Experimental and Molecular Medicine. 2002;34(3):177-83.

59. Czapiewski P, Welnicka-Jaskiewicz M, Seroczynska B, Skokowski J, Sejda A, Szade J, et al. CD99 CORRELATES WITH LOW CYCLIN D1, HIGH TOPOISOMERASE 2 alpha STATUS AND TRIPLE NEGATIVE MOLECULAR PHENOTYPE BUT IS PROGNOSTICALLY IRRELEVANT IN BREAST CARCINOMA. Polish Journal of Pathology. 2015;66(3):269-75.

60. Zucchini C, Manara MC, Pinca RS, De Sanctis P, Guerzoni C, Sciandra M, et al. CD99 suppresses osteosarcoma cell migration through inhibition of ROCK2 activity. Oncogene. 2014;33(15):1912-21.

61. Sciandra M, Marino MT, Manara MC, Guerzoni C, Grano M, Oranger A, et al. CD99 Drives Terminal Differentiation of Osteosarcoma Cells by Acting as a Spatial Regulator of ERK 1/2. Journal of Bone and Mineral Research. 2014;29(5):1295-309.

62. Lee KJ, Yoo YH, Kim MS, Yadav BK, Kim Y, Lim D, et al. CD99 inhibits CD98-mediated beta 1 integrin signaling through SHP2-mediated FAK dephosphorylation. Experimental Cell Research. 2015;336(2):211-22.

63. Lee KJ, Kim Y, Yoo YH, Kim M-S, Lee S-H, Kim C-G, et al. CD99-Derived Agonist Ligands Inhibit Fibronectin-Induced Activation of beta 1 Integrin through the Protein Kinase A/SHP2/Extracellular Signal-Regulated Kinase/PTPN12/Focal Adhesion Kinase Signaling Pathway. Molecular and Cellular Biology. 2017;37(14).

64. Lee KJ, Kim Y, Yoo YH, Kim MS, Lee SH, Kim CG, et al. CD99-Derived Agonist Ligands Inhibit Fibronectin-Induced Activation of beta 1 Integrin through the Protein Kinase A/SHP2/Extracellular Signal-Regulated Kinase/PTPN12/Focal Adhesion Kinase Signaling Pathway. Molecular and Cellular Biology. 2017;37(14).

65. Jung TY, Choi YD, Kim YH, Lee JJ, Kim HS, Kim JS, et al. Immunological Characterization of Glioblastoma Cells for Immunotherapy. Anticancer Research. 2013;33(6):2525-33.

66. Gellini M, Ascione A, Flego M, Mallano A, Dupuis ML, Zamboni S, et al. Generation of Human Single-chain Antibody to the CD99 Cell Surface Determinant Specifically Recognizing Ewing's Sarcoma Tumor Cells. Current Pharmaceutical Biotechnology. 2013;14(4):449-63.

67. Moricoli D, Carbonella DC, Dominici S, Fiori V, Balducci MC, Guerzoni C, et al. Process development of a human recombinant diabody expressed in E-coli: engagement of CD99-induced apoptosis for target therapy in Ewing's sarcoma. Applied Microbiology and Biotechnology. 2016;100(9):3949-63.

68. Celik H, Sciandra M, Flashner B, Gelmez E, Kayrakilogiu N, Allegakoen DV, et al. Clofarabine inhibits Ewing sarcoma growth through a novel molecular mechanism involving direct binding to CD99. Oncogene. 2018;37(16):2181-96.

69. Livak KJ, Schmittgen TD. Analysis of relative gene expression data using real-time quantitative PCR and the 2(-Delta Delta C(T)) Method. Methods. 2001;25(4):402-8. 
70. Dobin A, Davis CA, Schlesinger F, Drenkow J, Zaleski C, Jha S, et al. STAR: ultrafast universal RNA-seq aligner. Bioinformatics. 2013;29(1):15-21.

71. Li B, Dewey CN. RSEM: accurate transcript quantification from RNA-Seq data with or without a reference genome. Bmc Bioinformatics. 2011;12.

72. Wagner GP, Kin, K., Lynch, V.J. Measurement of mRNA abundance using RNA-seq data: RPKM measure is inconsistent among samples | SpringerLink. Theory in Bioscience. 2012;131(4):5.

73. Ritchie ME, Phipson B, Wu D, Hu Y, Law CW, Shi $W$, et al. limma powers differential expression analyses for RNA-sequencing and microarray studies. Nucleic Acids Research. 2015;43(7).

74. DeLuca DS, Levin JZ, Sivachenko A, Fennell T, Nazaire MD, Williams C, et al. RNA-SeQC: RNAseq metrics for quality control and process optimization. Bioinformatics. 2012;28(11):1530-2.

75. Anders $\mathrm{S}$, Huber W. Differential expression analysis for sequence count data. Genome Biol. 2010;11(10):R106.

76. Abramoff MD. Image processing with ImageJ. Biophotonics international. 2004;11(7):36-42.

77. Galatro TF, Sola P, Moretti IF, Miura FK, Oba-Shinjo SM, Marie SK, et al. Correlation between molecular features and genetic subtypes of Glioblastoma: critical analysis in 109 cases. Medical Express. 2017;4(5):M170504.

78. Huang DW, Sherman BT, Tan Q, Collins JR, Alvord WG, Roayaei J, et al. The DAVID Gene Functional Classification Tool: a novel biological module-centric algorithm to functionally analyze large gene lists. Genome Biol. 2007;8(9):R183.

79. Bernard G, Zoccola D, Deckert M, Breittmayer JP, Aussel C, Bernard A. The E2 molecule (CD99) specifically triggers homotypic aggregation of $\mathrm{CD} 4(+) \mathrm{CD} 8(+)$ thymocytes. Journal of Immunology. 1995;154(1):26-32.

80. Lou O, Alcaide P, Luscinskas FW, Muller WA. CD99 is a key mediator of the transendothelial migration of neutrophils. Journal of Immunology. 2007;178(2):1136-43.

81. Dworzak MN, Froschl G, Printz D, De Zen L, Gaipa G, Ratei R, et al. CD99 expression in Tlineage ALL: implications for flow cytometric detection of minimal residual disease. Leukemia. 2004;18(4):703-8.

82. Sciandra M, Marino MT, Manara MC, Guerzoni C, Grano M, Oranger A, et al. CD99 Drives Terminal Differentiation of Osteosarcoma Cells by Acting as a Spatial Regulator of ERK $1 / 2$. Journal of Bone and Mineral Research. 2014;29(5):1295-309.

83. Kim SH, Shin YK, Lee IS, Bae YM, Sohn HW, Suh YH, et al. Viral latent membrane protein 1 (LMP-1)-induced CD99 down-regulation in B cells leads to the generation of cells with Hodgkin's and Reed-Sternberg phenotype. Blood. 2000;95(1):294-300.

84. Calderwood DA. Integrin activation. Journal of Cell Science. 2004;117(5):657-66.

85. Higgs HN, Pollard TD. Regulation of actin polymerization by Arp2/3 complex and WASp/Scar proteins. Journal of Biological Chemistry. 1999;274(46):32531-4.

86. Dayel MJ, Mullins RD. Activation of Arp2/3 complex: Addition of the first subunit of the new filament by a WASP protein triggers rapid ATP hydrolysis on Arp2. Plos Biology. 2004;2(4):476-85.

87. Clucas J, Valderrama F. ERM proteins in cancer progression. Journal of Cell Science. 2014;127(2):267-75.

88. Meng J. Distinct functions of dynamin isoforms in tumorigenesis and their potential as therapeutic targets in cancer. Oncotarget. 2017;8(25):41701-16.

89. Pankova K, Rosel D, Novotny M, Brabek J. The molecular mechanisms of transition between mesenchymal and amoeboid invasiveness in tumor cells. Cellular and Molecular Life Sciences. 2010;67(1):63-71.

90. Krakhmal NV, Zavyalova MV, Denisov EV, Vtorushin SV, Perelmuter VM. Cancer Invasion: Patterns and Mechanisms. Acta Naturae. 2015;7(2):17-28.

91. Zhong J, Paul A, Kellie SJ, O'Neill GM. Mesenchymal migration as a therapeutic target in glioblastoma. J Oncol. 2010;2010:430142. 
92. Cha J, Kang S-G, Kim P. Strategies of Mesenchymal Invasion of Patient-derived Brain Tumors: Microenvironmental Adaptation. Scientific Reports. 2016;6.

93. Humphries MJ. Cell adhesion assays. Molecular Biotechnology. 2001;18(1):57-61.

94. Humphries MJ, Reynolds A. Cell-to-cell contact and extracellular matrix. Current Opinion in Cell Biology. 2009;21(5):613-5.

95. Schwartz MA, Horwitz AR. Integrating adhesion, protrusion, and contraction during cell migration. Cell. 2006;125(7):1223-5.

96. Chaturvedi A, Hoffman LM, Jensen CC, Lin Y-C, Grossmann AH, Randall RL, et al. Molecular dissection of the mechanism by which EWS/FLI expression compromises actin cytoskeletal integrity and cell adhesion in Ewing sarcoma. Molecular Biology of the Cell. 2014;25(18):2695-709.

97. Gupton SL, Waterman-Storer CM. Spatiotemporal feedback between actomyosin and focaladhesion systems optimizes rapid cell migration. Cell. 2006;125(7):1361-74.

98. Palecek SP, Loftus JC, Ginsberg MH, Lauffenburger DA, Horwitz AF. Integrin-ligand binding properties govern cell migration speed through cell-substratum adhesiveness. Nature. 1997;385(6616):537-40.

99. Dimilla PA, Barbee K, Lauffenburger DA. Mathematical-model for the effects of adhesion and mechanics on cell-migration speed Biophysical Journal. 1991;60(1):15-37. 


\section{ANEXO 1}

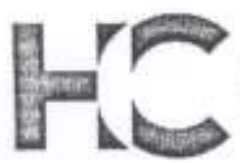

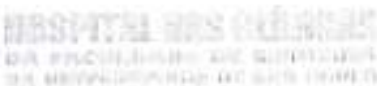

\section{APROVAÇÃO}

A Comissão de Ética para Análise de Projetos de Pesquisa - CAPPesq da Diretoria Clinica do Hospital das Clínicas e da Faculdade de Medicina da Universidade de São Paulo, em sessão de 26.10.06. APROVOU o Protocolo de Pesquisa $n^{\circ} 995 / 06$, intifulado: "Estudo da expressāo aberrante em tumores do sistema nervoso central de genes envolvidos em placenta", apresentado pelo Departamento de Neurologia.

Cabe ao pesquisador elaborar e apresentar à CAPPesq, os relatórios parciais e final sobre a pesquisa (Resoluçẩo do Conselho Nacional de Saúde $n^{\circ} 196$, de 10.10.1996, inciso IX. 2. letra "c")

Pesquisador(a) Responsável: Suely Kazue Nagahashi Marie

CAPPesq, 26 de Outubro de 2006.

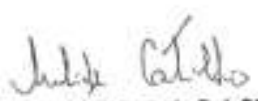

PROF. DR. EUCLIDES AYRES DE CASTILHO Presidente da Comissāo de Ética para Análise de Projetos de Pesquisa

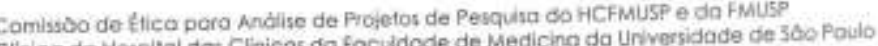

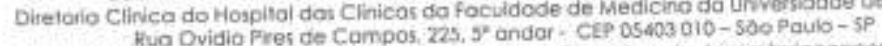

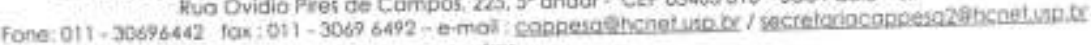




\section{ANEXO 2}

\section{BMC Cancer}

CD99 expression in glioblastoma molecular subtypes and functional analysis in a human glioblastoma cell line -Manuscript Draft-

\begin{tabular}{|c|c|c|}
\hline \multicolumn{3}{|l|}{ Manuscript Number: } \\
\hline Full TiEe: & \multicolumn{2}{|c|}{$\begin{array}{l}\text { CD99 expression in globiastoma molecular subtypes and functional analysis in a } \\
\text { human glioblastoma cell line }\end{array}$} \\
\hline Article Type: & \multicolumn{2}{|l|}{ Research article } \\
\hline Section/Category: & \multicolumn{2}{|l|}{ Cell and molecular biology } \\
\hline \multirow[t]{2}{*}{ Funding Information: } & $\begin{array}{l}\text { Fundaçâo de Amparo à Pesquisa do } \\
\text { Estado de Sâo Paulo } \\
(2015 / 036145-5)\end{array}$ & Dr Sueli Mieko Shinjo \\
\hline & $\begin{array}{l}\text { Fundaçâo de Amparo a Pesquisa do } \\
\text { Estado de Sso Paulo } \\
\text { (2015/03995-9) }\end{array}$ & Mrs Lais Cavalca Cardoso \\
\hline Abstract: & \multicolumn{2}{|c|}{ 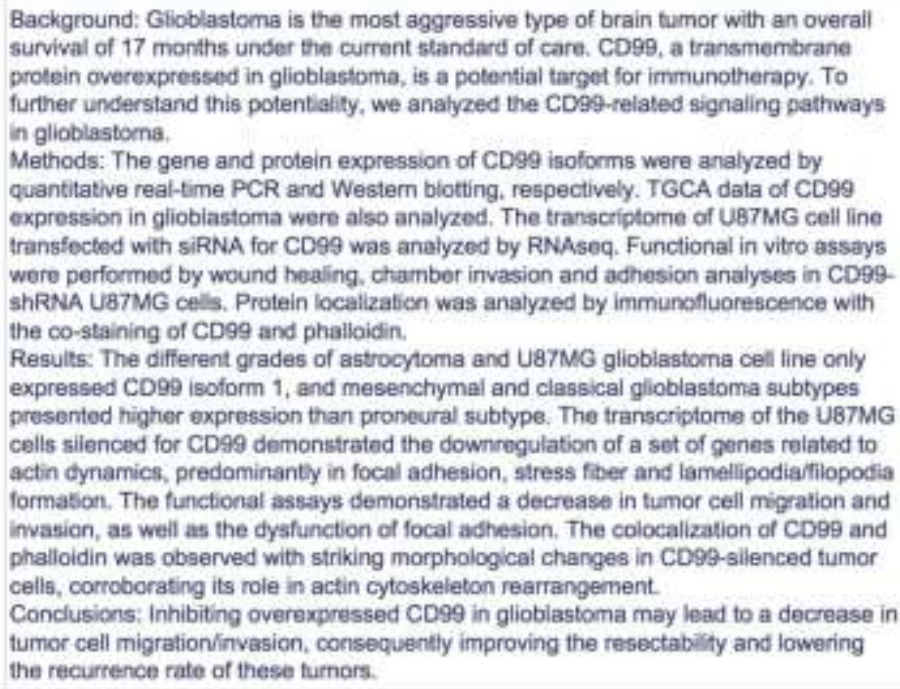 } \\
\hline Corresponding Author: & \multicolumn{2}{|c|}{$\begin{array}{l}\text { Suell Mieko Shinjo, Ph. D. } \\
\text { School of Medicine of University of Sao Paulo } \\
\text { Sao Paulo, SP BRAZIL }\end{array}$} \\
\hline \multicolumn{3}{|l|}{$\begin{array}{l}\text { Corresponding Author Secondary } \\
\text { Information: }\end{array}$} \\
\hline Corresponding Author's institution: & \multicolumn{2}{|c|}{ School of Medicine of University of Sao Paula } \\
\hline \multicolumn{3}{|l|}{$\begin{array}{l}\text { Corresponding Author's Secondary } \\
\text { Institution: }\end{array}$} \\
\hline First Author: & \multicolumn{2}{|l|}{ Lais Cavaica Cardoso, Msc. } \\
\hline \multicolumn{3}{|l|}{ First Author Secondary Information: } \\
\hline \multirow[t]{4}{*}{ Order of Authors: } & \multicolumn{2}{|l|}{ Lais Cavalca Cardoso, Msc } \\
\hline & \multicolumn{2}{|l|}{ Antonio Marcondes Lerario, Ph.D. } \\
\hline & \multicolumn{2}{|l|}{ Roseli da Silva Soares, Ph.D. } \\
\hline & \multicolumn{2}{|l|}{ Talita de Sousa Laurentino } \\
\hline Powered by $E$ & Sygly Kayng Nagahashi, Marig Ph Ph & is Systerns Corporation \\
\hline
\end{tabular}


Suell Mieko Shinjo, Ph.D

Order of Authors Secondary Information:

Opposed Reviewers:

Powered by Editorial Managens and ProduXXion Manggeno from Aries Systerns Corporation 
1 CD99 expression in glioblastoma molecular subtypes and functional analysis in

2 a human glioblastoma cell line

3 Lais Cavalca Cardoso', Antonio Marcondes Lerario², Roseli da Silva Soares ${ }^{1}$, Talita de

4 Sousa Laurentino ${ }^{1}$, Suely Kazue Nagahashi Marie ${ }^{13}$, Sueli Mieko Oba-Shinjo ${ }^{1 *}$

5

6 'Correspondence: suelimoba@usp.br

7 Universidade de Sao Paulo, Faculdade de Medicina (FMUSP), Department of

8 Neurology, Laboratory of Molecular and Cellular Biology (LIM 15), Sao Paulo, SP,

9 Brazil

10 2Department of Internal Medicine, Division of Metabolism, Endocrinology, and

11 Diabetes, University of Michigan, Ann Arbor, Michigan, USA

12 Universidade de Sao Paulo, Center for Studies of Cellular and Molecular Therapy

13 (NAP-NETCEM-NUCEL), Sao Paulo, Brazil

15 E-mail addresses:

16 Lais Cavalca Cardoso: lais.cavalca@yahoo.com.br

17 Antonio Marcondes Lerario: amlerario@gmail.com

18 Roseli da Silva Soares: roselicem@yahoo.com.br

19 Talita de Sousa Laurentino: talitinha-sous@hotmail.com

20 Suely Kazue Nagahashi Marie: sknmarie@usp.br

21 Sueli Mieko Oba-Shinjo: suelimoba@usp.br 


\begin{abstract}
28 Abstract
29 Background: Glioblastoma is the most aggressive type of brain tumor with an overall 30 survival of 17 months under the current standard of care. CD99, a transmembrane 31 protein overexpressed in glioblastoma, is a potential target for immunotherapy. To

32 further understand this potentiality, we analyzed the CD99-related signaling pathways

33 in glioblastoma.
\end{abstract}

34 Methods: The gene and protein expression of CD99 isoforms were analyzed by quantitative real-time PCR and Western blotting, respectively. TGCA data of CD99 expression in glioblastoma were also analyzed. The transcriptome of U87MG cell line transfected with siRNA for CD99 was analyzed by RNAseq. Functional in vitro assays were performed by wound healing, chamber invasion and adhesion analyses in CD99. shRNA U87MG cells. Protein localization was analyzed by immunofluorescence with the co-staining of CD99 and phalloidin.

41 Results: The different grades of astrocytoma and U87MG glioblastoma cell line only 42 expressed CD99 isoform 1, and mesenchymal and classical glioblastoma subtypes 43 presented higher expression than proneural subtype. The transcriptome of the U87MG 44 cells silenced for CD99 demonstrated the downregulation of a set of genes related to 45 actin dynamics, predominantly in focal adhesion, stress fiber and lamellipodia/filopodia 46 formation. The functional assays demonstrated a decrease in tumor cell migration and 47 invasion, as well as the dysfunction of focal adhesion. The colocalization of CD99 and 48 phalloidin was observed with striking morphological changes in CD99-silenced tumor 49 cells, corroborating its role in actin cytoskeleton rearrangement. Conclusions: Inhibiting overexpressed CD99 in glioblastoma may lead to a decrease in tumor cell migration/invasion, consequently improving the resectability and lowering the recurrence rate of these tumors. 


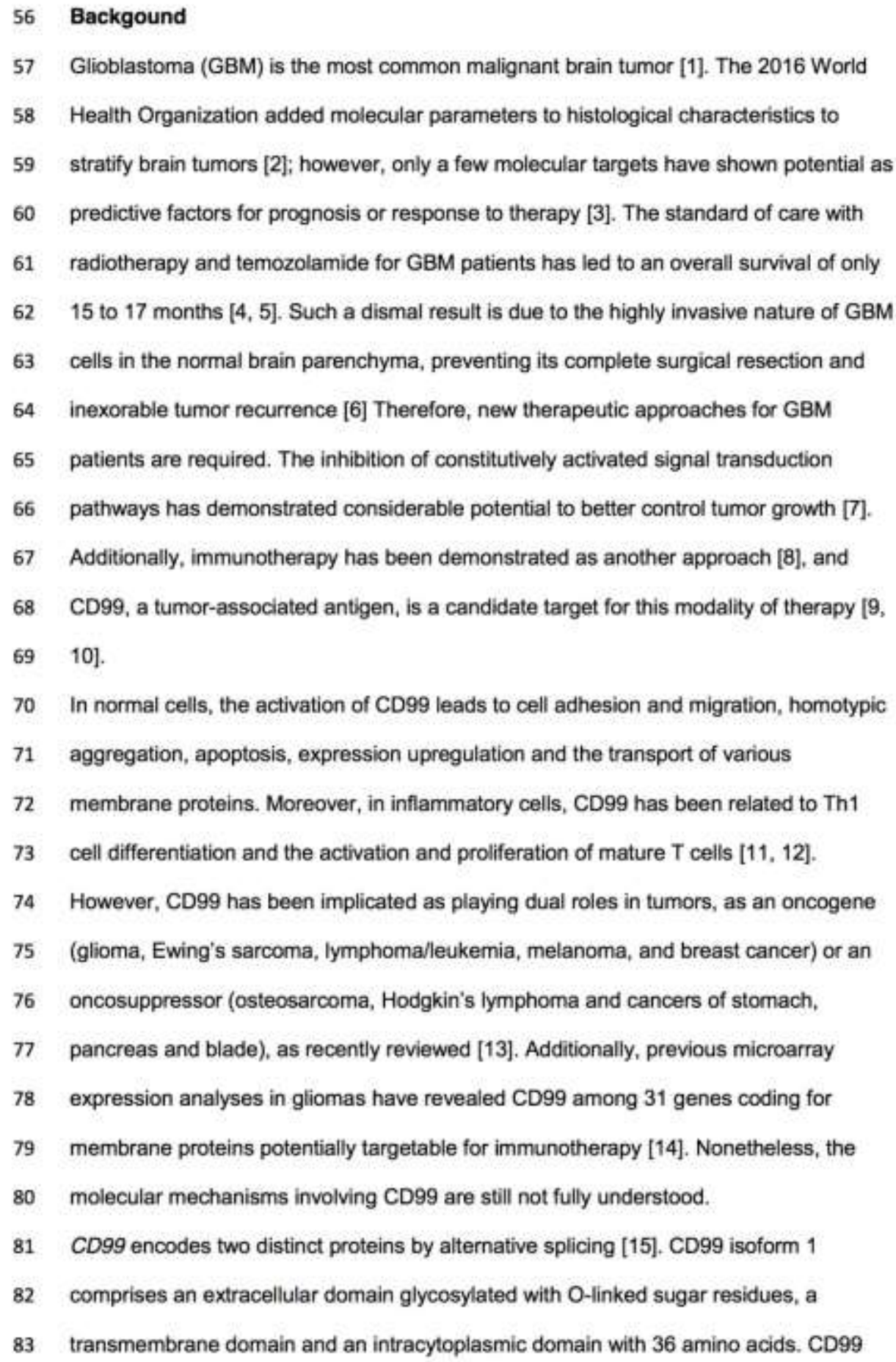
predictive factors for prognosis or response to therapy [3]. The standard of care with inexorable tumor recurrence [6] Therefore, new therapeutic approaches for GBM patients are required. The inhibition of constitutively activated signal transduction pathways has demonstrated considerable potential to better control tumor growth [7].

67 Additionally, immunotherapy has been demonstrated as another approach [8], and CD99, a tumor-associated antigen, is a candidate target for this modality of therapy $[9$, 10].

70 In normal cells, the activation of CD99 leads to cell adhesion and migration, homotypic

71 aggregation, apoptosis, expression upregulation and the transport of various

72 membrane proteins. Moreover, in inflammatory cells, CD99 has been related to Th1

73 cell differentiation and the activation and proliferation of mature T cells [11, 12]. However, CD99 has been implicated as playing dual roles in tumors, as an oncogene (glioma, Ewing's sarcoma, lymphoma/leukemia, melanoma, and breast cancer) or an oncosuppressor (osteosarcoma, Hodgkin's lymphoma and cancers of stomach, pancreas and blade), as recently reviewed [13]. Additionally, previous microarray expression analyses in gliomas have revealed CD99 among 31 genes coding for membrane proteins potentially targetable for immunotherapy [14]. Nonetheless, the molecular mechanisms involving CD99 are still not fully understood.

CD99 encodes two distinct proteins by alternative splicing [15]. CD99 isoform 1

comprises an extracellular domain glycosylated with $\mathrm{O}$-linked sugar residues, a 3. transmembrane domain and an intracytoplasmic domain with 36 amino acids. CD99 
84 isoform 2 is truncated at the intracytoplasmic domain, presenting only 28 amino acids

85 [12]. CD99 isoforms play distinct functional roles. On B lymphocytes, isoform 1

86 promotes cell-cell adhesion, while isoform 2 inhibits homotypic adhesion. Both

87 isoforms are required to induce apoptosis in thymocytes and immature T cells [15]. In

88 tumors, such as osteosarcoma, isoform 1 has been described as a potent suppressor

89 of cell migration and invasion, in contrast to isoform 2, which plays important role in

90 tumor cell migration and metastatic capacity [16]. Similarly, the CD99 isoform 2 shows

91 the enhanced invasive ability of human breast cancer cells [17].

92 In the present study, we examined the molecular mechanisms related to CD99 in

93 astrocytomas, especially in GBM, based on human tumor samples and an in vitro

94 cellular model.

95

96

97

98

99

100

101

102

103

104

105

106

107

108

109

110

111

\section{Methods}

\section{Cell cultures}

The human mesenchymal GBM cell line, U87MG, and the human embryonic kidney

cell line, HEK373T, from the American Type Culture Collection (ATCC) were

maintained in Dulbecco's Modified Eagle's medium (DMEM) (Thermo Fisher Scientific)

supplemented with $10 \%$ heat-inactivated fetal bovine serum (FBS) (Thermo Fisher

Scientific), antibiotics (100 IU/ml penicillin, $100 \mu \mathrm{g} / \mathrm{ml}$ streptomycin) in a humidified

atmosphere of $5 \% \mathrm{CO}_{2}$ in air at $37^{\circ} \mathrm{C}$. The cell lines were authenticated by short

tandem repeat DNA analysis with the commercial GenePrint 10 System (Promega).

\section{Casuistry}

Astrocytoma samples of different grades and non-tumoral brain tissues from epilepsy surgeries were collected during the surgical procedure and immediately frozen in liquid nitrogen after resection by a group at the Division of Neurosurgical of the Department of Neurology, School of Medicine, University of Sao Paulo. A total of 35 non-neoplastic (NN) samples and 145 tumor samples, comprised of 23 pilocytic astrocytomas (AGI), 
11226 low grade astrocytomas (AGII), 17 anaplastic astrocytomas (AGIII) and 79 GBMs,

113 were analyzed. The project was approved by the National Ethics Commission

114 (CONEP) and the local institutional Ethics Committee, under protocol number 830/01.

115 Post-informed consents were obtained from all patients included in the present study.

\section{Total RNA extraction and cDNA synthesis}

More than $80 \%$ of tumor tissue was ensured in all tumor samples. The RNeasy Mini Kit (Qiagen) was used for total RNA extractions. RNase-free DNase (Qiagen) treatment and quality and concentration assessments were performed. cDNA was obtained by reverse transcription, using SuperScript III reverse transcriptase, RNase inhibitor (RNaseOUT), random oligonucleotides and oligo dT, according to the manufacturer's recommendations (Thermo Fisher Scientific).After treatment with 1 U RNase H (Thermo Fisher Scientific) at $37^{\circ} \mathrm{C}$ for $30 \mathrm{~min}$ and at $72^{\circ} \mathrm{C}$ for $10 \mathrm{~min}$, cDNA was diluted in TrisEDTA buffer and stored at $-20^{\circ} \mathrm{C}$ for subsequent analysis.

\section{Quantitative real time PCR}

CD99 expression levels in tissue samples and cell lines were analyzed by quantitative real time PCR (qRT-PCR) by the SYBR Green method, on ABI 7500 apparatus (Thermo Fisher Scientific). Supporting Information Table 1 shows the sequences of primers for CD99 isoforms 1 and 2 and reference genes synthesized by MWG Biotech. All the reactions were performed in triplicate. The final reaction volume of each reaction was $10 \mu \mathrm{l}$, and contained $2.5 \mu \mathrm{l}$ of cDNA, $5 \mu \mathrm{l}$ of Power SYBR Green PCR Master Mix (Thermo Fisher Scientific) and $2.5 \mu l$ of primers in a pre-standardized concentration. The amplification conditions included an initial incubation at $50^{\circ} \mathrm{C}$ for $5 \mathrm{~min}$ and $95^{\circ} \mathrm{C}$ for $10 \mathrm{~min}$, followed by 40 cycles at $95^{\circ} \mathrm{C}$ for $15 \mathrm{~s}$ and $60^{\circ} \mathrm{C}$ for $60 \mathrm{~s}$. The expression value of CD99 was normalized with reference genes as the internal controls: HPRT, for cell experiments, and HPRT, GUSB and BCRP, for tissue analyses. For cell analysis, HPRT was used as the reference gene. Single product amplification was confirmed by 
140 analyzing its dissociation curve. The amplification efficiencies $\left.\left[E=10^{-(-19 b p e)}-1\right)\right]$ were

141 calculated using serial cDNA dilutions. Equation $2^{-4 c t}$ was applied in the calculation of

142 the relative gene expression for efficiency $(E)=100 \pm 10 \%$, where $\Delta \mathrm{Ct}=[$ mean $\mathrm{Ct}$ of

143

CD99)] - [mean Ct of HPRT or geometric mean of mean Ct of housekeeping

144

genes].[18]

145

Supplementary Tabela 1. PCR product size and sequence of primers for real time PCR

\begin{tabular}{|c|c|c|c|}
\hline Gene & $\begin{array}{l}\text { PCR product } \\
\text { (bp) }\end{array}$ & Orientation & Primer $\left(5^{\prime}-3^{\prime}\right)$ \\
\hline \multirow{2}{*}{$\begin{array}{c}\text { CD99 } \\
\text { isoform } 1\end{array}$} & \multirow{2}{*}{106} & Forward & GATTGTGGGGGCTGTCGT \\
\hline & & Reverse & САССТССССТTGTTСТGСАTT \\
\hline \multirow{2}{*}{$\begin{array}{c}\text { CD99 } \\
\text { isoform } 2\end{array}$} & \multirow{2}{*}{108} & Forward & GATTGTGGGGGCTGTCGT \\
\hline & & Reverse & TCCCTAGGTCTTCAGCCATCATT \\
\hline \multirow{2}{*}{ GUSB } & \multirow{2}{*}{101} & Forward & GAAAATACGTGGTTGGAGAGCTCATT \\
\hline & & Reverse & CCGAGTGAAGATCCCCTIITA \\
\hline \multirow{2}{*}{ HPAT } & \multirow{2}{*}{118} & Forward & TGAGGATITGGAAAGGGTGT \\
\hline & & Reverse & GAGCACACAGAGGGCTACAA \\
\hline \multirow{2}{*}{ BCRP } & \multirow{2}{*}{67} & Forward & CCTTCGACGTCAATAACAAGGAT \\
\hline & & Reverse & CCTGCGATGGCGTTCAC \\
\hline
\end{tabular}

\section{CD99-siRNA and Library preparations for NGS sequencing (RNAseq)}

CD99 siRNA was performed as previously described in experimental duplicates [9].

The libraries were constructed with the TruSeq Stranded Total RNA kit (lllumina) and

quantified by qRT-PCR using Kapa Library Quantification Kit (Kapa Biosystems). The

mean size of each library was determined on the Tapestation 2200 (Agilent

\section{Transcriptome analysis}


through STAR software [19]. Quantification of the gene expression data was performed through Feature Counts software $[20,21]$, and the data were normalized according to two different methods: RPKM and CPM [22]. Differential expression analysis (Bioconductor portal) was analyzed by the Limma-voom framework.[23] The raw data were initially log-transformed and normalized. Subsequently, differential expression between groups was analyzed by linear models and the application of moderate $t$ statistics. This analysis was performed with the RNAseq tool [24]. Finally, the analysis of RNAseq data (genes differentially expressed in cells silenced by siRNA compared the non-target control, NTC) was performed through the DAVID database (https//david.ncifcrf.gov/) for functional and pathway enrichment. RPKM values were transformed to z-scores for heat map visualization [25].

\section{TCGA data analysis}

The Cancer Genome Atlas (TCGA) GBM gene expression from RNAseq dataset were downioaded (Genomics Data Commons Data Portal - https://portal.gdc.cancer.gov/) and normalized by DEseq R software.

\section{Construction of recombinant lentivirus}

Two CD99 shRNA molecules were constructed in U87MG cells (MISSION shRNA Library, Sigma-Aldrich 5:-

CCGGGCGCGATAGCGCTAATAATTTCTCGAGAAATTATTAGCGCTATCGCGCTIIT

T-3', for control (scrambled), and 5'-

\section{CCGGGCGTITCAGGTGGAGAAGGAACTCGAGTTCCTTCTCCACCTGAAACGCTIT}

TTG-3' (clone 1) and 5:-

CCGGCGGATGGTGGTTTCGATTTATCTCGAGATAAATCGAAACCACCATCCGTIT

TG-3' (clone 2). The lentivirus transduction particles were prepared by co-transfection of $2 \times 10^{6}$ HEK293T cells with $9 \mu \mathrm{g}$ of pCMV-deltaR8.2 containing Gag and Pol genes, $0.9 \mu \mathrm{g}$ of pCMV-VSG-G expressing the G-protein of the vesicular stomatitis, and $9 \mu \mathrm{g}$ 
of pLKO.1 bearing the shRNAs. For transfection, the reagent FuGENE HD (Promega)

was added in antibiotic-free DMEM with $10 \%$ FBS. Lentiviral particles in the culture medium were collected at 48 and $72 \mathrm{~h}$, centrifuged, filtered $(0.4 \mu \mathrm{m})$, aliquoted and stored at $-80^{\circ} \mathrm{C}$ until further use.

\section{Generation of knockdown cell lines}

A total of $1 \times 10^{5}$ U87MG cells were infected with scrambled 1, scramble 2, shCD99-1 and shCD99-2 with DMEM containing $8 \mu \mathrm{g} / \mathrm{ml}$ of polybrene. At $24 \mathrm{~h}$ after transduction, the supernatant was removed and replaced with culture medium containing puromycin. The CD99 knockdown efficacy was assessed by qRT-PCR and Western blot analyses.

\section{Western blotting}

Cell protein extracts were obtained with urea/Chaps lysis buffer and protease inhibitor cocktail (Sigma-Aldrich). Total protein concentrations were determined by the Pierce BCA Protein Assay Kit (Thermo Fisher Scientific), Cell lysates ( $30 \mu \mathrm{g}$ of proteins) were separated by $4-12 \%$ gradient polyacrylamide gel electrophoresis (Thermo Fisher Scientific) in NuPAGE MOPS SDS electrophoresis buffer (Thermo Fisher Scientific) and transferred to a nitrocellulose membrane through the iBLOT system (Thermo Fisher Scientific). The membrane was incubated with mouse monoclonal anti-CD99 (1:1000, DN16, Abcam that recognized both isoforms) and mouse monocional anti- $\beta$ actin (1:20,000, clone AC-74, Sigma-Aldrich) as control for protein loading. A secondary antibody anti-mouse IgG $(1: 1,000$, Sigma-Aldrich) conjugated to peroxidase and the chemiluminescence detection system (Western Lightning Plus-ECL, Enhanced Chemiluminescence Substrate, Perkin Elmer) were used to visualize proteins in the membrane on the ImageQuant LAS4000 (GE Healthcare) apparatus.

\section{Wound healing migration assay}


213 A total of $2 \times 10^{5}$ cells/well of silenced cells and their respective controls (scrambled)

214 were grown on 24-well plates previously coated with poly-L-Lysine (Sigma-Aldrich),

215 until the cells reached confluence. The culture medium was removed, and a

216 discontinuity cell-free area was formed by scrapping monolayer with a micropipette tip.

217 Debris were removed by washing with PBS and then replaced with $2 \mathrm{~mL}$ of fresh

218 medium supplemented with $1 \%$ FBS. Images from three points along each wound were selected and acquired at different time intervals (zero, 6, 12 and $24 \mathrm{~h}$ ). The assays were performed in quadruplicates and in two independent assays. In parallel, a realtime assay was performed on Axiovert 200M Inverted Motorized Microscope (Carl Zeiss) and wound closure was recorded every $3 \mathrm{~h}$ for $24 \mathrm{~h}$. The assay was performed in duplicate and 3 different fields of each well were photographed. For both experiments, the cell-free areas were initially calculated as a percentage of the initial cell free area (time zero) and arbitrarily labeled $100 \%$. The percentage of the cell free area was calculated by ImageJ [26]. The percentage of invaded area at different times was determined by the difference of the area at time zero (100\%) minus the area free of cells [26].

\section{Invasion assay}

Invasion chambers were used according to the manufacturer's instructions (BD BioCoat Matrigel invasion assay; BD Biosciences). U87MG cells (shCD99-1 and 2 and controls) were maintained for $2 \mathrm{~h}$ in DMEM supplemented with $1 \%$ FBS. A total of $2.5 \mathrm{x}$ $10^{4}$ cells was suspended in $0.5 \mathrm{mI}$ DMEM supplemented with $1 \%$ FBS and seeded onto the upper compartment of the Matrigel-coated transwell inserts fitting 24-well plates. The bottom chamber was filled with $10 \%$ FBS as chemoattractant. Cells were incubated at $37^{\circ} \mathrm{C}$ for $18 \mathrm{~h}$. Non-invading cells were wiped away from the upper surface of the chamber. Invading cells were fixed with $4 \%$ paraformaldehyde, stained with $0.2 \%$ crystal violet $(0.2 \%$ in methanol $20 \%)$ and analyzed by inverted microscopy wit $10 \mathrm{x}$ magnification. The results were quantified by counting all the cells of the inserts in 
241 duplicate from two independent experiments. The invasion values were expressed as

242 the percentage of invaded cells in relation to the control.

243

244

245

246

247

248

\section{Adhesion assay}

U87MG shCD99-1 and shCD99-2 and controls were incubated for $2 \mathrm{~h}$ in DMEM supplemented with $1 \%$ FBS. A total of $5 \times 10^{4}$ cells were allowed to adhere to 96 -well plates for $3 \mathrm{~h}$ at $37^{\circ} \mathrm{C}$ in $5 \% \mathrm{CO}_{2}$. The cells were gently washed three times with PBS, and attached cells were quantified after incubation with PrestoBlue Cell Viability Reagent (Thermo Fisher Scientific) for $2 \mathrm{~h}$ at $37^{\circ} \mathrm{C}$ in $5 \% \mathrm{CO}_{2}$ in a humidified atmosphere by measuring the resulting fluorescent signal at $525 \mathrm{~nm}$ by using the GloMax - Multi Microplate Multimode Reader (Promega).

\section{Immunofluorescence}

For this analysis, $2 \times 10^{4}$ U87MG cells were plated onto coverslips previously coated with poly-L-Lysine (Sigma-Aldrich) and allowed to attach. After $24 \mathrm{~h}$, the cells were fixed in $4 \%$ paraformaldehyde in PBS for $90 \mathrm{~min}$ at $4^{\circ} \mathrm{C}$. Subsequently, the cells were washed 3 times with PBS for 5 min and permeabilized with $0.1 \%$ NP-40 (Abcam) in PBS for 30 min at $37^{\circ} \mathrm{C}$, followed by two washes with PBS for 5 min. Non-specific sites were blocked by incubating cells with $4 \%$ goat serum (Sigma-Aldrich) in PBS (block solution) for $30 \mathrm{~min}$ at $37^{\circ} \mathrm{C}$. The cells were incubated with the primary antibody antiCD99 conjugated with FITC (1:50, Thermo Fisher Scientific) and phalloidin labeled with Alexa Fluor 488 (1:50, Thermo Fisher Scientific) diluted in block solution. After incubation for $48 \mathrm{~h}$ at $4^{\circ} \mathrm{C}$, and three washes with PBS for $5 \mathrm{~min}$, the nuclei were counterstained with DAPI (1:1,000, Thermo Fisher Scientific) by incubating for $3 \mathrm{~min}$. Finally, the samples were washed 3 times with PBS for 5 min and embedded with mounting medium ProLong Gold Antifade Mountant (Thermo Fisher Scientific). Negative controls include complete reaction and absence of primary antibody. The 


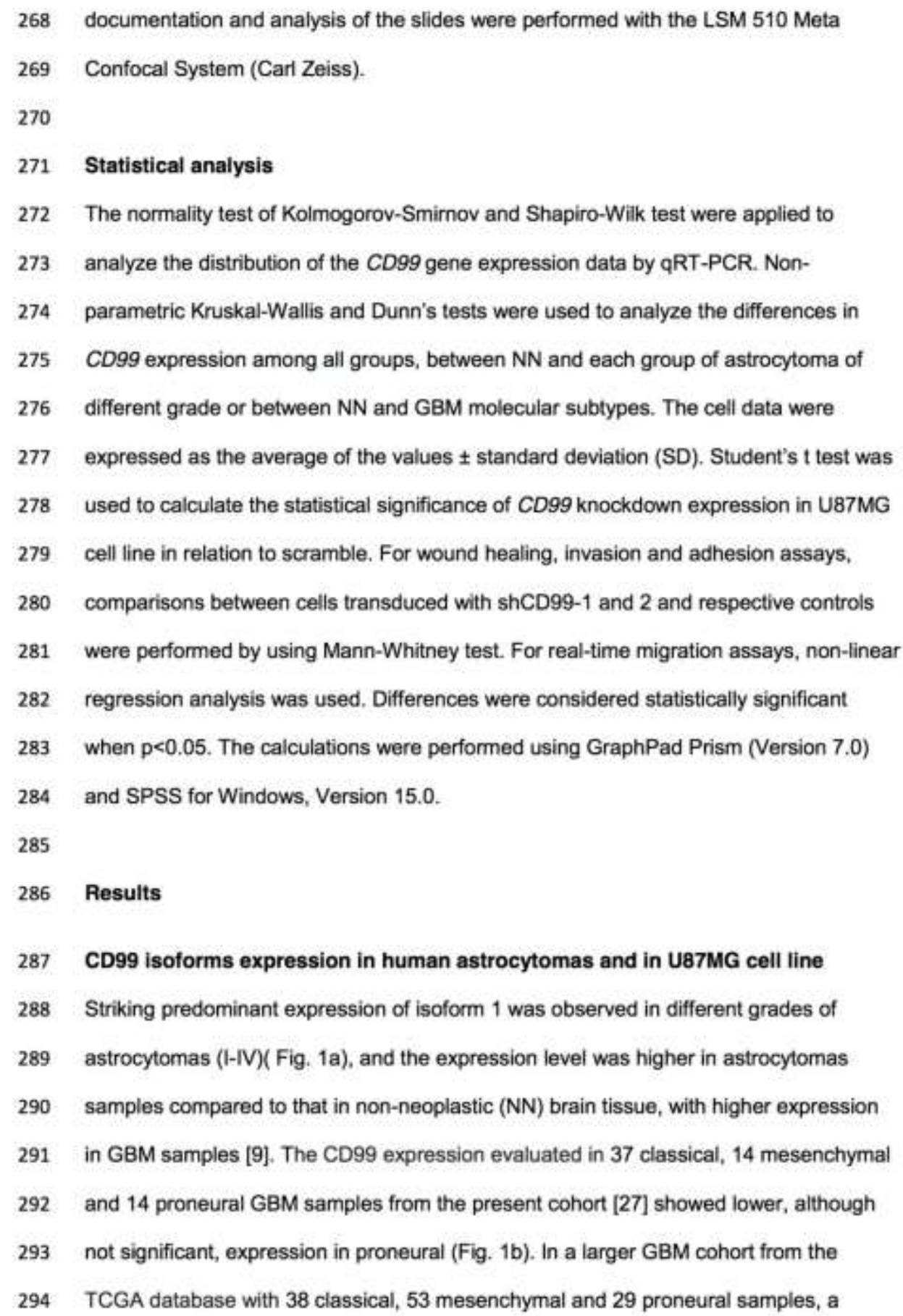
analyze the distribution of the CD99 gene expression data by qRT-PCR. Nonparametric Kruskal-Wallis and Dunn's tests were used to analyze the differences in CD99 expression among all groups, between $\mathrm{NN}$ and each group of astrocytoma of different grade or between NN and GBM molecular subtypes. The cell data were expressed as the average of the values \pm standard deviation (SD). Student's $t$ test was used to calculate the statistical significance of CD99 knockdown expression in U87MG cell line in relation to scramble. For wound healing, invasion and adhesion assays, comparisons between cells transduced with shCD99-1 and 2 and respective controls were performed by using Mann-Whitney test. For real-time migration assays, non-linear regression analysis was used. Differences were considered statistically significant when $p<0.05$. The calculations were performed using GraphPad Prism (Version 7.0) and SPSS for Windows, Version 15.0.

\section{Results}

\section{CD99 isoforms expression in human astrocytomas and in U87MG cell line} Striking predominant expression of isoform 1 was observed in different grades of astrocytomas (I-IV)( Fig. 1a), and the expression level was higher in astrocytomas samples compared to that in non-neoplastic (NN) brain tissue, with higher expression in GBM samples [9]. The CD99 expression evaluated in 37 classical, 14 mesenchymal and 14 proneural GBM samples from the present cohort [27] showed lower, although not significant, expression in proneural (Fig. 1b). In a larger GBM cohort from the TCGA database with 38 classical, 53 mesenchymal and 29 proneural samples, a 
significant higher expression of CD99 in classical and mesenchymal subtypes than that in proneural subtypes was observed (Fig. 1c). Additionally, the expression analysis of CD99 isoforms in the U87MG cell line confirmed the presence of only isoform 1 (Fig. 1d), which was also confirmed at the protein level by Western blotting with the detection of a unique band of $32 \mathrm{kDa}$ (Fig. 1e).

\section{Transcriptome analysis of CD99-siRNA U87MG}

The differential expression analysis of the U87MG knockdown for CD99 and NTC (CD99-siRNA vs NTC-siRNA) resulted in 2,670 genes, presenting statistical expression differences with $p \leq 0.01$ and $\log _{2}$ fold-change ranging from $\leq-1$ to $\geq 1 . C D 99$ presented the highest fold-change ( 4.1854 , corresponding to a 17.51 -fold decrease), confirming the efficiency of CD99 silencing. The enrichment analysis by DAVID algorithm showed two enriched clusters of GO Terms (Fig. 2a), with the first cluster related to cell adhesion. Then, we further investigated the specific genes associated with this cluster encoding membrane, extracellular matrix, stress fiber, focal adhesion and filopodia/lamellipodia proteins. A heat map and the differences in gene expression (fold-change) of these selected genes are presented in Figs. 2b and 2c, respectively. OPN (osteopontin) and LAMA5 (laminin 5) were downregulated, while FN1 (fibronectin 1). THBS1 (thrombospondin 1) and COL6A2 (alpha(a)2(VI) chain of type VI collagen) were upregulated when CD99 was silenced. The genes encoding transmembrane proteins, which interact with extracellular matrix proteins, such as CD44 and some integrin subunits (ITGB8, ITGA2, ITGAV, and ITGA5), were also upregulated.

\section{Functional analysis of CD99 involvement in GBM cell migration, invasion and} adhesion

To further study the GBM cell phenotype, permanent long-term CD99 knockouts were constructed, as CDg9-siRNA silencing was transitory, and after 7 days, its gene expression was recovered to approximately $50 \%$ of control NTC (data not shown). The 
323 two CD99-shRNA constructs significantly reduced CD99 expression to $20 \%$ and $3 \%$

324 when compared to the expression in the controls (scrambled) (Fig. 3a), which were

325 validated at the protein level by Western blotting (Fig. 3b).

326

327
The U87MG cell migration after CD99 knockout showed a significant decreased migratory activity compared to that of the control ( $p<0.0001$ ) (Fig.s 3c, 3d and 3e) by both image recording methods. However, shCD99-2 caused a lower effect in migration than shCD99-1 (Fig. 3c and 3e). The difference between the two shRNA constructs was more evident after $6 \mathrm{~h}$ in the monitored migration assay. An inhibitory invasion effect of $47 \%$ for shCD99-1 and $45 \%$ for shCD99-2 in relation to scramble was observed (Fig. 4a). The short-term adhesion assay for $3 \mathrm{~h}$ demonstrated the reduced adhesion of shCD99-1 compared to control $(p<0.05)$, in contrast to the increased adhesion of shCD99-2 in relation to control ( $p<0.0001$ ) (Fig. 4b). A residual $20 \%$ of CD99 expression in shCD99-1 may explain the opposing findings in this assay.

\section{CD99 colocalizes with F-actin}

The colocalization of CD99 with phalloidin was observed in the cell-cell contact regions and in lamellipodia in control U87MG cells, and CD99 expression was not detected in U87MG cells knocked down for CD99, as expected. Interestingly, relevant changes in morphology were observed in both U87MG shCD99-1 and 2 cells, consisting of the altered organization of actin microfilaments and cytoplasmic protrusions compared to that of controls. Moreover, actin distribution was more homogeneous in all adherent membrane cells in shCD99-1, while more spaced actin bundles were shown in shCD99-2 (Fig. 4c).

\section{Discussion}

CD99 has been described as a highly expressed tumor-associated antigen in GBM tissues and a potential target for synthetic multi-peptides vaccine or dendritic cell 
350 immunotherapy [10]. However, the functional role of CD99 in tumors has not yet been

351 fully elucidated, and the ligand for CD99 has not yet been identified. Thus far, the

352 current knowledge of CD99 functions derives from experiments of CD99 activation by

353 agonist monoclonal antibodies in hematopoietic and tumor cells $[28,29]$. In addition, knowledge of CD99-regulated pathways in the GBM is relatively sparse.

The findings of the present study show CD99 as a worthwhile target to be explored for therapeutic purposes.

\section{Expression of CD99 isoforms}

CD99 isoform 1 was the predominant isoform present in different malignant grades of human astrocytomas when compared to NN brain tissue as observed in other studies [10], and its expression was particularly higher in GBM when compared to lower malignant grade diffusely infiltrative astrocytomas [9], CD99 isoform 1 regulates lymphocyte adhesion mediated by the integrin LFA-1, in contrast to isoform 2, which inhibits the spontaneous adhesion of these cells via the LFA-I/ICAM pathway [30]. In tumors, CD99 isoforms regulate different functions in tumor malignancy. In osteosarcoma, isoform 1 plays a role in the modulation of cancer malignancy, acting as a potent immunosuppressant of migration and metastasis through c-Src repression [15. 16]. However, the CD99 isoform 2-transfected breast cell line showed superior ability to migrate compared to control, and this difference was not observed in the same cells transfected with the isoform $1[17,31]$. In addition, the expression of CD99 was associated with tumor progression in Ewing sarcoma and acute lymphoblastic leukemia [32] whereas in osteosarcoma [33], and in Hodgkin's lymphoma[34] CD99 has been reported as a tumor suppressor. In our GBM model, CD99 isoform 1 proved to be protumorigenic.

\section{Transcriptome analysis and signaling pathways modulated by CD99}


Interestingly, the U87MG CD99-siRNA transcriptome analysis pointed out that the most enriched processes related to downregulation of CD99 were cell-cell adherent junction and adhesion in accordance to previously reported CD99 roles in tumors. We hypothesize that CD99 may modulate integrin inside-out signaling pathway through activation of G-protein $\beta / \gamma$ subunit/c-Scr/FAK1/Talin. Talin binds to ITGB3 cytoplasmatic tails and induces conformational changes in their extracellular domains, resulting in an increase integrin affinity for ligands [35]. Alternatively, CD99 may activate caveolin-1 via ITGAV or ITGA5, and Caveolin-1 thus activates FAK1. Once FAK1 is activated, vinculin activates $\alpha$-actin in promoting cell adhesion and stress fiber formation. Moreover, FAK1 may activate CDC42/RAC that regulates Arp2/3-mediated actin polymerization and consequent orientation of cell migration [36]. Recently, another pathway has been described in a breast cancer model, where CD99-derived agonist ligands inhibit fibronectin-mediated $\beta 1$ integrin activation through the SHP2/ERK/PTPN12/FAK1 signaling pathway [37]. The suppression of $\beta 1$ integrin activity by CD99 activation may occur through the dephosphorylation of focal adhesion kinase (FAK1) at Y397 [38]. Therefore, the present transcriptome data and the findings of previous studies suggest that extracellular matrix targets together with tumor-associated antigens, including CD99 and integrins, participate in a cytosolic downstream pathway intermediated by FAK and c-Src. In fact, the analysis of focal adhesion and regulation of actin cytoskeleton pathways in the present transcriptome data demonstrated the downregulation of RhoGap expression (ARHGAP5 and ARHGAP35), DIAPH1, MLC (MYL5, MYL6B and MYL12B), related to the stress of fiber formation. Similarly, the downregulation of several targets downstream of FAK, Rac family small GTPase 2 ( $A A C 2)$, cytoplasmic FMR1 interacting protein 2 (CYFIP2), WAS protein family member 1 (WASF1), BAl1-associated protein 2 (BAIAP2), and actin-related protein 2/3 complex subunit $1 \mathrm{~A}$ and $1 \mathrm{~B}$ (ARPC1A and $A R P C 1 B$ ), were detected, which were related to 
404 filopodia and lamellipodia formation by actin branch regulation essential for cell

405 migration.

406 Moreover, Ezrin (EZR), radixin ( $R D X)$ and moesin (MSM), three highly homologous

407

408

409

410

411

412

413

414

415

416

417

418

419

420

421

422

423

424

425

426

427

428

429

430

431

protein members of the FERM essential for linking the actin cytoskeleton to the cell membrane [39] were downregulated when CD99 was silenced, which further disorganizes the actin cytoskeleton and may prevent cell migration. Similarly, Dynamin 2 (DNMZ) and cortactin (CTTM) were also downregulated with the reduction of CD99 expression, and these proteins participate in cell migration by stabilizing $\mathrm{F}$-actin bundles in filopodia $[40,41]$.

\section{Influence of CD99 on migration, invasion and cell adhesion}

The functional assays with U87MG CD99-shRNA demonstrated that CD99 downregulation resulted in decreased migration and invasion of tumor cells. GBM cells use a mesenchymal mode of migration and invasion similar to fibroblasts $[42,43]$; however, GBM U87MG cells overexpressing CD99 have presented a higher proportion of amoeboid migration with high cortical tension and low adhesion to ECM than that in control cells $[44,45]$.

Decreased cell motility after CD99 silencing in GBM cells may be related to dysregulation of stress fiber formation, focal adhesion and particularly to the dysregulation of filopodia and lamellipodia formation according to the downregulated set of genes identified by the transcriptome analysis (Fig. 5). In fact, the overexpression of isoform 1 in osteosarcoma cell lines similarly modulated the expression of genes essential for remodeling the actin cytoskeleton and cell invasion through ARP2 and ARPC1A of the Arp2/3 complex [16, 46]. These previous reports corroborate the present results of the transcriptome analysis that the dysfunction of the Arp $2 / 3$ complex is an important node for the regulation of cell motility. The functional assays with U87MG CD99-shRNA also showed the dysfunction of cell adhesion, suggesting that this function in U87MG cells is dependent on the amount of 
432 CD99 expressed in the cells. The complete or near complete knockout of CD99 $(98 \%$

433 knockdown with shRNA CD99 2) presented a higher number of adhered cells in

434 relation to control and in contrast to shRNA CD99 1 with $20 \%$ residual CD99. This

435

436

437 difference may be explained by distinct stimulus to produce extracellular matrix component and consequent distinct activation of signaling pathways. In this context, our transcriptome analysis showed the increased expression of fibronectin with CD99 silencing. Cells present different organization of cytoskeleton actin in response to different concentrations of fibronectin. Low concentrations of fibronectin result in few but highly dynamic adhesions, while the actin polymerization patterns are less organized. On the other hand, high concentrations of fibronectin result in abundant but less dynamic adhesions and actin. Medium concentrations of fibronectin cause high migration rates, moderate adhesions and very dynamic actin rate [47]. The previous observations are consistent with the present results of the in silica analysis of the U87MG CD99-siRNA RNASeq data. Immunofluorescence and ultrasound microscopy findings after the activation of Ewing's sarcoma cells with an anti-CD99 agonist antibody also corroborate the ability of CD99 to control cell cytoskeleton remodeling and form adherent junctions and focal adhesions [48]. The present immunofluorescence images also localized CD99 staining at the cell membrane in cellcell contact regions (lamellipodia) in U87MG controls and showed CD99 co-localized with phalloidin. Interestingly, when CD99 was absent, striking morphological changes were observed in U87MG CD99-shRNA cells, characterized by reduced cell surface with phalloidin staining predominantly located at the periphery of the cells in shCD99-1 and sparser in the middle surface in shCD99-2. The thick peripheral F-actin bundles have been associated with low adhesion strength, whereas high adhesion strength was associated with small focal adhesion distributed throughout the ventral surface connected to many small F-actin bundles covering the entire cell $[49,50]$. These previous descriptions correspond to the staining differences observed between the two 
459 CD99-shRNA constructs (Fig - 4) and reinforce the difference in the strength adhesion

460 observed between them.

461

462

\section{CD99 is upregulated in mesenchymal subtype of GBM}

Interestingly, the TCGA GBM dataset analysis showed that the most aggressive subtype of GBM, the mesenchymal subtype, presented the highest expression of CD99, as well as the identified genes coding for plasma membrane and extracellular matrix proteins related to $C D 99$. Functional analyses demonstrated that reducing the expression of CD99 decreases migration and invasion of the tumor cells. Therefore, therapeutic strategies to downregulate CD99 may improve tumor resectability and may reduce the probability of tumor recurrence. Further knowledge on the downstream molecular mechanisms that lead CD99 to modify the cellular actin dynamics may enable the identification of other druggable targets to improve the outcome of this dreadful tumor.

\section{Conclusions}

In conclusion, the present study showed that isoform 1 of CD99 is exclusively present in human astrocytomas and the GBM cell line U87MG and regulates functions, such as cytoskeleton remodeling, cell migration, invasion and adhesion. The present transcriptome data of CD99 silenced GBM cells suggest that CD99 modulates FAK $1 / \mathrm{C}$ Src signaling pathways related to actin cytoskeleton dynamics. The downregulation of this pathway through CD99 knockout may enable the regulation of the migration and invasion of GBM cells, particularly in the mesenchymal subtype, and may improve the clinical outcome, thereby improving tumor resectability and decreasing the tumor recurrence rate.

\section{Abbreviations}

AGI: pilocytic astrocytomas; AGII: low grade astrocytomas; 
487 AGIII: anaplastic astrocytomas; ARPC1A actin-related protein $2 / 3$ complex subunit 1A;

488 ARPC1B: actin-related protein 2/3 complex subunit 1B; ATCC: American Type Culture

489 Collection; BAIAP2: brain-specific angiogenesis inhibitor (BAl1)-associated protein 2;

490 BCRP: breast cancer resistance protein; COL6A2: alpha(c)2(VI) chain of type VI

491 collagen; CPM: counts per million; Ct: cycle threshold; HPRT: CTTN: cortactin;

492 CYFIP2: cytoplasmic FMR1 interacting protein 2; DMEM: Dulbecco's Modified Eagle's

493 medium; DNM2: dynamin 2; E: efficiency; RNAseq: RNA sequencing; EZR: ezrin,

494 FAK1: focal adhesion kinase 1; FBS: fetal bovine serum; FN1: fibronectin 1; THBS1:

GBM: glioblastoma; GO: gene ontology; GUSB: glucuronidase beta; hypoxanthine

phosphoribosyltransferase 1; ITGA2: integrin subunit alpha 2; ITGA5: integrin subunit

alpha 5; ITGAV: integrin subunit alpha V; ITGB8: integrin subunit beta 8, LAMA5:

laminin 5; MSN: moesin; NN: non-neoplastic; NTC: non-target control; OPN: osteopontin; qRT-PCR: quantitative real time PCR; RAC2: Rac family small GTPase 2; RDX: radixin; RPKM: reads per kilobase million; shRNA: short hairpin RNA; TCGA:

\section{Declarations}

\section{Ethics approval and consent to participate}

The project was approved by the National Ethics Commission (CONEP) and the local

institutional Ethics Committee, under protocol number 830/01.

508

\section{Consent for publication}

510

Not applicable.

511

512 Availability of data and material

The datasets used and/or analyzed during the current study are available from the

corresponding author on reasonable request. 
515

516

517

518

519

520

521

522

523

524

525

526

527

528

529

530

531

532

533

534

535

536

537

538

539

540

541

542

\section{Competing interests}

The authors declare that they have no competing interests

\section{Funding}

Sao Paulo Research Foundation (FAPESP), grants 2015/03995-9 and 2015/03614-5,

Conselho Nacional de Pesquisa (CNPq), Fundaçăo Faculdade de Medicina (FFM), and

Faculdade de Medicina da USP (FMUSP).

\section{Authors' contributions}

LCC, RSS and TSL execute the experimental analysis, interpreted the data and prepared the manuscript draft, AMC analyzed the transcriptome data, SKNM and SMOS conceived the experimental design of study, LCC, SKNM and SMOS wrote and revised the manuscript. All authors read and approved the final version of the manuscript.

\section{Acknowledgments}

Not applicable.

\section{Figure captions}

Fig. 1. Expression CD99 in astrocytomas of different malignant grades and the U87MG cell line. (a) Relative quantification of messenger RNA of CD99 isoforms 1 and 2 in 23 pilocytic astrocytoma (AGI), 26 low grade astrocytoma (AGII), 17 anaplastic astrocytoma (AGIII), 79 GBM, and 35 non-neoplastic (NN) tissue samples. The relative expression values were calculated based on the geometric mean of the HPRT, BCRP and GUSB housekeeping expression levels of each sample. Differences among groups were significant ( $p<0.0001$, Kruskal-Wallis test). The horizontal bar indicates the mean 
543 of each group ${ }^{\cdots * *} p<0.0001,{ }^{* *} p<0.001,{ }^{* *} p<0.01$ (Dunn's test). (b) CD99

544 expression levels GBM molecular subtypes in the present series determined by qRT-

545 PCR and (c) in TCGA database determined by RNAseq. Differences among groups

546 were significant (Kruskal-Wallis test) for TCGA cases $(p=0.0031)$. (d) Relative

547 quantification of messenger RNA for CD99 isoforms 1 and 2 in GBM cell line U87MG.

548 HPRT was used as a reference gene. The results were expressed as the means of 2 independent experiments. (e) Representative Western blot showing the expression of CD99 in U87MG. $\beta$-actin was used as a control in the experiment. Only one band corresponding to isoform 1 with $32 \mathrm{kDa}$ was observed.

Fig. 2. Transcriptome analysis of U87MG cell line knockdown for CD99 by siRNA. (a) The two most enriched clusters of GO Terms determined by the DAVID annotation cluster analysis of differentially expressed genes after CD99 knock down (ps0.01). (b) Heat map representing expression of genes coding for membrane, extracellular matrix, stress fiber, focal adhesion and filopodia/lamellipodia proteins. RPKM values of experimental duplicates were normalized by $z$-score (c) The $\log _{2}$ fold-change (FC) of genes represented in the heat map.

Fig. 3. Effects of CD99 knockdown by shRNA on U87MG cell line on migration, (a) Quantification of the mRNA levels in U87MG for CD99 knockdown (shRNA) and control (scrambled) for two clones (shCD99-1 and shCD99-2). HPRT was used as a reference gene for the analysis. (b) Western blot analysis of the CD99 expression in U87MG cell line after transduction with shCD99-1 and shCD99-2 and controls (scramble). $\beta$-actin was used as control for protein loading. Graphs represent 3 independent experiments. The asterisks ("*"p<0.005) indicate statistically significant differences of shCD99-1 and shCD99-2 and their respective controls. (c) U87MG cells transfected with shCD99-1 and shCD99-2 showed reduced migratory activity compared to that of controls. The graph represents the area invaded by the cells at $0,6,18$ and $24 \mathrm{~h}$ after wound 
571 healing. The result was expressed as the means \pm standard error of the mean

572 (quadruplicates) of two independent experiments. Asterisks indicate statistically

573 significant differences of the CD99 silenced cells in relation to their controls at different

574 times ( $\cdots \cdots p<0.0001$ and $\cdots p<0.05)$; ANOVA variance, followed by Bonferroni's test.

575 (d) Representative photomicrographs of wound closure of U87MG cell line at $0,6,18$

576 and $24 \mathrm{~h}, 10 \mathrm{x}$ magnification. (e) Reduced migration was observed each $3 \mathrm{~h}$ for a period

577 of $24 \mathrm{~h}$. U87MG cells knocked down with shCD99-1 (closed circle) and shCD99-2

578 (closed triangle) showed reduced migratory activity when compared to respective controls, scrambled 1 (open circle) and scrambled 2 (open triangle). The result was expressed as the means \pm standard error (sextuplicate). The asterisk indicates statistically significant difference of cells silenced for CD99 in relation to scrambled at different times (**** p<0.0001; non-linear regression analysis).

Fig. 4. Role of CD99 in invasion and adhesion of the U87MG cell line, and colocalization of CD99 and phalloidin. (a) Transwell invasion assay showing decreased U87MG invasion after CD99 knockdown (shCD99-1 and 2) when compared to that of its controls (scrambled 1 and 2), Graph represents percentage of invaded cells in relation to the control (means \pm standard errors of the means) in two independent experiments conducted in duplicate (Students $t^{\prime}$-test, * $p<0.05$ ). The images show representative fields of U87MG cells that invaded and crossed the inserts (40x magnification). (b) Adhesion of U87MG cells was evaluated at $3 \mathrm{~h}$ after seeding onto the plate, and the viability was measured. The shCD99-1 U87MG cells attached less to the plate, while shCD99-2 U87MG cells attached more compared to its controls. The graph expresses the average of sextuplicate of two independent experiment. .... $p<0.001$. (c) Immunofluorescence showing that CD99 (green) and phalloidin (red) colocalize at cell-cell junctions and lamellipodia. Nuclei were stained with DAPI (blue). U87MG cell line knocked down for CD99 and controls. The images were analyzed by confocal microscopy by using a $40 \mathrm{x}$ objective. 
599

600

601

602

603

604

605

606

607

608

609

610

611

612

613

614

615

616

617

618

619

620

621

622

623

624

625

626
Fig. 5. Schematic representation of the KEGG focal adhesion and actin regulation of cytoskeleton pathways, showing the plasma membrane and extracellular matrix target, and downstream pathways through C-SRC and FAK with corresponding intermediate targets involved in stress fiber formation, focal adhesion, filopodia and lamellipodia formation. The gene symbol or the symbol for a group of genes is represented by a blue rectangle when downregulated or a pink rectangle when upregulated, according to the CD99-siRNA U87MG transcriptome analysis. The specific downregulated genes of each group are annotated next to the corresponding rectangle, and the size of blue juxtaposed circles is proportional to fold change. Below the plasma membrane, on right side, the ERM complex is represented linked to actin polymer, and at the actin branching site, Arp2/3 complex - cortactin (CTTN) - N-WASP - dynamin 2 (DMN2) are represented in lamellipodia and filopodia formation. All components were downregulated when CD99 was silenced, demonstrating their role in the reduction of cell migration.

\section{References}

1. lacob G, Dinca EB. Current data and strategy in glioblastoma multiforme. J Med Life. 2009;2:386-93.

2. Louis DN, Perry A, Reifenberger G, von Deimling A, Figarella-Branger D, Cavenee WK, Ohgaki H, Wiestler OD, Kleihues P, Ellison DW. The 2016 World Health Organization Classification of Tumors of the Central Nervous System: a summary. Acta Neuropathologica, 2016;131:803-20.

3. Verhaak RG, Hoadley KA, Purdom E, Wang V, Qi Y, Wilkerson MD, Miller CR, Ding L, Golub T, Mesirov JP. Alexe G, Lawrence M, O'Kelly M, Tamayo P. Weir BA, Gabriel S, Winckler W, Gupta S, Jakkula L, Feiler HS, Hodgson JG, James CD, Sarkaria JN, Brennan C, Kahn A, Spellman PT, Wilson RK, Speed TP, 
Gray JW, Meyerson M, Getz G, Perou CM, Hayes DN; Cancer Genome Atlas Research Network. An integrated genomic analysis identifies clinically relevant subtypes of glioblastoma characterized by abnormalities in PDGFRA, IDH1. EGFR and NF1. Cancer Cell. 2010;17:98-110.

4. Keunen O, Taxt T, Gruner R, Lund-Johansen M, Tonn JC, Paviin T, Bjerkvig R, Niclou SP, Thorsen F. Multimodal imaging of gliomas in the context of evolving cellular and molecular therapies. Adv Drug Deliv Rev, 2014;76:98-115.

5. Soomro SH, Ting LR, Qing YY, Ren M. Molecular biology of glioblastoma: Classification and mutational locations. J Pak Med Assoc. 2017; 7:1410-4.

6. Qin R, Zhou JX, Chen C, Xu T, Yan Y, Ma YS, Zheng ZL, Shen YP, Lu YC, Fu D. Chen JX. LIN28 is Involved in Glioma Carcinogenesis and Predicts Outcomes of Glioblastoma Multiforme Patients. Plos One, 2014;9.e86446.

7. Xu YY, Gao P, Sun $Y$, Duan YR. Development of targeted therapies in treatment of glioblastoma. Cancer Biol Med. 2015;12:223-37.

8. Zhang JG, Kruse CA, Driggers L, Hoa N, Wisoff J, Allen JC, Zagzag D, Newcomb EW, Jadus MR. Tumor antigen precursor protein profiles of adult and pediatric brain tumors identify potential targets for immunotherapy. $J$ Neurooncol. 2008;88:65-76.

9. Urias U, Marie SKN, Uno M, da Silva R, Evagelinellis MM, Caballero OL, Stevenson BJ, Silva WA, Simpson AJ, Oba-Shinjo SM. CD99 is upregulated in placenta and astrocytomas with a differential subcellular distribution according to the malignancy stage. J Neurooncol. 2014;119:59-70.

10. Jung TY, Choi YD, Kim YH, Lee JJ, Kim HS, Kim JS, Kim SK, Jung S, Cho D. Immunological characterization of glioblastoma cells for immunotherapy. Anticancer Res. 2013;33:2525-33.

11. Bernard G, Raimondi V, Alberti I, Pourtein M, Widjenes J, Ticchioni M, Bernard A. CD99 (E2) up-regulates alpha4beta1-dependent T cell adhesion to inflamed vascular endothelium under flow conditions. Eur J Immunol. 2000;30:3061-5. 
12. Hahn JH, Kim MK, Choi EY, Kim SH, Sohn HW, Ham DI, Chung DH, Kim TJ, Lee WJ, Park CK, Ree HJ, Park SH, CD99 (MIC2) regulates the LFA-1/ICAM-1mediated adhesion of lymphocytes, and its gene encodes both positive and negative regulators of cellular adhesion. Joumal of Immunology. 1997; 159:2250-8.

13. Manara MC, Pasello M, Scotlandi K. CD99: A Cell Surface Protein with an Oncojanus Role in Tumors. Genes (Basel). 2018;9:159.

14. Persson O, Krogh M, Saal LH, Englund E, Liu J, Parsons R, Mandahl N, Borg A, Widegren B, Salford LG. Microarray analysis of gliomas reveals chromosomal position-associated gene expression pattems and identifies potential immunotherapy targets. J Neurooncol. 2007;85:11-24.

15. Alberti I, Bernard G, Rouquette-Jadanian AK, Pelassy C, Pourtein M, Aussel C, Bernard A. CD99 isoform expression dictates T-cell functional outcomes. FASEB J. 2002;16:1946-8.

16. Zucchini C, Manara MC, Pinca RS, De Sanctis P, Guerzoni C, Sciandra M, Lollini PL, Cenacchi G, Picci P, Valvassori L, Scotlandi K. CD99 suppresses osteosarcoma cell migration through inhibition of ROCK2 activity. Oncogene. 2014:33:1912-21.

17. Byun H-J, Hong I-K, Kim E, Jin Y-J, Jeoung D-I, Hahn J-H, Kim Y-M, Park SH, Lee H. A splice variant of CD99 increases motility and MMP-9 expression of human breast cancer cells through the AKT-, ERK-, and JNK-dependent AP-1 activation signaling pathways. J Biol Chem. 2006;281:34833-47.

18. Livak KJ, Schmittgen TD. Analysis of relative gene expression data using realtime quantitative PCR and the 2(-Delta Delta $C(T)$ ) Method. Methods. 2001;25:402-8.

19. Dobin A, Davis CA, Schlesinger F, Drenkow J, Zaleski C, Jha S, Batut P, Chaisson M, Gingeras TR. STAR: ultrafast universal RNA-seq aligner. Bioinformatics. 2013;29:15-21. 
20. Li B, Dewey CN. RSEM: accurate transcript quantification from RNA-Seq data with or without a reference genome. BMC Bioinformatics. 2011;12:323.

21. Liao Y, Smyth GK, Shi W. featureCounts: an efficient general purpose program for assigning sequence reads to genomic features. Bioinformatics. 2014:30:923-30.

22. Wagner GP, Kin, K., Lynch, V.J. Measurement of mRNA abundance using RNA-seq data: RPKM measure is inconsistent among samples. Theory Biosc. 2012;131:281-5.

23. Ritchie ME, Phipson B, Wu D, Hu Y, Law CW, Shi W, Smyth GK. limma powers differential expression analyses for RNA-sequencing and microarray studies. Nucleic Acids Res. 2015;43:e47.

24. DeLuca DS, Levin JZ, Sivachenko A, Fennell T, Nazaire MD, Williams C, Reich M, Winckler W, Getz G. RNA-SeQC: RNA-seq metrics for quality control and process optimization. Bioinformatics. 2012;28:1530-2.

25. Huang DW, Sherman BT, Tan Q, Collins JR, Alvord WG, Roayaei J, Stephens R, Baseler MW, Lane HC, Lempicki RA. The DAVID Gene Functional Classification Tool: a novel biological module-centric algorithm to functionally analyze large gene lists. Genome Biol. 2007;8:R183.

26. Abramoff MD. Image processing with ImageJ. Biophotonics International. $2004 ; 11: 36-42$.

27. Galatro TF, Sola P, Moretti IF, Miura FK, Oba-Shinjo SM, Marie SK, Lerario AM. Correlation between molecular features and genetic subtypes of Glioblastoma: critical analysis in 109 cases. Medical Express. 2017;4:M170504.

28. Hahn MJ, Yoon SS, Sohn HW, Song HG, Park SH, Kim TJ. Differential activation of MAP kinase family members triggered by CD99 engagement. FEBS Lett. $2000 ; 470: 350-4$

29. Pasello M, Manara MC, Scotlandi K. CD99 at the crossroads of physiology and pathology. J Cell Commun Signal. 2018;12:55-68. 
30. Lou O, Alcaide P. Luscinskas FW, Muller WA, CD99 is a key mediator of the transendothelial migration of neutrophils. J Immunol. 2007;178:1136-43.

31. Lee HJ, Kim E, Jee B, Hahn JH, Han K, Jung KC, Park SH, Lee H. Functional involvement of src and focal adhesion kinase in a CD99 splice variant-induced motility of human breast cancer cells. Exp Mol Med. 2002;34:177-83.

32. Dworzak MN, Froschl G, Printz D, De Zen L, Gaipa G, Ratei R, Basso G, Biondi A, Ludwig WD, Gadner H. CD99 expression in T-lineage ALL: implications for flow cytometric detection of minimal residual disease. Leukemia. 2004;18:703. 8.

33. Sciandra M, Marino MT, Manara MC, Guerzoni C, Grano M, Oranger A Lucarelli E, Lollini P-L, Dozza B, Pratelli L, Renzo MF, Colombo MP, Picci P Scotlandi K. CD99 drives terminal differentiation of osteosarcoma cells by acting as a spatial regulator of ERK 1/2. J Bone Miner Res. 2014; 29:1295-309.

34. Kim SH, Shin YK, Lee IS, Bae YM, Sohn HW, Suh YH, Ree HJ, Rowe M, Park SH. Viral latent membrane protein 1 (LMP-1)-induced CD99 down-regulation in B cells leads to the generation of cells with Hodgkin's and Reed-Stemberg phenotype. Blood. 2000; 95:294-300.

35. Calderwood DA. Integrin activation. J Cell Sci. 2004:117:657-66.

36. Dayel MJ, Mullins RD. Activation of Arp $2 / 3$ complex: Addition of the first subunit of the new filament by a WASP protein triggers rapid ATP hydrolysis on Arp2. Plos Biol. 2004;2:476-85

37. Lee KJ, Kim Y, Yoo YH, Kim MS, Lee SH, Kim CG, Park K, Jeoung D, Lee H, Ko IY, Hahn JH. CD99-Derived Agonist Ligands Inhibit Fibronectin-Induced Activation of beta 1 Integrin through the Protein Kinase A/SHP2/Extracellular Signal-Regulated Kinase/PTPN12/Focal Adhesion Kinase Signaling Pathway. Mol Cell Biol. 2017;37:e00675-16.

38. Lee KJ, Yoo YH, Kim MS, Yadav BK, Kim Y, Lim D, Hwangbo C, Moon KW. Kim D, Jeoung D, Lee H, Lee JH, Hahn JH. CD99 inhibits CD98-mediated beta 
1 integrin signaling through SHP2-mediated FAK dephosphorylation. Exp Cell Res. 2015;336:211-22.

39. Clucas J, Valderrama F. ERM proteins in cancer progression. J Cell Sci. 2015;128:1253.

40. Meng J. Distinct functions of dynamin isoforms in tumorigenesis and their potential as therapeutic targets in cancer. Oncotarget. 2017;8:41701-16.

41. MacGrath SM, Koleske AJ. Cortactin in cell migration and cancer at a glance. J Cell Sci. 2012;125:1621-26.

42. Krakhmal NV, Zavyalova MV, Denisov EV, Vtorushin SV, Perelmuter VM. Cancer Invasion: Patterns and Mechanisms. Acta Naturae, 2015;7:17-28.

43. Zhong J, Paul A, Kellie SJ, O'Neill GM. Mesenchymal migration as a therapeutic target in glioblastoma. J Oncol. 2010; 2010:430142.

44. Cha J, Kang S-G, Kim P. Strategies of Mesenchymal Invasion of Patientderived Brain Tumors: Microenvironmental Adaptation. Sci Rep. 2016;6:24912.

45. Seol HJ, Chang JH, Yamamoto J, Romagnuolo R, Suh Y, Weeks A, Agnihotri S, Smith CA, Rutka JT. Overexpression of CD99 Increases the Migration and Invasiveness of Human Malignant Glioma Cells. Genes Cancer. 2012;3:535-49.

46. Scotlandi K, Zuntini M, Manara MC, Sciandra M, Rocchi A, Benini S, Nicoletti G, Bernard G, Nanni P, Lollini PL, Bernard A, Picci P. CD99 isoforms dictate opposite functions in tumour malignancy and metastases by activating or repressing c-Src kinase activity. Oncogene. 2007;26:6604-18.

47. Schwartz MA, Horwitz AR. Integrating adhesion, protrusion, and contraction during cell migration. Cell. 2006;125:1223-25.

48. Chaturvedi A, Hoffman LM, Jensen CC, Lin $Y-C$, Grossmann AH, Randall RL, Lessnic SL, Weim AL, Beckerle MC. Molecular dissection of the mechanism by which EWS/FLI expression compromises actin cytoskeletal integrity and cell adhesion in Ewing sarcoma. Mol Biol Cell. 2014;25:2695-709. 
766 49. Dimilla PA, Barbee K, Lauffenburger DA. Mathematical model for the effects of 767 adhesion and mechanics on cell migration speed. Biophys J. 1991;60:15-37.

768 50. Palecek SP, Loftus JC, Ginsberg MH, Lauffenburger DA, Horwitz AF. Integrin769 ligand binding properties govern cell migration speed through cell-substratum 770 adhesiveness. Nature. 1997;385:537-40. 

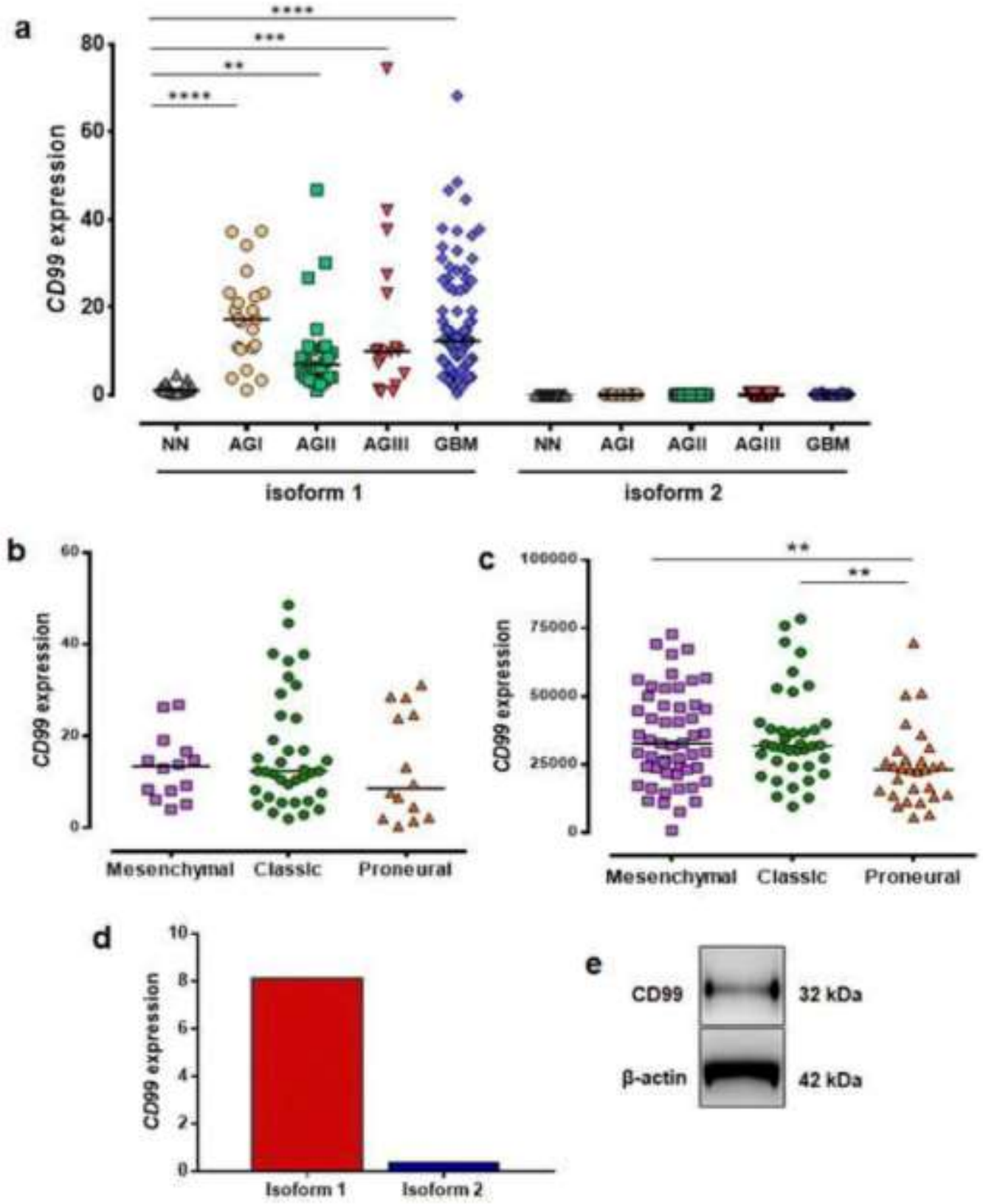
cell-cell adherens junction cadherin binding involved in cell-cell adhesion cell-cell adhesioe

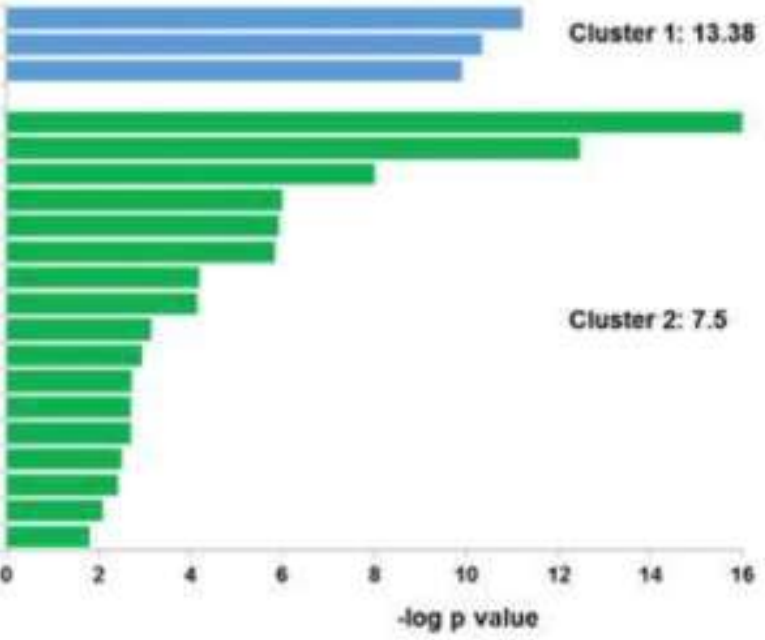

nucleoside phosphate-binding reolen:ATP Serine/threonine-protein kinase protein kinase activity protein serine/threonine kinase activity domain Protein kinase Serine/threonine -protein kinase, active site protein phospherylation Protein kinase, catalytic domain active site: Proton acceptor Protein kinase-tike dounain Protein kinase, ATP binding site

tog p value

b

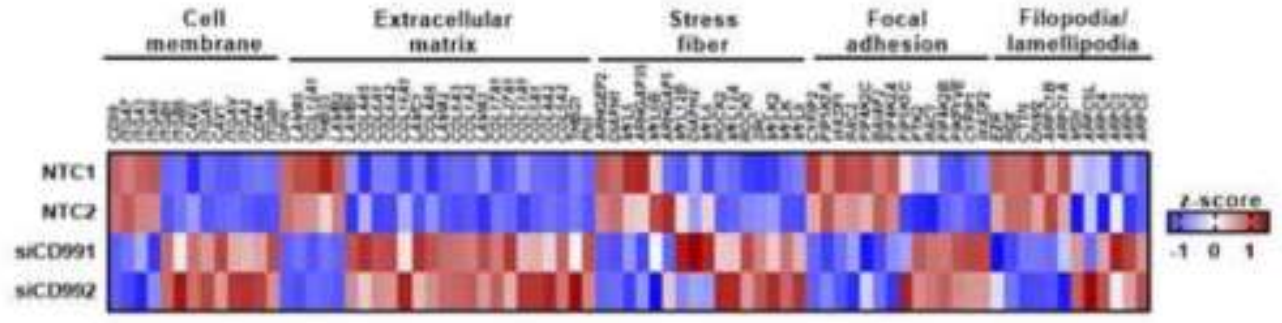

c

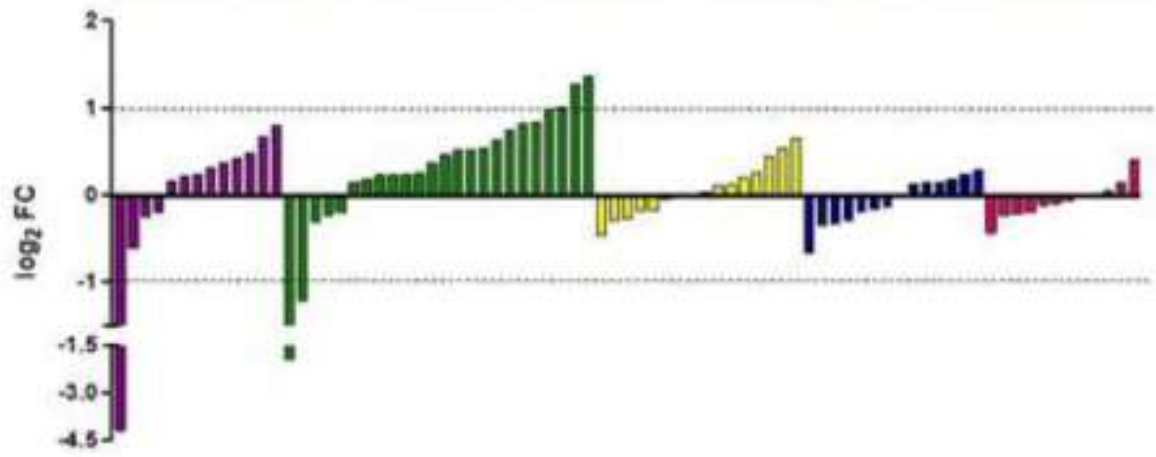


a

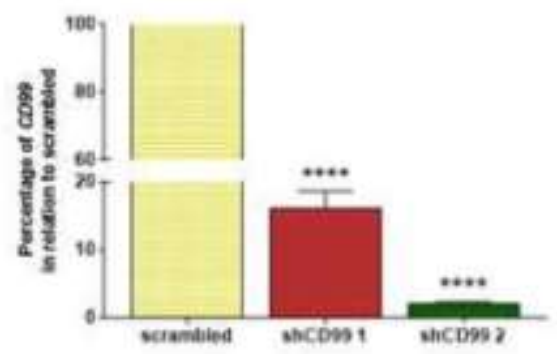

b

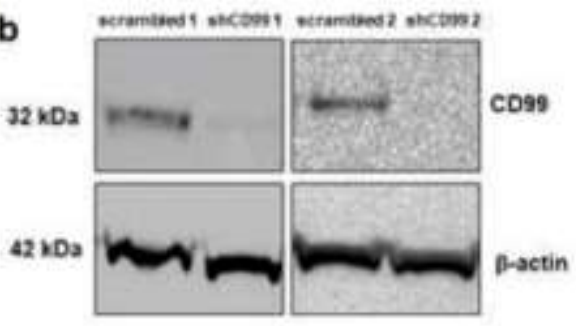

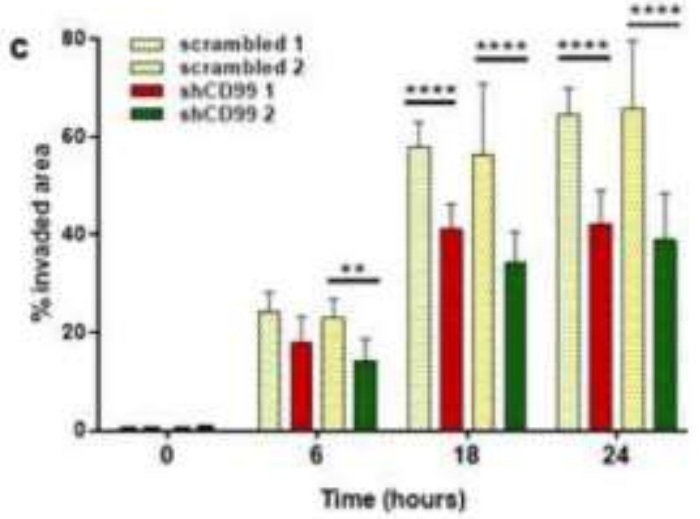

d
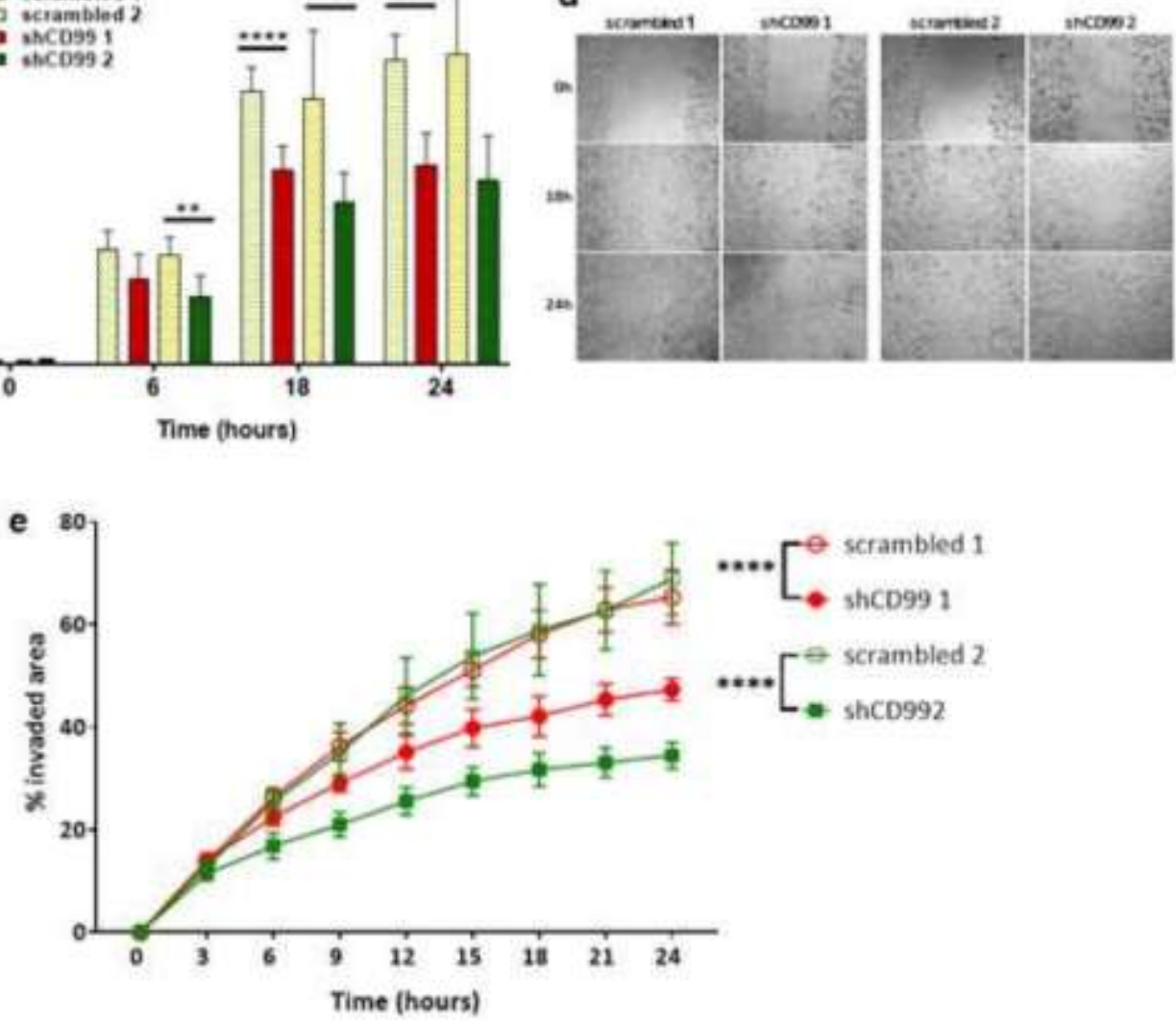
a

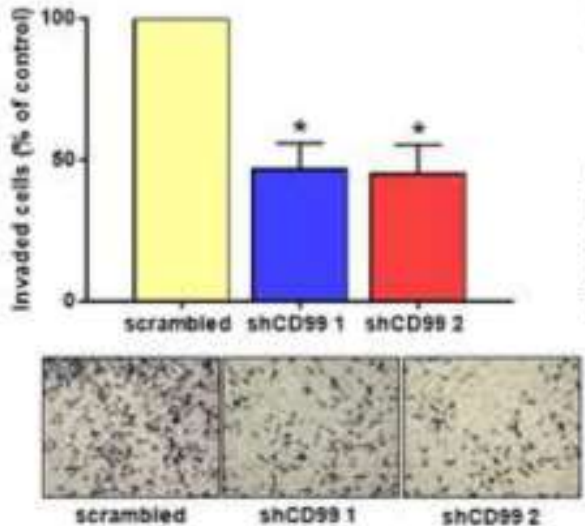

b

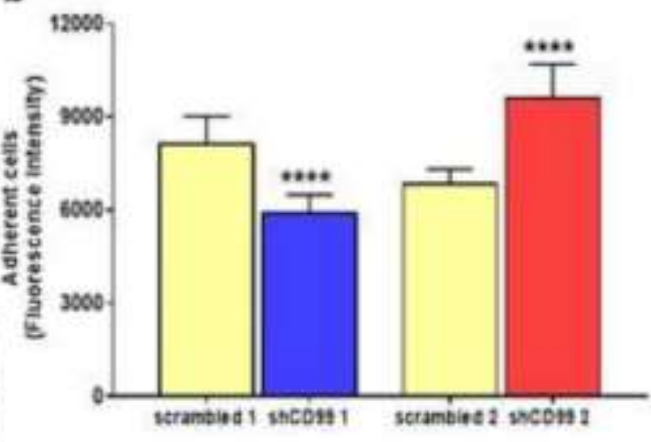

c.

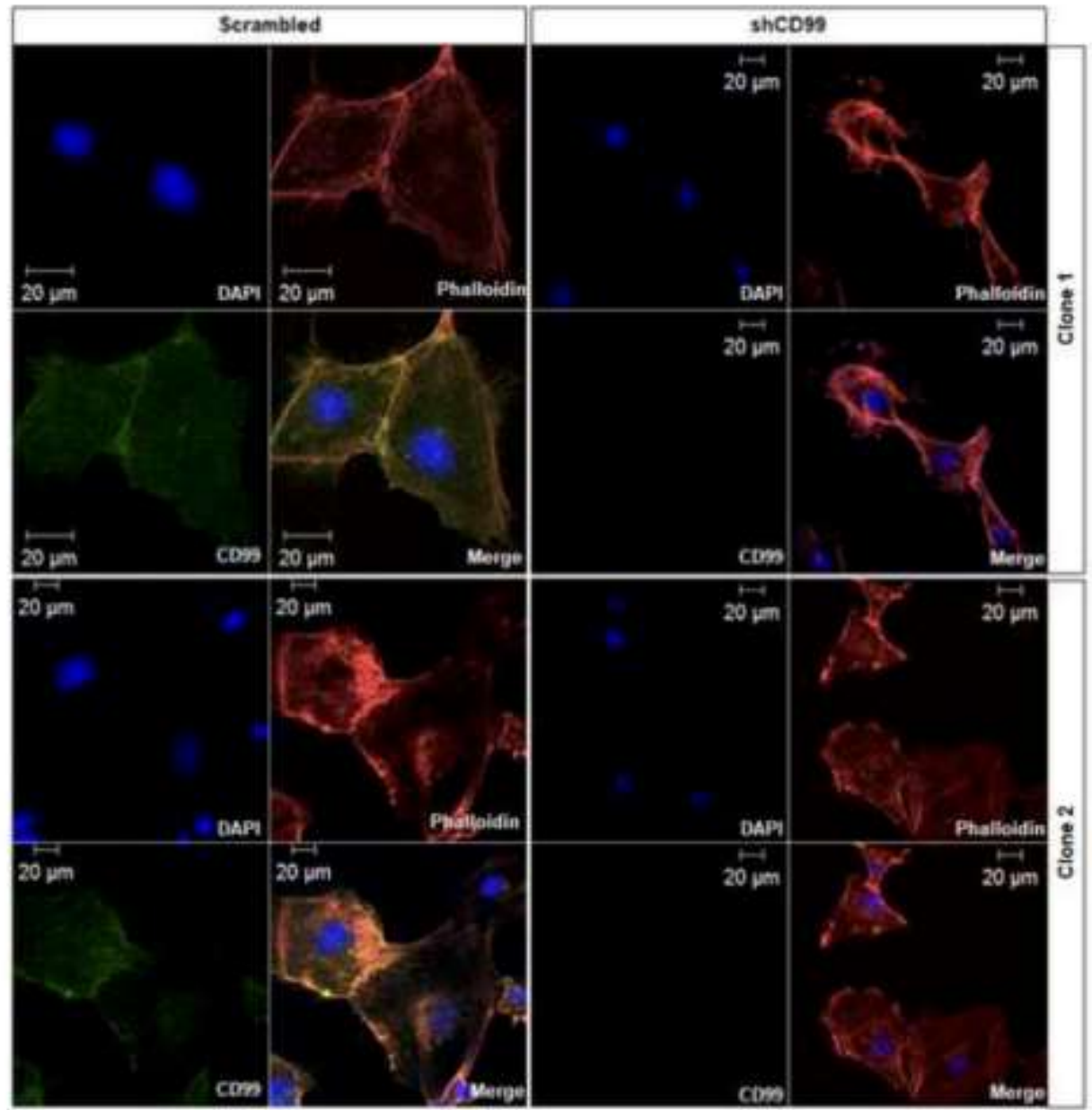




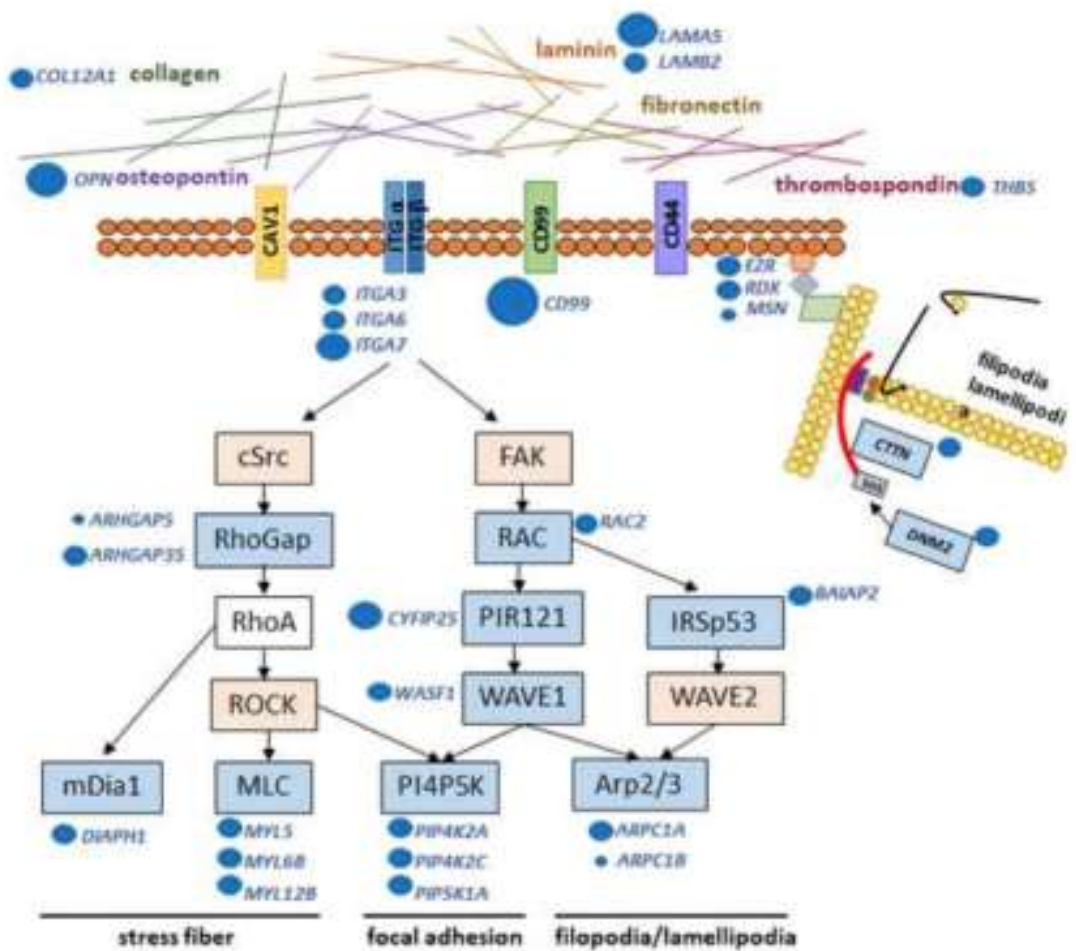

a) Ant/3 